\title{
Technical Evaluation of Electrical Resistivity Methods at the Department of Energy Hanford Site
}

Prepared for the U.S. Department of Energy

Assistant Secretary for Environmental Management

Project Hanford Management Contractor for the

U.S. Department of Energy under Contract DE-AC06-96RL13200

\section{FLUOR.}

P.O. Box 1000

Richland, Washington 


\section{Technical Evaluation of Electrical Resistivity Methods at the Department of Energy Hanford Site}

Document Type: TI

D. S. Kaback

Geomatrix Consultants, Inc.

L. Pellerin

Green Engineering, Inc.

D. LaBrecque

Multi-Phase Technologies, LLC

Date Published

March 2008

Prepared for the U.S. Department of Energy

Assistant Secretary for Environmental Management

Project Hanford Management Contractor for the

U.S. Department of Energy under Contract DE-AC06-96RL13200

\section{FLUOR.}

P.O. Box 1000

Richland, Washington
Program/Project: SGW

D. Isaacson

Rensselaer Polytechnic Institute

L. Slater

Rutgers University

L. B. Bentley

University of Calgary 
SGW-34795

Revision 0

TRADEMARK DISCLAIMER

Reference herein to any specific commercial product, process,

or service by trade name, trademark, manufacturer, or

otherwise, does not necessarily constitute or imply its

endorsement, recommendation, or favoring by the United

States Government or any agency thereof or its contractors or

subcontractors.

This report has been reproduced from the best avallable copy.

Printed in the United States of America 


\section{TABLE OF CONTENTS}

1.0 INTRODUCTION .............................................................................................

1.1 THE PROBLEM 1-1

1.2 OVERVIEW OF RECENTLY COMPLETED RESISTIVITY PROJECTS $1-1$

$\begin{array}{lll}1.3 & \text { OBJECTIVES } & 1-2\end{array}$

1.4 APPROACH $1-2$

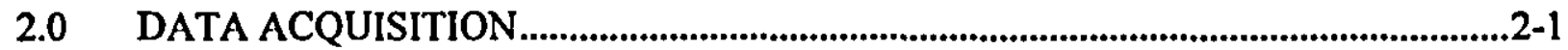

2.1 EVALUATION OF RECENTLY COMPLETED AND ONGOING ELECTRICAL RESISTIVITY PROJECTS AT HANFORD $2-1$

2.1.1 Survey Design .....................................................................................................2-1

2.1.2 Instrumentation ................................................................................................................2-2

2.1.3 Array Configuration (Pole-to-Pole) ......................................................................2-4

2.1.4 Well-To-Well (WTW) Approach ........................................................................2-6

2.2 SUGGESTED IMPROVEMENTS FOR FUTURE PROJECTS INVOLVING

ELECTRICAL RESISTIVITY METHODS $\quad 2-7$

2.2.1 Survey Design .....................................................................................................2-7

2.2.2 3D Acquisition .................................................................................................................2-8

3.0 DATA RELIABILITY AND QUALITY CONTROL …..................................................3-1

3.1 EVALUATION OF RECENTLY COMPLETED AND ONGOING ELECTRICAL RESISTIVITY PROJECTS AT HANFORD 3-1

3.1.1 Instrument Calibration and Drift.............................................................................3-1

3.1.2 Noise Evaluation .............................................................................................3-1

3.1.3 Environmental Conditions ................................................................................3-3

3.1.4 Documentation.................................................................................................3-4

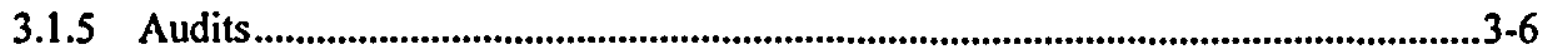

3.2 SUGGESTED IMPROVEMENTS FOR FUTURE PROJECTS INVOLVING ELECTRICAL RESISTIVITY METHODS $\quad 3-6$

3.2.1 Instrument Calibration and Drift................................................................................3-6

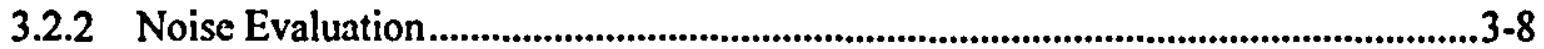

3.2.3 Environmental Conditions ............................................................................3-8

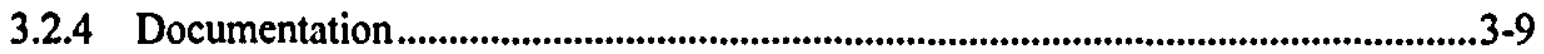

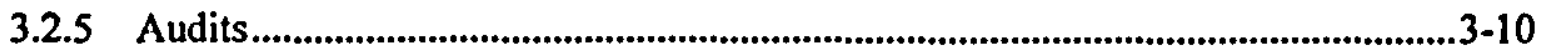

4.0 DATA PROCESSING AND PRESENTATION......................................................4-1

4.1 EVALUATION OF RECENTLY COMPLETED AND ONGOING ELECTRICAL RESISTIVITY PROJECTS AT HANFORD 4-1

4.1.1 Processing ............................................................................................................4-1

4.1.2 HRR Data Plotting Method............................................................................4-1

4.1.3 2D Inversion................................................................................................................4-4

4.1.4 3D Inversion..............................................................................................4-8

4.1.5 Solution Appraisal ........................................................................................4-9

4.1.6 Data Presentation .............................................................................................4-9 
4.2 SUGGESTED IMPROVEMENTS FOR FUTURE PROJECTS INVOLVING ELECTRICAL RESISTIVITY METHODS $\quad$ 4-10

4.2.1 The HRR Data Plotting Method (HRRDPM) .........................................................4-10

4.2.2 2D and 3D Inversion........................................................................................ 4-10

4.2.3 Solution Appraisal .......................................................................................4-11

4.2.4 Data Presentation ................................................................................................4-11

5.0 HYDROGEOLOGICAL INTERPRETATION AND VALIDATION ...........................5-1

5.1 EVALUATION OF RECENTLY COMPLETED AND ONGOING ELECTRICAL RESISTIVITY PROJECTS AT HANFORD 5-1

5.1.1 Theoretical Basis for Plume Detection from Resistivity Measurements: Applicability to the Hlanford Site ......................................................................................................................5-1

5.1.2 Comparison of Resistivity with Borehole Data ............................................................5-2

5.1.3 Petrophysics ..............................................................................................................5-6

5.1.4 Geostatistics ...............................................................................................................5-7

5.2 SUGGESTED IMPROVEMENTS FOR FUTURE PROJECTS INVOLVING ELECTRICAL RESISTIVITY METHODS $\quad 5-8$

5.2.1 Borehole Data and Methods...............................................................................5-8

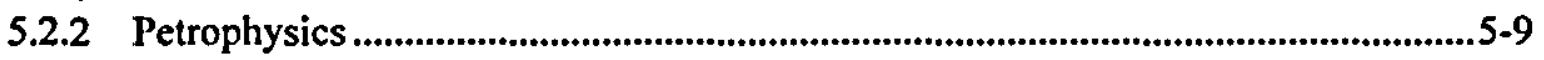

5.2.3 Geostatistics ........................................................................................................................5-9

6.0 EVALUATION OF THE SAMPLING \& ANALYSIS PLAN FOR BC CRIBS AND

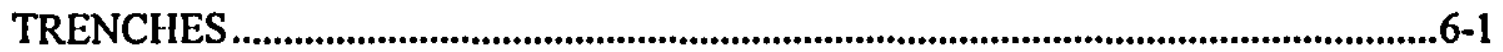

7.0 CONCLUSIONS AND RECOMMENDATIONS ........................................................... 7-1

7.1 INTRODUCTION 7-1

7.2 SUMMARY OF STRENGTHS AND LIMITATIONS OF THE ELECTRICAL RESISTIVITY METHOD $\quad 7-1$

7.2.1 Cultural Effects ..........................................................................................................

7.2.2 Plume Delineation......................................................................................................7-1

7.2.3 Plume Chemistry.......................................................................................................... 7-2

7.3 PANEL RECOMMENDATIONS

7.4 RESPONSE TO FOUR KEY QUESTIONS 7-3

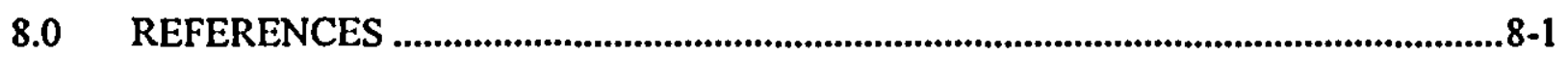


SGW-34795, Rev. 0

TABLES

Table 1. Summary of selected 2D inversion model parameters and inversion statistics 4-6

\section{FIGURES}

Figure 2.1. 3D inversion using the data acquired in 2005 only (left) and with the addition of 2006 data (right) at the BCCT .................................................................................................2-2

Figure 2.2. The pole-pole array configuration ...............................................................................2-5

Figure 2.3. Responses of (A) a plume model for the (B) Schlumberger, (C) pole-dipole, (D) dipole-dipole and (E) pole-pole arrays are plotted as apparent resistivity HRR pseudo-depth

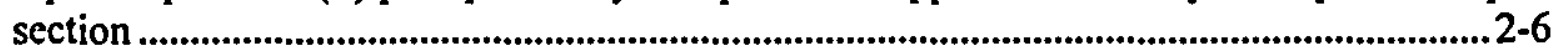

Figure 2.4. Inversion of WTW and surface inversion for the T Tank Farm, illustrating the difference in sensitivity between the array configurations .....................................................2-7

Figure 3.1. Data series from Line HHRN1, collected in 2005, showing large outliers............... 3-2 Figure 3.2. Detail of data series from Line HHRN1, collected in 2005, showing presence of unusual features in the data collected using channel 1 of the SuperSting ${ }^{\mathrm{TM}}$.........................3-3

Figure 3.3. Figure from Rucker 2007 presentation showing data replaced using cubic-spline

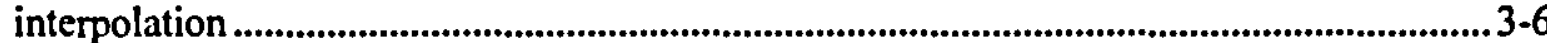

Figure 3.4. Example of calibrator circuit ...........................................................................................3-7

Figure 4.1. (a) Model of a simple plume in a half space and corresponding (b) apparent resistivity pseudosection, (c) HRRDPM apparent resistivity plot or nonlinear pseudosection, (d) robust and (e) smooth inversion

Figure 4.2. Three models showing (a) a plume and groundwater, (b) two plumes and groundwater, and (c) three plumes and groundwater, and the corresponding HRR apparent resistivity plots

Figure 4.3. Interpretation of BCCT Lines 1 and 2 using the HIRRDPM ....................................4-4

Figure 4.4. HRR plot of a single plume ( $10 \mathrm{ohm}$-meters) and a pipe $(0.01 \mathrm{ohm}$-meter $)$ in a homogeneous background of 1,000 ohm-meter (above) and corresponding 2D inversion. 4-5

Figure 4.5. 2D inverse models for the profile lines described in Table 1

Figure 4.6. 3D inverse model of the BCCT using data acquired in 2004-06 decimated by half 4-8

Figure 4.7. Collage of 3D inverse models for the four areas of the T Tank Farm...................... 4-9

Figure 5.1. Exposed trench face showing layered heterogeneity in Hanford's 200 East Area... 5-3

Figure 5.2. Borehole data from C4191 (1) lithology showing laminar clay layers as black bands

(b) ${ }^{99} \mathrm{Tc}$ concentrations (c) fluid conductivity (d) nitrate .......................................................5-4

Figure 5.3. Comparison of (1) 2D smoothness-constrained resistivity inversion along ' $L$ ine 1 ' of resistivity data from the BCCT with (b) the pore fluid conductivity measured from cores of the $\mathrm{C} 4191$ borehole

Figure 5.4. The correlation between $\mathrm{NO}_{3}$ concentration in $\mathrm{C} 4191$ and conductivity plotted at depth based on the HRRDPM as presented to the panel

Figure 5.5. The correlation between $\rho$ and nitrate $\left(\mathrm{NO}_{3}\right)$ concentration based on a well within the $\mathrm{T}$ Tank Farm as presented to the panel 
Figure 5.6. Cross-plot of modeled versus measured resistivity based on the parallel conduction model (a) no surface conduction (b) surface conduction........................................................5-7

Figure 5.7. Concept of resistivity formation logging from metal-cased boreholes ....................... 5-9

\section{APPENDICES}

Appendix A Workshop Agenda ...............................................................................................

Appendix B Attendee List ............................................................................................................................ B-1

Appendix C Stakeholder Comments and Questions............................................................................. 


\section{ACRONYMS}

bgs

BCCT

CERCLA

CFR

$\mathrm{CCU}$

CY

DOW

DWS

ERDF

$\mathrm{FH}$

HASP

HGET

HRRDPM

MCL

NA

NTU

OU

QA

RAM

RCRA

SGLS

TBD

TD

WAC

WCH

WTW below ground surface

BC Cribs and Trenches

Comprehensive Environmental Response, Compensation, and Liability Act

Code of Federal Regulations

Cold Creek unit

calendar year

description of work

drinking water standard

Environmental Restoration Disposal Facility

Fluor Hanford, Inc.

Health and Safety Plan

Hanford General Employee Training

HRR Data Plotting Method

maximum concentration limit

not applicable

nephelometric turbidity units

operable unit

quality assurance

Regulatory Analysis Memorandum

Resource Conservation and Recovery Act of 1976

spectral gamma logging system

to be determined

total depth

Washington Administrative Code

Washington Closure Hanford, LLC

well-to-well 
SGW-34795, Rev. 0

\section{METRIC CONVERSION CHART}

If You Know

Length

Inches

Inches

Feet

Yards

Miles

Area

sq. inches

sq. feet

sq. yards

sq. miles

Acres

Mass (weight)

Ounces

Pounds

Ton

Volume

Teaspoons

Tablespoons

fluid ounces

Cups

Pints

Quarts

Gallons

cubic feet

cubic yards

Temperature

Fabrenheit

Radioactivity

Picocuries
Into Metric Units

Multiply By To Get

25.4

2.54

0.305

0.914

1.609

6.452

0.093

0.0836

2.6

0.405

28.35

0.454

0.907

\section{5}

15

30

0.24

0.47

0.95

3.8

0.028

0.765

subtract 32,

then

multiply by

$5 / 9$

37

liters

liters
Out of Metric Units

If You Know

Multiply By To Get

Length

millimeters

centimeters

meters

meters

kilometers

Area

sq. centimeters

0.155

10.76

1.196

0.4

2.47

0.035

ounces

2.205

pounds

1.102

ton

Volume

milliliters

0.033

fluid ounces

2.1

1.057

0.264

35.315

1.308

pints

liters

liters

cubic meters

cubic meters

cubic meters

cubic meters

Celsius

Temperature

Celsius

multiply by

Fahrenheit

$9 / 5$, then add

32

Radioactivity

millibecquerel millibecquerel

0.027

picocuries 


\section{EXECUTIVE SUMMARY}

\section{Introduction}

There is a continuing need for cost-effective subsurface characterization within the vadose zone and groundwater at the U.S. Department of Energy (DOE) Hanford Site, Richland, Washington. With more than 1600 liquid and solid waste sites and 200 burial sites, contaminants have migrated to and through the vadose zone. In addition, future groundwater plumes may be generated from contaminants presently in the vadose zone. Relatively low-cost geophysical techniques can provide spatially extensive data that may provide information about the presence and extent of some contaminants. Recent electrical resistivity surveys at Hanford have provided encouraging results for mapping of some contaminants, such as nitrate, in the vadose zone. Because mobile radionuclides and trace elements may have been transported with nitrate through the vadose zone, the method may be used to map some mobile contaminants of concern, such as technetium $-99\left({ }^{99} \mathrm{Tc}\right)$. Validation of these recent electrical resistivity survey results remains to be completed.

Electrical resistivity surveys have been conducted at various waste sites in the 200 Area of the Hanford Site: BC Cribs and Trenches (BCCT), T, S, U, C, B Tank Farms and the Purex Plant. Surveys have been completed using surface and well-to-well (WTW) array configurations. The goals of the surveys, as described by Fluor Hanford and CH2MHill Hanford staff, were to test the applicability of resistivity methods in identifying the presence of and mapping approximate extent of contaminant plumes within the vadose zone.

To obtain an independent technical review, DOE provided support to convene an expert panel to review the results of the recent electrical resistivity surveys and make recommendations regarding future work to confirm the completed surveys and to design and conduct new surveys. Panel participants included: Dr. Laurence Bentley', University of Calgary; Dr. David Isaacson, Rensselaer Polytechnic Institute; Dr. Douglas LaBrecque, Multi-Phase Technologies, LLC; Dr. Louise Pellerin, Green Engineering, Inc.; and Dr. Lee Slater, Rutgers UniversityNewark. Dr. Dawn Kaback, Geomatrix Consultants, Inc., acted as panel facilitator and report editor. The panel participated in a three-day workshop in Richland, WA, during the week of April 16, 2007.

\section{Objectives}

The overall goal of the project was to evaluate the utility of electrical resistivity methods for characterizing contaminants of potential concern in the vadose zone in the 200 Area of the Hanford Site. The panel was asked to perform the following activities:

1. Evaluate recently completed and ongoing electrical resistivity projects at Hanford in terms of methodology used, results obtained, and lessons learned, with specific focus on

a. data collection (e.g., electrode placement, electrode composition, instrumentation)

b. data processing (e.g., inversion methods)

\footnotetext{
${ }^{1}$ Dr. Bentley was unable to attend the workshop, but provided substantive technical review of the document after reading the background materials provided to the panel.
} 

c. data reliability
d. data confirmation
e. data interpretation.

2. Review plans for confirmation of current and future electrical resistivity projects.

3. Suggest specific improvements to each of the above activities as part of the recommendations for future projects where electrical resistivity will be utilized. Recommendations should include discussion of an approach to vadose-zone characterization that could include other geophysical and non-geophysical methods.

At the beginning of the workshop, the Panel was also asked to provide answers to four key questions:

1. Can electrical resistivity methods be used at sites containing significant cultural features, i.e. piping, tanks, etc.?

2. Can electrical resistivity methods be useful for guiding the installation of new wells for subsurface characterization?

3. Can electrical resistivity methods be used to determine the shape (lateral and vertical extent) of a vadose-zone contaminant plume? ${ }^{2}$

4. Can electrical resistivity be used to determine the nature and concentration of contaminants in the vadose zone?

\section{Findings}

Electrical resistivity methods can be a cost-effective means to estimate variations in the subsurface resistivity over a target area or volume. As a result of their deliberations, the panel found that the recent geophysical surveys completed at Hanford have demonstrated that electrical resistivity is useful for estimating the location of high-concentration nitrate plumes in the vadose zone and may prove to be a useful tool for guiding locations for future boreholes for site characterization and monitoring purposes. The scientific basis for this finding relies upon identification of areas of lower resistivity, due to high concentrations of nitrate (tens of ohm-m) in pore waters, within the relatively high-resistivity geologic media of the unsaturated Hanford and Ringold Formations (hundreds of ohm-m). The panel supports the hypothesis that the resistivity method may also provide some indication of the presence and extent of other mobile contaminants, such as ${ }^{99} \mathrm{Tc}$, co-located with the nitrate, but will not be useful for contaminants, such as uranium, which may be more highly sorbed to surfaces of grains within the sedimentary units. Validation of the resistivity method for Hanford applications is of critical importance and should ideally be conducted prior to design of future resistivity surveys. Given the present state of knowledge, the panel recommends that the electrical resistivity method be utilized in combination with other characterization tools to support remedial decision-making.

The panel's findings, as well as the report, are organized according to the above evaluation components, items la through $1 \mathrm{e}$ in the "Objectives" Section. In addition, the panel reviewed plans for confirmation of the geophysical surveying results at the BC Cribs and Trenches, and provided recommendations for making improvements for future electrical resistivity surveys.

1.0 2 It should be noted that the term "plumen as used in this report may refer to resistivity anomalies in the vadose zone, not in the more traditional sense of a contaminant plume in the saturated zone. 
Response to Question 1. The panel found that the resistivity work completed at Hanford todate has not conclusively demonstrated that the method can provide reliable data in areas containing significant cultural features. However, the panel believes that independent mapping of infrastructure, careful survey design, and sophisticated processing using 3D inversion and interpretational approaches may enable separation of the response of the infrastructure from that of the conductive plumes and the geological heterogeneities in the subsurface. If this is found to be the case, the electrical resistivity method would be useful at sites with significant cultural features. The panel provides further discussion of a recommended approach to address Question \#1 in the body of the report. The panel cautions that distortion and/or cultural noise may be too high in some areas to acquire useable data.

Response to Question 2. The panel believes that electrical resistivity surveys, when implemented using best practices, as described in this report, can provide a useful guide for designing future site characterization programs, supporting selection of borehole locations for characterization and monitoring.

Response to Question 3. The panel believes that electrical resistivity methods should provide good resolution of the top and lateral extent of a conductive plume. However, the bottom of a conductive plume will be less well resolved. Advanced methods integrating both surface and subsurface electrode arrays, such as well-to-well and well to surface arrays, should be used to improve the resolution of the bottom of the plume; these approaches are recommended at locations where determination of the base of the plume is of interest. The panel cautions that without these advanced methods, there will be a greater uncertainty regarding the bottom of the plume. Confirmation drilling will always be required to support the plume delineation activity.

Response to Question 4. Electrical resistivity cannot be used to identify the specific nature of the contaminants, especially those present at concentrations in the parts per billion or parts per million levels, or to distinguish between different types of contaminants. However, because nitrate is also present in the pore waters at concentrations of tens and hundreds of thousands of parts per million, anomalous conditions, as compared to the natural subsurface resistivity, have been identified. Integrating the knowledge of the nature of the contaminants from borehole data, further investigation regarding estimation of concentrations from the resistivity data should be conducted to determine its feasibility. The panel urges caution, however, because of the uncertainties in geophysical imaging and petrophysical relationship.

\section{Data Acquisition Findings}

Recent electrical resistivity surveys at the Hanford Site were designed within logistical constraints of the survey area. Instrumentation used for the surveys was appropriate. The selection of survey parameters was based on general experience, and not model-based survey design. As such, it is not known whether the acquired data sets were optimized.

The panel is concerned with the acquisition of data at sites such as the tank farms, which are complicated by above and below ground infrastructure, including tanks, pipes, roads, and powers lines. These features can cause electrical interference, resulting in noisy or distorted data. The panel recognizes that existing wells at the $S$ Tank Farm were resourcefully used as transmitters and receivers in a well-to-well (WTW) array to reduce effects of the infrastructure. 
This type of array can give an estimate of the horizontal extent of a plume in an area of significant infrastructure, but cannot be used to resolve the vertical dimension of the plume. For surface resistivity surveys at sites with significant infrastructure, the panel recommends that the effect of the infrastructure for a given array must be systematically examined to ensure that the effect has been fully considered in the interpretation of subsurface conditions. The panel recommends use of both WTW and surface surveys in combination with systematic evaluation of the contribution of infrastructure at these types of sites.

The panel cannot comment on the quality of data acquired, because they did not receive information on instrument calibration or documentation related to data accuracy and reliability.

\section{Data Processing Findings}

The approach to data processing for electrical resistivity surveys at the Hanford Site has evolved from calculation of an apparent resistivity depth of investigation transformation, called High Resolution Resistivity (HRR), to state-of-the-art three-dimensional (3D) inversion of the data. The HRR data plotting method (HRRDPM) is a means of representing measurement data, which results in a smooth, volume-averaged approximation of the resistivity of the subsurface. The transition to processing with inversion, which is a method of modeling the data conditioned on constraints that promote a geologically plausible model structure, is applauded by the panel. In a complex environment, resistivity values estimated from inversion are closer to the true earth resistivity values than apparent resistivity values and have fewer measurement artifacts. Therefore, interpretations of plumes in 3D space, sensitivity analyses, and survey design should always be based upon inversion results. The 3D inversion results observed by the panel were most reasonable and promising of all processing and presentation methods. The 3D inversion model for the BCCT is very encouraging. Data from other surveys already completed should be processed similarly prior to any interpretation of subsurface conditions. The panel is concerned about the following data processing issues.

- It was difficult for the panel to assess data processing methods, due to the lack of information about error cutoff values for elimination of poor quality data points. Some references to data processing steps that could substantially alter data interpretations were made.

- Filters were used to improve the appearance of the HRRDPM plots rather than modeling. Filtering may create effects that interfere with the subsequent inversion of the data.

- A 2D model study was initiated to understand the response and resolution of the plume target within the presence of a pipeline with limited success. This 2D inversion should be re-examined, possibly by an independent geophysical expert.

- The 3D image was achieved with half of the acquired data; it is unclear whether the full dataset would more accurately resolve plume geometry.

\section{Data Presentation Findings}

Many of the results were presented with non-standard color scales. The use of different color scales to compare different results may be misleading, because it embeds interpretation through choice of color scale within the presentation. Volume rendering for isocontours is good for 3D visualization; however, defining the appropriate resistivity contour value is problematic. The 
panel recommends the design of a standard template, based on a statistical assessment of the range of resistivity typically encountered at the Hanford site, for presentation of resistivity images. Such a template would facilitate comparisons of resistivity images allowing assessment of spatial and temporal variations across the site. Variations to highlight particular features should only be used after images are presented with the standard color scale

\section{Interpretation Findings}

The comparison of geophysical survey results at the BCCT with the data at borehole $\mathrm{C} 4191$ is very encouraging for indirect mapping of the nitrate, and possibly the ${ }^{99} \mathrm{Tc}$, plume in 3D space in the vadose zone. However, this interpretation is based upon data from a single borehole, and further invasive characterization is critical to confirming the performance of the method. To estimate concentrations of contaminants, such as nitrate (question \#4), in the subsurface using resistivity data, petrophysical studies to investigate the relationship between resistivity and both moisture content and ionic concentration must be further investigated. In addition, the spatial variability of electrical resistivity due to geological heterogeneity needs to be quantified. The panel believes that such petrophysical research on the electrical properties of the vadose zone at Hanford is essential for improving the interpretation of existing and future resistivity data. The panel is generally supportive of the approach employed in the initial stage of research, but identified a number of issues that must be addressed: 1) the accuracy of the petrophysical measurements, and 2) the inconsistencies between the petrophysical data and established models for current flow in porous media.

\section{Recommendations and Suggested Improvements for Future Projects}

The following recommendations reflect the unique nature of the Hanford Site. Data acquisition costs are high, consequences of either false positive or false negative results are substantial, and data acquisition can be especially difficult. Consequently, some of the quality control procedures and recommendations are more rigorous than the normal standards of professional practice. Because the DOE Hanford Site contractors do not necessarily have in-house geophysical experts, the panel recommends they acquire the services of an independent expert in electrical resistivity methods to assist with future procurements (RFP preparation), technical oversight during conduct of the work, and independent review of results.

\section{Data Acquisition and Data Quality Recommendations}

Given the difficulty and expense of data acquisition and the potential impact of decisions based upon the geophysical data, it is of utmost importance that rigorous survey design be conducted, so that data acquisition is efficient and target resolution is of necessary quality to support remedial decisions. Because plumes, geology, and infrastructure are all 3D, 3D surveys, processing, and interpretations, which will achieve the highest accuracy and resolution, are recommended for future projects, because they will impact remedial decisions worth millions of dollars.

Survey design includes 1) determining the region of interest, 2) assessing the impact of environmental conditions, 3) minimizing the impact of cultural noise, and 4) quantifying limits of resolution. Survey design can be performed with numerical or scale modeling simulation. The panel recommends that survey design be used to evaluate the merit and economic viability 
of multiple data acquisition approaches, such as various surface arrays, WTW arrays, and surface-to-well arrays, especially at locations of high infrastructure.

The panel strongly recommends comprehensive documentation that includes quality control procedures and checks on data accuracy, which should include system calibration checks, reciprocal checks, and repeated measurements of targeted portions of surveys, following the suggestions for documentation of data acquisition outlined in Fogwell et al. (2006). In addition, both internal and external audits should be performed. Because of the scale of ongoing and planned surveys at the Hanford Site, the panel recommends that at least one external audit performed by an independent geophysical contractor, including at least a pointby-point data comparison of one line segment and data acquisition on one or more full survey lines to perform a full comparison of survey methodology, should be conducted.

\section{Data Processing and Presentation Recommendations}

The HRRDPM should only be used for data quality evaluation and internal processing. It should not be used as a primary method for determining subsurface resistivity, for making interpretations, or for making presentations.

Three-dimensional inversion should be used as the principal method for determining, interpreting, and presenting estimates of the subsurface resistivity. Because $3 \mathrm{D}$ inversion is the most accurate method on which to base interpretation, it is least subject to artifacts due to infrastructure; because the problems under investigation are $3 \mathrm{D}$, the panel recommends this approach to data processing and presentation. In limited circumstances, $2 \mathrm{D}$ inversion may be appropriate, if the resistivity distribution varies only in two dimensions. A priori information, including locations of pipes, tanks, and other structures, should be incorporated into forward and inverse models to improve accuracy of the models. The misfit between the measured and modeled data should be determined and displayed to allow an assessment of the significance of the presented models.

Numerical models should be verified by quantitative comparison with experimental model studies. These results should be used to determine achievable resolution quantitatively. The resistivity of the experimental model should be compared quantitatively with the reconstructed resistivity to determine the reliability of the reconstructions in the given setting. A priori information should be incorporated as an additional inversion constraint when available. The quality of the inversion results should be evaluated. Results should show the fit between the measured and simulated data from reconstructed models. Another recommended test is to predict data points that have not been used in the inversion and compare them with measured data. Data and error analysis should be presented in quantitative, as well as graphical, form.

In most instances, the same standard gray or color scales should be used throughout a survey. If non-standard color scales are used, then detailed explanations should be provided on the reasons for and choice of non-standard scales. A local grid should be well defined and easy to follow between survey maps and model results.

\section{Data Confirmation and Petrophysics Recommendations}

The panel recommends that Fluor and $\mathrm{CH} 2 \mathrm{MH}$ Hill place the objective of obtaining confirmation data to evaluate the inverted resistivity images as highest priority in the next data collection 
program. We understand that plans are underway to do this at BCCT and similar efforts should be conducted at other sites where surveys have already been performed, prior to acquisition of data at any new site. The panel also recommends an expert evaluation of geophysical logging technologies that could be used to obtain confirmation data from existing cased wells. In addition, a thorough review of existing borehole data should be performed to extract useful information.

Because resistivity imaging is an indirect method for mapping contamination, it is critical that the petrophysical basis of the interpretation is clearly specified. This requires the collaboration of an expert in resistivity properties of soils. In general, the panel was impressed by the efforts to apply geostatistical concepts, and further exploration of such ideas is encouraged.

\section{Review of BC Cribs and Trenches Sampling and Analysis Plan}

The panel was charged with reviewing the draft Sampling and Analysis Plan (SAP) for validating the resistivity surveys at the BCCT Area. The panel believes that current validation for all the completed surveys is limited to one borehole at BCCT and a few wells at the T Tank Farm. The decision to embark on a program of verification drilling is strongly endorsed, as it is clear that validation of the geophysics is urgently needed to demonstrate the capabilities of the technology with respect to contaminant plume delineation.

The BCCT SAP proposes up to five boreholes, placed at locations based on the resistivity results. The borehole locations are based on the structure generated using the HRRDPM, rather than the structure observed in 3D inversions. The panel strongly recommends that the five borehole locations proposed in this plan be reevaluated based on resistivity inversion results for the BCCT, and the SAP be subsequently revised to provide inversion-based justification for the borehole locations. It is important that the confirmation drilling include multiple borehole locations in various locations that span regions where contamination is suspected and where it is not. 
SGW-34795, Rev. 0

This page intentionally left blank

Ex-8 


\subsection{INTRODUCTION}

\subsection{THE PROBLEM}

The U.S. Department of Energy (DOE) Hanford Site, located near Richland, Washington (WA) consists of approximately 600 square miles. At the site, there are more than 1600 liquid and solid waste sites and 200 burial sites, many of which have contributed contaminants to the vadose zone and groundwater. Approximately eighty square miles of groundwater contain a variety of hazardous and radioactive contaminants at levels above drinking water standards. Emerging and future groundwater plumes may be generated from contaminants in the vadose zone. As such, there is a continuing need for cost-effective subsurface characterization and monitoring both within the vadose zone and saturated zone.

Conventional sampling techniques for characterizing or monitoring the shallow subsurface typically involve collecting core samples and acquiring hydrological measurements and/or geophysical log data from boreholes. Due to difficult drilling conditions and safety requirements at Hanford, intrusive characterization methods (e.g., drilling) are expensive, and by nature, only represent a tiny portion of the subsurface at this very large site. Also, because the subsurface at Hanford consists of highly heterogeneous sediments, a few small samples of a contaminated area cannot accurately represent its field-scale character. When the size of the contaminated site is large relative to the scale of the hydrological or geological heterogeneity, such as is usually the case at Hlanford, data obtained at point locations or within a borehole are unlikely to capture key information about field-scale heterogeneity, making characterization a challenging task.

It is well known that geophysical surveys can provide spatially extensive geophysical data at relatively low cost; however, it is also recognized that geophysical methods provide only indirect information about the subsurface properties of interest. Despite this limitation, geophysical methods can provide valuable characterization data, when applied properly in conjunction with other characterization methods.

\subsection{OVERVIEW OF RECENTLY COMPLETED RESISTIVITY PROJECTS}

Over the last fifty years, many geophysical methods have been used at the Hanford Site for subsurface characterization with a range of successes (Last and Horton, 2000). Most recently, electrical resistivity methods have been applied at a variety of locations within the Hanford Site with the goal of mapping contaminant plumes in the vadose zone. At the first location where the method was tested, BC Cribs and Trenches (BCCT), the contaminant of most concern is technetium-99 $\left({ }^{99} \mathrm{Tc}\right)$ (Rucker and Benecke, 2006). However, nitrate was also introduced into the subsurface at the same time as the ${ }^{99} \mathrm{Tc}$. Because ${ }^{99} \mathrm{Tc}$ and nitrate are both highly mobile, it is believed that they have been transported together in the vadose zone at this location.

Electrical resistivity methods were applied in an attempt to map zones of high total dissolved solids, primarily nitrate, associated cations, and trace elements (including radionuclides) in the vadose zone.

Since 2004, electrical resistivity surveys have been conducted at various waste sites in the 200 Area of the Hanford Site, where the vadose zone is approximately 65 meters thick. At the BCCT, resistivity methods were used to delineate a nitrate ${ }^{\rho 9} \mathrm{Tc}$ plume in the vadose zone 


\section{SGW-34795, Rev. 0}

beneath shallow liquid waste disposal units. Subsequently, resistivity surveys, including surface and/or well-to-well (WTW), have been conducted at T, S, and U Tank Farms (Rucker et al., 2006a, b, and c). Additional surveys are being completed at C and B Tank Farms and at the Purex Plant.

\subsection{OBJECTIVES}

The overall goal of this project was to convene an expert panel for evaluation of the utility of electrical resistivity methods to characterize contaminants in the vadose zone in the 200 Area of the Hanford Site. The expert panel was charged with the following activities:

1. Evaluate recently completed and ongoing electrical resistivity projects at Hanford in terms of methodology used, results obtained, and lessons learned, with specific focus on

a. data collection (e.g., electrode placement, electrode composition, instrumentation)

b. data processing (e.g., inversion methods)

c. data reliability

d. data confirmation

e. data interpretation.

2. Review plans for confirmation of current and future electrical resistivity projects.

3. Suggest specific improvements to each of the above activities as part of the recommendations for future projects where electrical resistivity will be utilized.

4. Consider alternative approaches to vadose-zone characterization that could include other geophysical and non-geophysical methods.

The panel was also asked to provide answers to four key questions:

1. Can electrical resistivity methods be used at sites containing significant cultural features, i.e. piping, tanks, etc.?

2. Can electrical resistivity methods be useful for guiding the installation of new wells for subsurface characterization?

3. Can electrical resistivity methods be used to determine the shape (lateral and vertical extent) of a vadose-zone contaminant plume?

4. Can electrical resistivity be used to determine the nature and concentration of contaminants in the vadose zone?

\subsection{APPROACH}

In the spring of 2007, Fluor Hanford identified a number of technical experts from academia, and industry to participate as an expert panel to review the results of recent geophysical surveys conducted at the Hanford Site. Panel participants include: Dr. Laurence Bentley, University of Calgary $^{2}$; Dr. David Isaacson, Rensselaer Polytechnic Institute; Dr. Douglas LaBrecque, MultiPhase Technologies, LLC; Dr. Louise Pellerin, Green Engineering, Inc.; and Dr. Lee Slater, Rutgers University-Newark. Dr. Dawn Kaback, Geomatrix Consultants, Inc., acted as panel

\footnotetext{
${ }^{2}$ Unable to attend the workshop; provided technical review of the draft and final report.
} 


\section{SGW-34795, Rev. 0}

facilitator and report editor. Reports describing the results of the BCCT (Rucker and Benecke, 2006) and T, S, and U Tank Farms resistivity surveys (Rucker et al., 2006a, b, and c) were reviewed by the expert panel prior to the workshop. The panel participated in a three-day workshop in Richland, WA during the week of April 16, 2007. The workshop agenda is provided in Appendix A; a list of workshop participants is provided in Appendix B.

During the first two days, presentations on site geology, hydrology, historical operations, and current contaminant plumes, as well as presentations on completed and ongoing geophysical projects, were given by staff from Fluor Hanford, CH2MHill Hanford, Pacific Northwest National Laboratory, and the geophysical contractor. A broad stakeholder group was in attendance for many of these presentations. Both Washington Department of Ecology and Environmental Protection Agency staff provided their regulatory perspectives at the beginning of the workshop. The stakeholder audience was very active, asking numerous questions during the presentations. Some also provided comments and additional questions via email. These stakeholder viewpoints are provided in Appendix C. The remainder of the workshop involved internal panel discussions and an out-briefing to the broad stakeholder group at the conclusion of the workshop. After the workshop, the panel prepared this report to document their findings and recommendations.

Section 1.0 of the report provides introductory information, such as background, goal/objectives of the project, and approach. Sections 2-5 focus on the panel's evaluation of recently completed and ongoing projects and suggested improvements for future projects for the following topics: data acquisition (Section 2), data reliability and quality control (Section 3 ), data processing and presentation (Section 4), and hydrogeological interpretation and validation (Section 5). Some of the recommended approaches may already be routinely performed, but were included in the report, because either this information was unknown by the panel or it was included because of its importance. Section 6 provides reviewer comments on confirmation plans for the BCCT, and Section 7 presents conclusions and recommendations by the panel. 
SGW-34795, Rev. 0

This page intentionally left blank 


\subsection{DATA ACQUISITION}

Data acquisition at Hanford, especially at the tank farms, is complicated by above and below ground infrastructure, such as tanks, pipes, roads and powers lines. These features can cause electrical interference with the measured voltage signal resulting in noisy or distorted data. Site access may be limited, because of safety and/or physical restrictions, e.g., electrodes cannot be placed above tanks or on an active road. Because of these difficulties and expense of performing surveys at the Hanford Site, it is important that surveys are optimally designed. Given the challenges of data acquisition, it is of utmost importance that survey design be properly conducted, so that data acquisition is efficient and effective. A good survey design will identify the most important measurements, given the logistical constraints on the project. Questions to ask at the survey design stage might include:

1. is profile acquisition sufficient or is a three-dimensional (3D) grid necessary to resolve the targets of interest?

2. how important is the infrastructure and what is the best method to minimize its impact on the survey?

Buried infrastructure challenges the ability to acquire, interpret, and visualize resistivity data. Shallow subsurface and above-surface structures (e.g., pipelines, well heads, overhead power lines, tanks, metal buildings) can prevent access or contribute electrical and magnetic responses that mask changes caused by subsurface hydrogeological changes. At sites such as the tank farms, the location of electrodes for surface geophysical surveys can be significantly limited.

\subsection{EVALUATION OF RECENTLY COMPLETED AND ONGOING ELECTRICAL RESISTIVITY PROJECTS AT HANFORD}

\subsubsection{Survey Design}

Survey design is a critical part of any project, whether it be experimental or a production survey, so that the best effort is made to collect the correct data in a cost-effective manner. Recent electrical resistivity surveys were designed within logistical constraints of the survey area. Electrode and line separations along two-dimensional (2D) profiles were selected, based on experience for the given geological conditions and target properties, and the assumption that the interpretation would be 2D (profile oriented). A lot of detail is known about these sites from engineering and historical plans, ground penetrating radar (GPR), magnetic and electromagnetic (EM) surveys, and borehole data. However, because the target (plume), geology and infrastructure are all $3 D, a$ a survey design would have been a preferred approach.

A 3D forward modeling code was used to test the response due to infrastructure, but was not used for survey design. At the BCCT, insufficiencies in the data set were recognized after substantial data acquisition in 2004 and 2005, and another field campaign targeting the northeastern portion of the site was undertaken in 2006 . The data were inverted with and without the 2006 data; results of both are shown in Figure 2.1, with significantly different results. 


\begin{abstract}
Proper survey design would have optimized data collected and should have eliminated the need for a second field effort. As the selection of survey parameters was based on general experience, not experimental design, it is not clear whether all the data needed to be collected, or whether the collected data were optimally located or sufficient to meet the survey objective. Because of computational limitations, the data set was decimated by half for 3D inversion. At the tank farms, inter-electrode spacing was 3 meters, but only 6-meter spacing data were used for inversion with very reasonable results. The panel recommends an analysis be conducted to determine the difference in technical results and associated costs between the models using the decimated and full datasets.
\end{abstract}

With FY05 Data

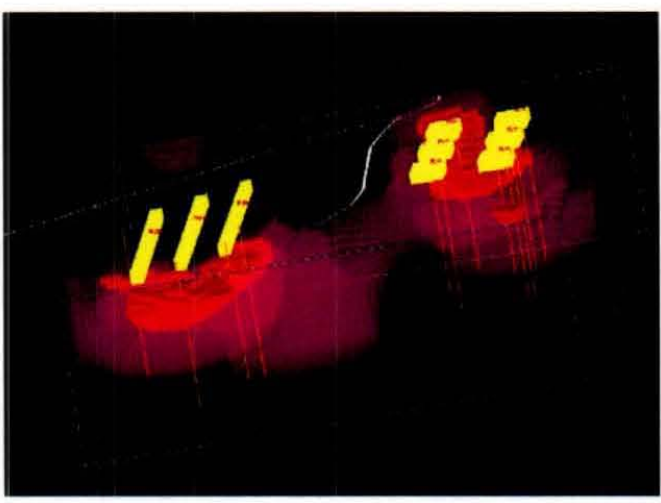

+ FY06 Data

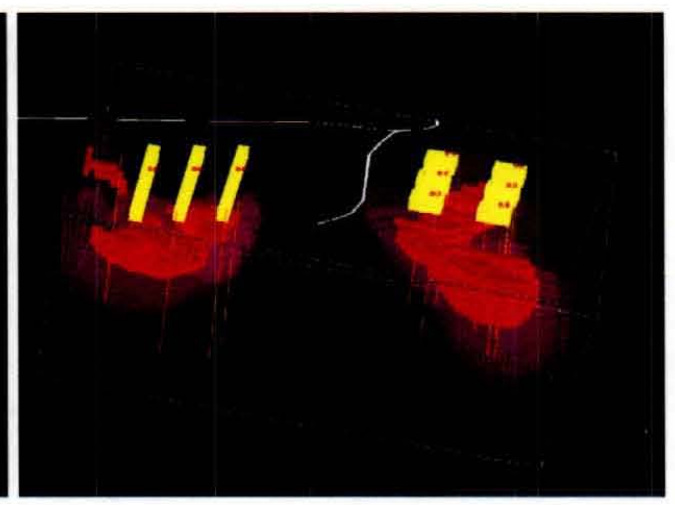

Figure 2.1. 3D inversion using the data acquired in 2005 only (left) and with the addition of 2006 data (right) at the BCCT

Survey design should include determining the region of interest and the resolution limits to detect or image target structures (plume size and shape). Through either numerical or scale modeling, a simulation is used to optimize data acquisition parameters. Optimal electrode number and placement should be modeled to achieve target delineation with desired resolution. Numerical simulation and experimental model studies give quantitative results on the ability to distinguish features of interest. The modeling/sensitivity analysis was based on apparent resistivity (data) plots, not parameter estimation (inversion), and as discussed later in the report, cannot be used to develop quantitative estimates of resolution.

\title{
2.1.2 Instrumentation
}

Resistivity data were acquired using an Advanced Geosciences, Inc. (AGI) SuperSting ${ }^{\mathrm{TM}}$ R8 resistivity instrument in the pole-pole array configuration. The unit is a DC-powered, battery operated, low voltage, low amperage, automatic, eight-channel resistivity and IP system. This system employs the SuperSting ${ }^{\mathrm{TM}}$ Swift ${ }^{\mathrm{TM}}$ general purpose cables that can be attached in series. Each cable segment contains four smart electrodes. Each electrode has the capability of acting as either a low-amperage current transmitter or as potential measuring receiver. The Sting R8 has the capability of automatically switching between electrodes without having to physically move the electrode connections after initial set-up. The Sting R8 was used in a survey line spread of 72 smart electrodes with source-potential electrode spacings ranging from two to 150 
meters. The survey line was moved forward incrementally by removing a 12-electrode segment from the trailing end of the survey line spread and placing it at the front of the spread between measurements. Roll-along surveys can also be performed for 3D surveying. However, roll-along can only be performed in the X-direction and the cable needs to be laid out back and forth in the Y-direction, as specified in Advanced GeoSciences (AGI, 2005).

The percentage standard deviation for each data point is recorded with the SuperSting ${ }^{\mathrm{TM}} \mathrm{R} 8$ as a measure of the quality of the data point. The measurement at each data point is repeated several times and the mean of those values is reported as the measured value. The percentage standard deviation of the data point is the ratio of an estimated measurement standard deviation of the repeated measurements divided by their mean. The percentage standard deviation was used to edit data. Data points with a percentage standard deviation greater than some percentage were deleted, but this was not always documented. The limitations in using the percentage standard deviation to estimate data accuracy are discussed under quality control in the report.

If used within the parameters described in the instruction manual (AGI, 2005), the SuperSting ${ }^{\mathrm{TM}} \mathrm{R} 8$ is an acceptable system for performing resistivity surveys within the BCCT. Other instruments that provide similar quality data do, however, exist. Problems in acquiring IP data with the SuperSting ${ }^{\text {TM }}$ were reported in the T Tank Farm Report (Rucker et al, 2006c). If IP data are to be recorded during future surveys, these IP data acquisition issues will need to be addressed with the manufacturer before using the SuperSting ${ }^{\mathrm{TM}}$ to acquire additional IP data. Secondly, adding additional electrodes and cables would have reduced logistical problems with acquiring data in restricted areas within the tank farms. With sufficient cables, it should be possible to automatically perform entire lines with the instrument at a single location outside of the restricted area.

\subsubsection{Induced Polarization (IP)}

Although IP data can be simultaneously acquired with resistivity data using the SuperSting ${ }^{\mathrm{TM}}$ R8/IP system, IP data were acquired on only one line through BCCT Trench 216-B-26. The stated objective was to determine whether or not IP data would provide additional insight into the character of the plume. The geophysical contractor (Rucker, 2007b) concluded that no discernible pattern related to the plume was evident in the data, and IP brought no benefit to characterize the plume. However, details of the IP survey configuration or IP data were not presented to the panel. Rucker (2007a) stated that the SuperSting ${ }^{\mathrm{TM}}$ was recording unreliable IP data. The IP surveys that were conducted appear to have been extremely limited in scope and do not allow conclusions to be drawn regarding the utility of the method at Hanford.

IP data can be very useful for investigating lithology containing clay lenses, for monitoring data quality, and can provide real-time field information that can be used to modify the data acquisition plan. However, IP signals are much smaller $(1 / 100)$ than resistivity signals, and thus, are more susceptible to contamination by noise. The method is also very sensitive to infrastructure, which may produce large negative IP anomalies. The use of IP in environmental applications has been limited, most likely due to noisy industrial environments, such as 
Hanford. Evaluation of the utility of IP at Hanford would require measurements on more than a single line and confirmation that the SuperSting ${ }^{\mathrm{TM}}$ unit is recording meaningful IP data.

It is unclear whether non-polarizable electrodes, which contain a metal-liquid solution junction, such as $\mathrm{Pb}-\mathrm{PbCl}$ or $\mathrm{Cu}-\mathrm{CuSO}_{4}$, were used. These electrodes can improve data quality by removing polarization effects at the electrodes. If IP is to be used for investigating lithology at Hanford, non-polarizable electrodes, which are more expensive to purchase and deploy than standard stainless steel electrodes, would be required; if IP is being used simply to identify strong anomalies, such as cultural effects, standard electrodes may be used.

\subsubsection{Other Methods}

Magnetics, EM, and GPR data were acquired with mixed degrees of success. The surveys were used primarily to delineate infrastructure. The density of infrastructure rules out the use of the transient EM method; coupling with pipes, power lines and other metallic features within as much as 100-200 meters can distort transient EM data. These infrastructure-induced signals can be difficult to detect in the data, leading to the risk of inaccurate interpretations.

Downhole geophysical logging methods using specialized technologies, such as those provided by Schlumberger Water Services, in existing cased boreholes may provide valuable characterization information and should be considered for new boreholes. It is important to consider the types of subsurface characterization information of interest and whether these advanced tools can provide such information in cased boreholes in the unsaturated zone.

\subsubsection{Array Configuration (Pole-to-Pole)}

The choice of array configuration has been an ongoing discussion in the literature for years. Roy and Apparao (1971) has been cited for the superiority of the pole-pole method for shallow surveys, because it provides higher data density, has increased signal-to-noise ratio, and requires less transmitted energy. Using forward and inverse numerical simulations, Sasaki (1992) states "when the instrumental accuracy is high, the dipole-dipole array is more suitable for resolving complex structures than the pole-pole array. The pole-dipole array gives somewhat less resolution than the dipole-dipole array, but yields greater signal strength; thus, the pole-dipole array may be a good compromise between resolution and signal strength." Beard and Trip (1995) came to a similar conclusion. Dahlin and Zhou (2004) used forward and inverse numerical modeling and determined relative anomaly effects for the different arrays varying with the geological models. However, the relatively high anomaly effects of pole-pole, moving gradient, and Wenner surveys do not always give a high-resolution image. In the modern era of multiple channel measurements and inversion codes, there is no need to strictly utilize classical arrays. Non-standard arrays and mixed configurations may have the best combination of acquisition efficiency and image sensitivity (Wilkinson et al., 2006). Description of other array configurations can be found in the literature, such as Telford et al. (1990). Many more references can be cited, but it is clear that to determine optimal array configuration and related resolution, numerical studies specific to the survey area should be performed. 


\section{SGW-34795, Rev. 0}

For the Hanford surveys, the pole-pole array, which has one electrode from each of the current and potential pairs fixed effectively at infinity, while the other current and potential electrodes within the survey area are located at a separation of 'a' as shown in Figure 2.2, was used. Subsequent electrodes are separated by ' $n a$ ' spacings, where " $n$ " is an integer. Practically, the infinite electrodes are spaced approximately 2 to 10 times the distance of the furthest separation of the survey's electrodes, which can be up to 200 meters apart. The pole-pole survey at the BCCT included a fixed a-spacing of 3 meters and $\mathrm{n}$ increased from 1 to 27 .

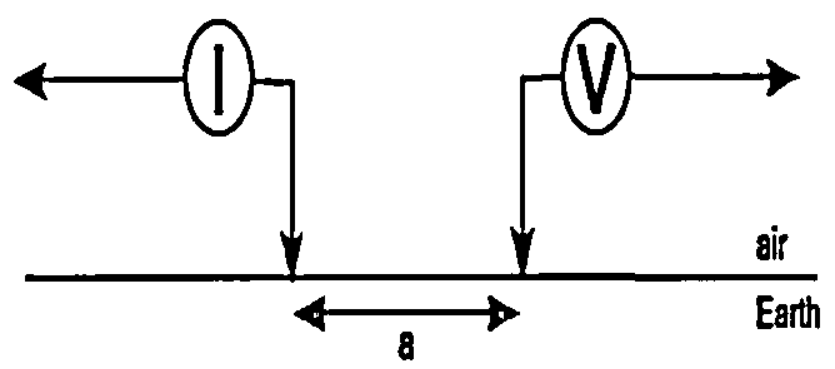

Figure 2.2. The pole-pole array configuration

The geophysical contractor presented a model study at the workshop to demonstrate the strengths of various arrays and the choice of the pole-pole array. In Figure 2.3, a plume was modeled and the responses for the Schlumberger, pole-dipole, dipole-dipole and pole-pole arrays were plotted as apparent resistivity pseudo-depth sections. Because different pseudodepth scales were used, a black line was drawn to indicate the $20 \mathrm{~m}$ depth. Inspection of these responses indicates that the pole-pole is a suitable choice. However, the synthetic data were not inverted to test the resolution of each array, and the effect of the infrastructure for a given array was not examined. 

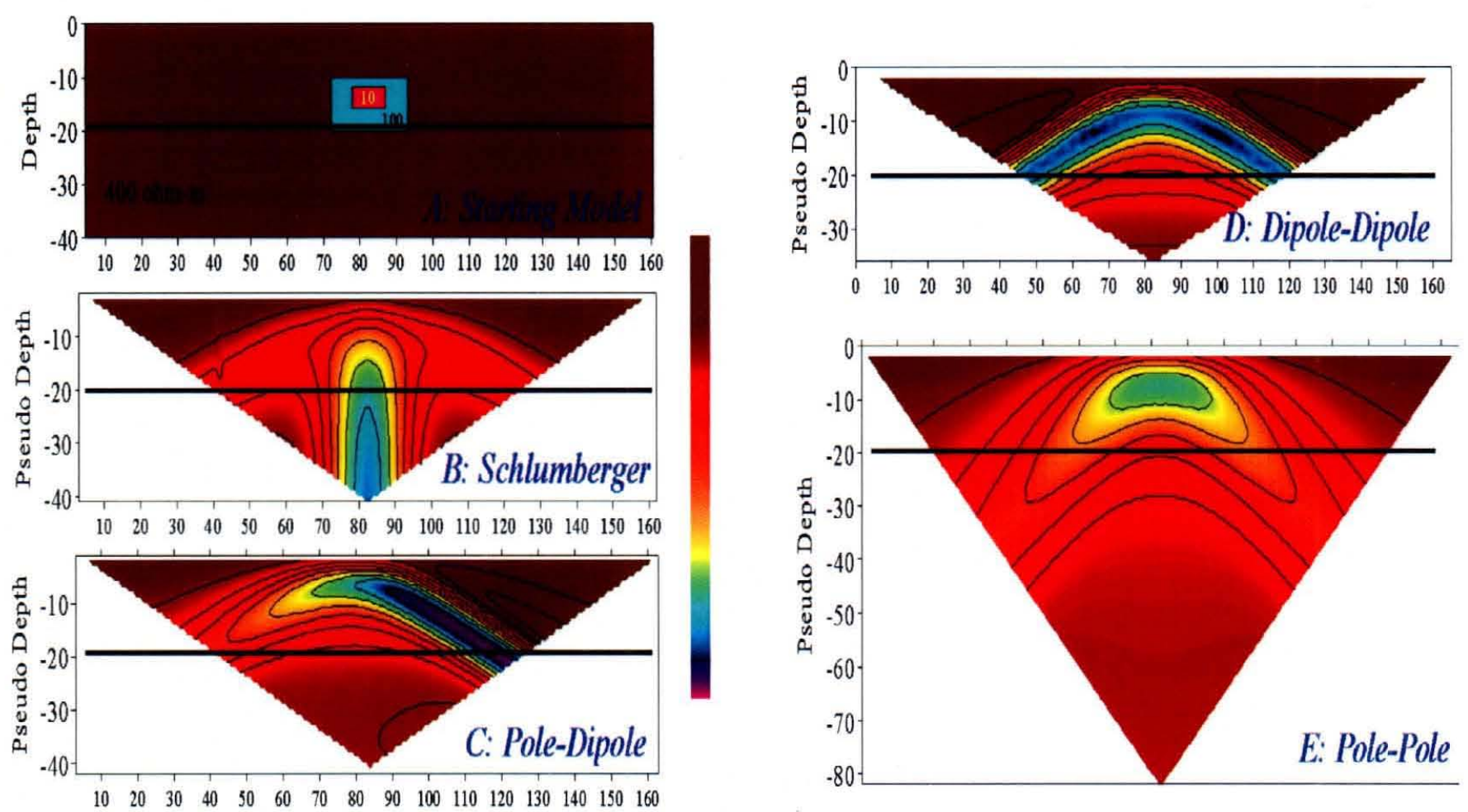

Figure 2.3. Responses of (A) a plume model for the (B) Schlumberger, (C) pole-dipole, (D) dipole-dipole and (E) pole-pole arrays are plotted as apparent resistivity HRR pseudo-depth section

\subsubsection{Well-To-Well (WTW) Approach}

Because it is very challenging to work in areas of high infrastructure, such as the tank farms, existing wells were resourcefully used as transmitters and receivers in what is referred to as the well-to-well (WTW) approach. Drywells (in the vadose zone) and groundwater wells, which are between 7 and $80 \mathrm{~m}$ deep at T Tank Farm, were modeled as a linear set of electrically conductive cells (line source) of values of $0.001 \mathrm{ohm}-\mathrm{m}$.

The advantage of incorporating wells into the survey design in areas of high infrastructure is that much of the electrode grounding exists below the metallic structure, reducing excitation of the infrastructure. Major disadvantages of the WTW configuration are that wells may not be optimally located or of sufficient density to resolve the target. More significantly, the use of a linear line source, (i.e. the wells) means that the inversion yields a 2D image with no vertical information.

At the T Tank Farm, the WTW data was used to map the plume within the tank farm, but as depth information was not recovered, results can only be observed in plan view. The level of agreement between the WTW \& surface images, shown in Figure 2.4, ( $50 \%$ overlap) indicates that aside from the lack of depth resolution, the sensitivity of the WTW is different from a surface array. One or both arrays are not sensitive to the target and data may be distorted by infrastructure, the inversion may not be properly implemented, or there may be other reasons. 
Sensistivity analysis of the array configurations and appraisal of the inverse solutions would be helpful to determine the false positives/negatives. Uncertainty of the solution would also help to account for the discrepancy.

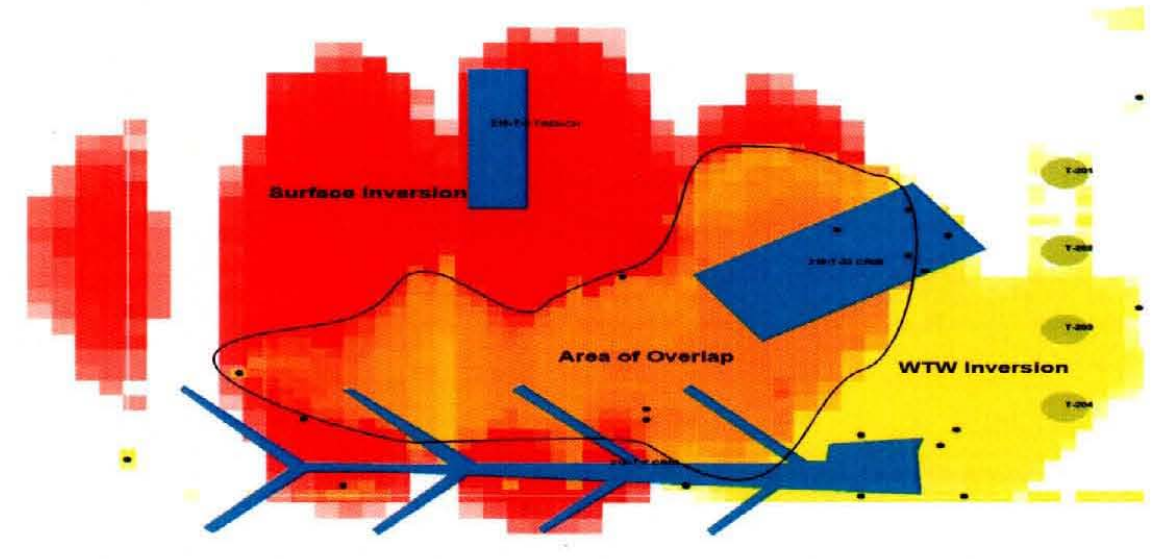

Figure 2.4. Inversion of WTW and surface inversion for the T Tank Farm, illustrating the difference in sensitivity between the array configurations

(Rucker, 2007a)

\subsection{SUGGESTED IMPROVEMENTS FOR FUTURE PROJECTS INVOLVING ELECTRICAL RESISTIVITY METHODS}

\subsubsection{Survey Design}

We recommend a systematic survey design, which includes the following approach, be employed:

1. Determine the region of interest: identify the volumes, shapes, and boundaries of the regions to image.

2. Determine the possible infrastructure within the region of interest: identify the possible pipes, tanks, and structures that might influence the current flow within the region of interest.

3. Determine the "resolution" needed to detect or image useful structures, e.g., plume size and shape within the region of interest: identify quantitatively the features of the structures that one would want to be able to resolve in order to obtain a useful image. For example, one might want to distinguish a plume of a given size at a given depth whose conductivity differed from the background by larger than a given amount; this should be addressed through survey design.

4. Create a $3 D$ forward simulation ${ }^{3}$ : create a numerical model of the region of interest containing simulated infrastructure as well as the structures of interest to determine the extent to which it is possible to achieve the desired resolution. Use

\footnotetext{
${ }^{3}$ Even if the proposed study consists of 2D profiles and inversion, one objective of this simulation is to explore resolution and image artifacts caused by out-of-plane resistivity variations due to $3 \mathrm{D}$ heterogeneity.
} 
this model to calculate the signals (voltages) that would result from the proposed measurements. Determine if the signals from structures of the desired size and contrast differ enough from the background, so that they can be detected by the proposed methodology.

5. Create a scale model: test the predictions of the numerical model with measurements made on a physical scale model. This ensures that the assumptions of the numerical methods, as well as the assumptions made about the accuracy of the instrumentation, are correct. For example, compare measured voltages from the scale models with voltages computed from the numerical model predictions obtained for several possible plume and background structures. Obtain quantitative measures of the accuracy with which the simulations agree with the measurements through a variety of approaches, including the square root of the sum of the square of the differences between the numerical and scale model voltages and the voltages measured on the scale model, or the maximum of the absolute values of the deviations between the measured and modeled voltages normalized by the largest numerical value.

6. Simulate forward data for a variety of electrode locations and numbers: perform numerical simulations of the ability to resolve the features of interest with each proposed configuration to optimize the electrode number and location. When a subset of optimal electrode locations has been determined by numerical simulation, they should be tested and confirmed by a scale model study.

When using the survey design methodology described above, an effort should be made to simulate highly heterogeneous subsurface media, such as the Hanford Formation. This might be done using a deterministic set of perturbations to a uniform background or by using statistical models of complex backgrounds. The reason to attempt to simulate the complex geology is that a target might be marginally detected using a uniform background, but might not be detected or imaged in a complex geology with a heterogeneous background.

\subsubsection{D Acquisition}

We recommend 3D data acquisition be used to achieve the highest resolution and confidence levels required for these surveys.

1. Use surface-to-well, in addition to WTW and surface-to-surface data collection: careful survey design considerations will be needed to overcome the problems caused by infrastructure. The use of all possible electrode locations in the design stage should help determine which electrode locations increase the sensitivity of the data set to the desired structures. Addition of surface-to-well data will provide a larger number of voxels that may be reconstructed, and hence, a higher resolution of the desired structures, including critical depth resolution.

2. Determine the optimal location and minimum number of electrodes needed to achieve the desired resolution: use forward simulation, including infrastructure, to determine the locations for which a minimum number of electrodes may achieve the desired resolution. Test the numerical predictions by using a scale model. Give quantitative measures of the accuracy of the numerical models in predicting the measured data from the scale models.

3. Use 3D array configurations: 
a. Current electrodes - determine the optimal patterns of current excitation to use by simulating $3 \mathrm{D}$ array configuration, as opposed to $2 \mathrm{D}$ profile-oriented arrays. For example, $\mathrm{N}$ lines of $\mathrm{K}$ electrodes when excited one line at a time as repeated for 2D data collection yield NxK currents and result in currents that primarily travel from the current electrode to the voltage electrode. Because conductivity variations far from current paths will have little effect on the measurements, some numerical and model experimentation with current patterns may improve the signal to noise or sensitivity of the measurements to target structures. This explains why use of surface-to-well in addition to WTW arrays should increase the ability to distinguish and image targets.

b. Voltage electrodes - when $\mathrm{N}$ lines of $\mathrm{K}$ electrodes are used with 2D voltage measurement patterns, there are $\mathrm{NxKxK}$ voltage measurements that result. When 3D patterns of voltage measurements are used, there are $\mathrm{NxKxNxK}$ voltage measurements that result. This increase in the number of measurements should result in improved sensitivity and resolution. Simulations should be used to determine the minimal number and optimal location of patterns that result in the desired sensitivity to changes in conductivity in the structures of interest. The model study, which is must less expensive, is used to optimize the field deployment, thereby reducing costs, while predicting achievable depth of investigation and resolution.

4. Test by numerical simulation and experimental model studies: proposed electrode number, location, transmitter, and receiver configurations should be tested by numerical simulation and the results confirmed by synthetic model studies.

5. Give quantitative results on the ability to distinguish features of interest: the results of these studies should be quantitative measures of the ability of the proposed patterns to distinguish and image potential targets of interest. Confidence in the success of the proposed field study will be increased, if the surveys over known targets compare favorably with predictions from synthetic model studies. 
SGW-34795, Rev. 0

This page intentionally left blank 


\subsection{DATA RELIABILITY AND QUALITY CONTROL}

\subsection{EVALUATION OF RECENTLY COMPLETED AND ONGOING ELECTRICAL RESISTIVITY PROJECTS AT HANFORD}

Previous publications of the recent electrical resistivity surveys at Hanford include little information on data quality and no quantitative assessments of data quality. The panel strongly recommends fully documenting quality control procedures and reporting the results of these procedures in project reports. The discussion below is confined to quality control procedures that were documented in reports reviewed and presentations given to the panel and where possible, direct observations of the data provided.

\subsubsection{Instrument Calibration and Drift}

In geophysics, calibration generally refers to testing or adjusting an instrument, such that it provides consistent, accurate readings of geophysical data. Resistivity instruments are designed to measure the ratio of resulting electrical potential to transmitted current. The unit of measure is Ohms. Instrument calibration, as used here, is accomplished by performing instrument readings on a known, highly accurate, NTS traceable standard.

The rated accuracy of the AGI SuperSting ${ }^{\mathrm{TM}}$ is $1 \%$. The manufacturer recommends that the instrument calibrations be repeated annually. Although it may have been done, the geophysical contractor did not provide documentation indicating that additional instrument calibration checks were performed on a routine basis.

\subsubsection{Noise Evaluation}

The AGI SuperSting ${ }^{\mathrm{TM}}$, like most modern microprocessor-controlled geophysical instruments, provides an estimate of the data standard deviations, which is referred to as the percentage standard deviation. While collecting readings, the system averages over a number of repeated waveforms. In geophysics, these repeated waveforms are referred to as stacks and the averaging process as stacking. By assuming each stack is an independent estimate of the data value, the instrument can use them to estimate the standard deviation of the data that were used to make the reported average value. However, because the stacks are collected by the same electronics over a period of only a few seconds, the errors are not statistically independent; thus, true errors in the data are underestimated, and in some cases, dramatically underestimated. This method thus does not provide a reliable method of assessing data accuracy and reliability.

More reliable tests of data accuracy and reliability, such as reciprocal checks and independent repeats of partial data sets, do not appear to have been performed on surface electrical resistivity data in the BCCT surveys. At the T Tank Farm, at least one section was repeated in to assess the effects of different electrode types (Rucker et al., 2006c), but there was no quantitative analysis of these results provided to the panel and there was no description of routine survey procedures. Rucker et al. (2006c) indicate that "limited" repeats were made during routine operations, but the panel was not provided any quantitative assessment of data repeatability. The data were examined by the panel, based on the principle that electrical potentials are continuous and generally smoothly varying within the earth (Hallof, 1992). Figures 3.1 and 3.2 show excerpts from data collected in 2005 (Rucker and Benecke, 2006) 
along Line 1 extracted from file HRRLN1A.stg. After the data were sorted and plotted by transmitter locations, the receiver values were plotted versus the electrode location. Pole-pole data usually show smooth continuous decrease in potentials away from the current electrode. In this case, a small group of receivers clustered around point $330 \mathrm{~m}$ show extremely large values of potential. These data probably reflect large errors in the received data. Ideally, occurrences such as this are noted and investigated in the field. Although these data appear to be in error by an order of magnitude, the percentage standard deviations recorded by the SuperSting ${ }^{\mathrm{TM}}$ are all less then $1 \%$. This indicates that percentage standard deviation reported by the instrument is a poor measure of overall data accuracy.

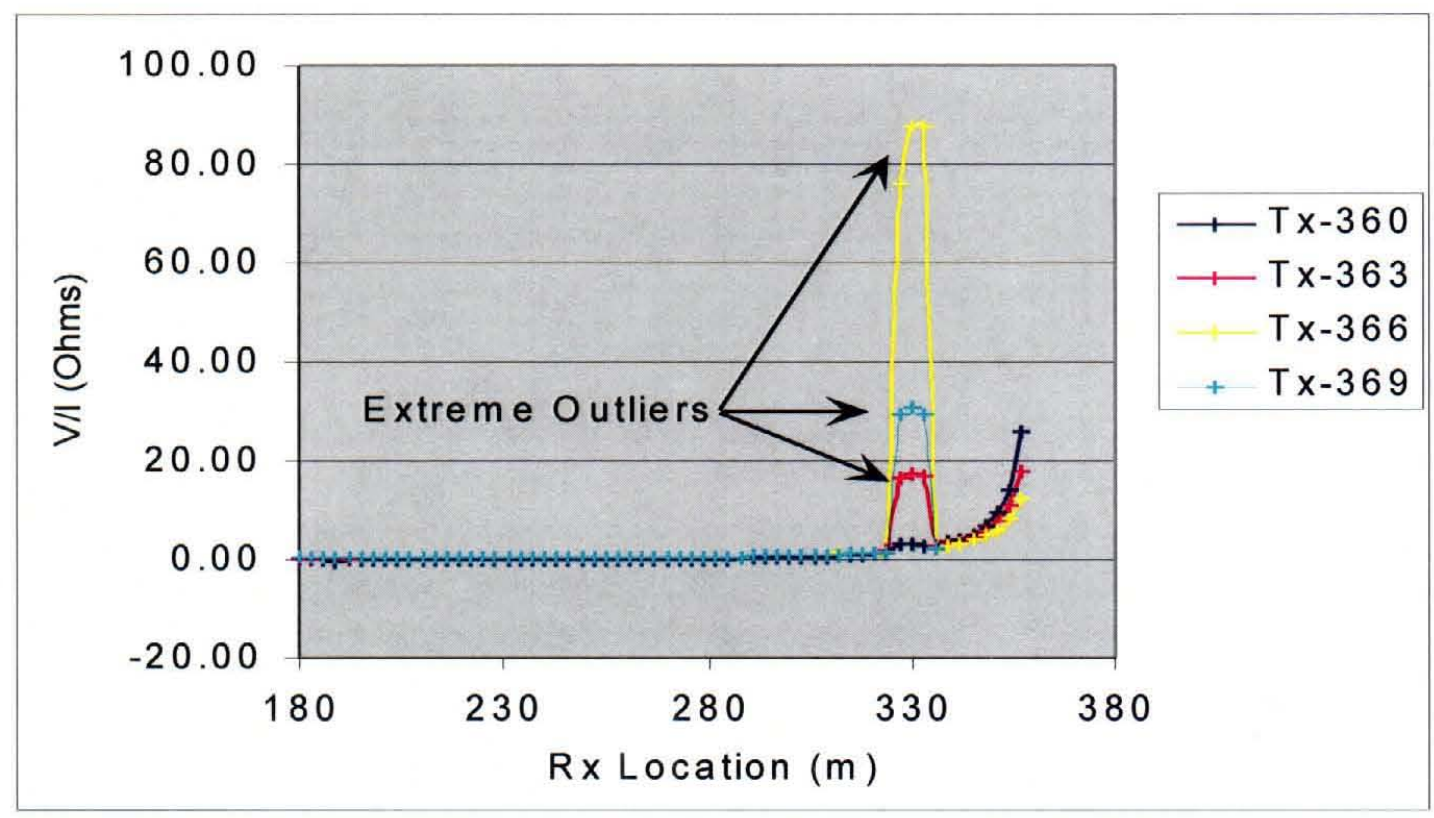

Figure 3.1. Data series from Line HHRN1, collected in 2005, showing large outliers (data series are plotted as a function of receiver electrodes locations for four transmitting electrode locations 360, 363, 366, and $369 \mathrm{~m}$ ) (Rucker and Benecke, 2006)

Figure 3.2 shows a detailed view of the same data series in Figure 3.1, which was collected using a transmitter electrode located at $360 \mathrm{~m}$ deviate from the expected smooth curve for all of the data collected using Channel 1 of the SuperSting ${ }^{\mathrm{TM}}$. Closer examination shows a smaller, but notable, problem in data collected with other transmitter electrode locations. The correlation between these effects and the channel used to collect them indicates that the errors almost certainly result from an instrumentation problem either in the SuperSting ${ }^{\mathrm{TM}}$ or the Swift ${ }^{\mathrm{TM}}$ cables. The percentage standard deviation calculated by the SuperSting ${ }^{\mathrm{TM}}$ is not adequate to detect these errors; reciprocal measurements or repeated surveys will provide better estimates of data errors. The level of acceptable errors depends upon the data quality objectives listed in the Project QA Plan or Data Quality Objectives Report. 


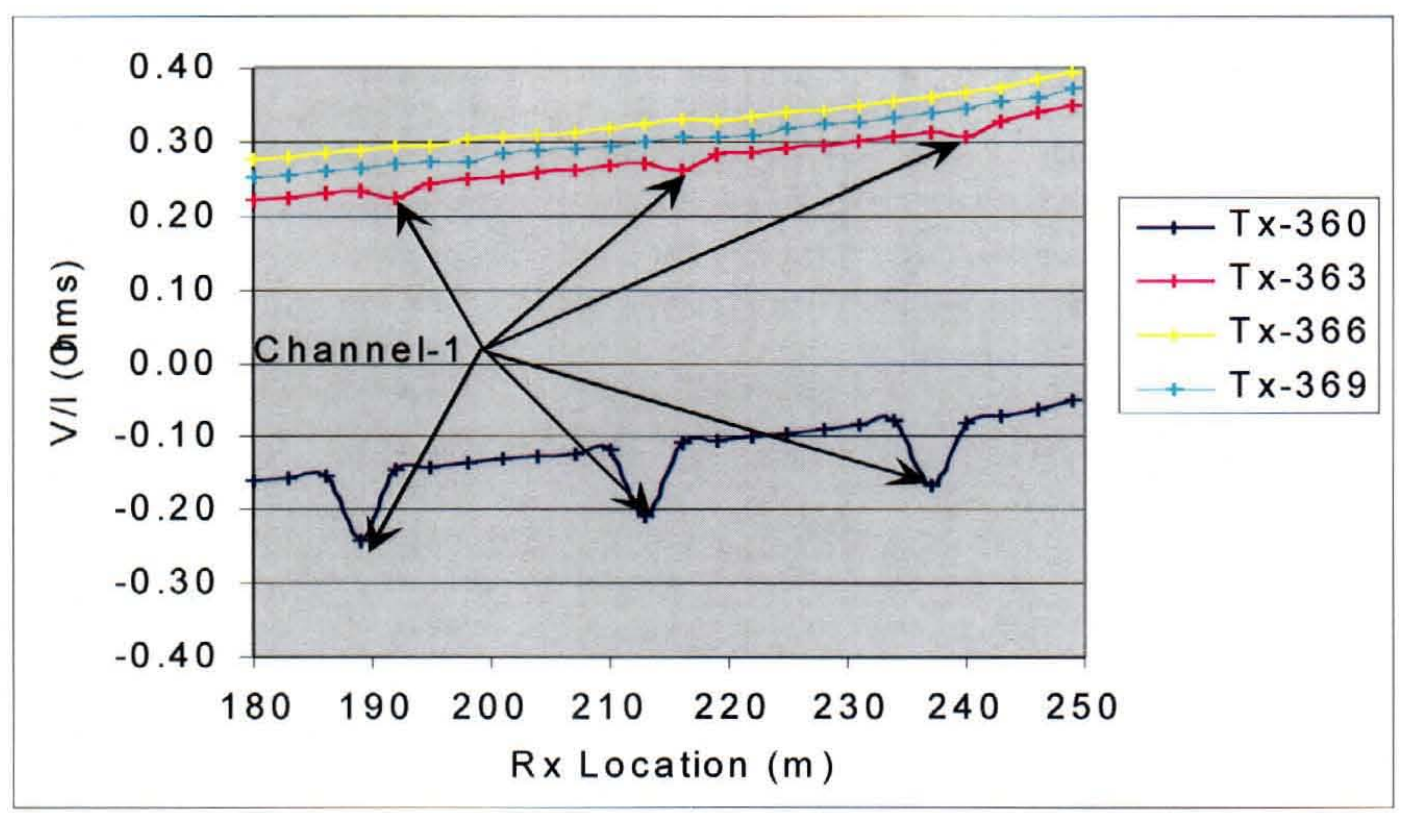

Figure 3.2. Detail of data series from Line HHRN1, collected in 2005, showing presence of unusual features in the data collected using channel 1 of the SuperSting ${ }^{T M}$

(data series are plotted as a function of receiver electrodes locations for four transmitting electrode locations 360, 363, 366, and $369 \mathrm{~m}$ ) (Rucker and Benecke, 2006)

\subsubsection{Environmental Conditions}

Two types of environmental effects are present in surveys: cultural effects and effects of rainfall events and seasonal temperature changes, which can change the subsurface resistivity over time. These changes in subsurface resistivity can interfere with the imaging results and may also impact the performance of the geophysical hardware. Inversion routines are used to extract deep resistivity structures in the presence of shallow structures. However, the available inverse model packages don't account for changes in the model over time. Thus, large changes in shallow resistivity structure midway through a survey violate the basic assumptions of inverse solutions and will have adverse, unpredictable effects on produced images. Data sets that require weeks or months to collect should avoid combining data collected in late winter when the ground temperature is lowest and late summer when the ground temperature is highest.

In-situ electrical resistivity is largely a function of the pore water volumetric content, salinity, temperature and the cation exchange capacity of the soil (Waxman and Smits, 1968). As the cation exchange capacity is unlikely to change, the primary concerns are large changes in temperature, salinity, and water content. Diurnal temperature changes persist only a few centimeters into the ground. Annual temperatures are significant only in the top few meters of the surface (Kapplemeyer and Haenel, 1974). Temperature changes are of significant concern for time-lapse comparisons and interpretation of resistivity values within the top few meters of the surface. It is also necessary to consider temperature when data values will be compared quantitatively with petrophysical models. However, as the resistivity work reviewed by the 
panel is primarily concerned with characterization rather than monitoring of time variations and the emphasis is on deeper targets, the issues associated with temperature changes are easily managed (e.g., concern only if data sets collected over long periods of time are jointly interpreted, in which case portions of the data should be repeated to determine if large changes have occurred). More problematic is precipitation, such as rainfall events that potentially could cause large changes in near-surface moisture content. Usually these problems will be localized to either natural (ponds or large puddles) or man-made (infiltration basins, retention ponds, French drains) infiltration zones. Although water is often poured on electrodes during surveys to lower electrode resistance, the amount of water is generally too small to substantially impact survey results.

A secondary consideration is the effect of environmental conditions on equipment. For all resistivity systems, rainfall can create both safety hazards and unwanted conduction paths. It is important to keep connectors and face panels containing connectors dry. Crews should avoid allowing cables and wires to be submerged in puddles. Some versions of the SuperSting ${ }^{\mathrm{TM}}$ Swift ${ }^{\mathrm{TM}}$ electrodes are not water tight, and should not be used, if there is standing water on the ground (AGI, 2005). Water can enter and corrode the electrodes, permanently damaging them. A number of systems, including the SuperSting ${ }^{\mathrm{TM}}$, will tend to overheat, if used on hot days.

Cultural interference is the presence of features, such as pipelines, powerlines, and fences, which create signals that interfere with imaging of subsurface data. These features interfere with resistivity measurements in two ways: 1) they create electrical noise that interferes with the reception of the potentials induced by the transmitter, and 2) they can create strong in-situ electrical responses that can mask subsurface features of interest. In previous work at Hanford, magnetic and electromagnetic surveys for locating and delineating cultural effects, such as pipelines, were performed. Ideally, this survey information should be used to reduce the effects of these cultural features in the resistivity data. Because of the large number of cultural effects on many of the sites, the effects were included in at least some of the data inversion schemes.

\subsubsection{Documentation}

\subsubsection{Documentation for Data Acquisition}

In the AGI SuperSting ${ }^{\mathrm{TM}}$ and other microprocessor-controlled acquisition systems, at the start of each survey line, the principal operator must enter the survey configuration information, including line and file designations, array type, electrode locations, timing information, and signal acquisition parameters into the system through a series of menus and submenus. For the data made available to the panel, a generic data acquisition configuration was recorded, without entering actual electrode coordinates and entered $0,0 \mathrm{~m}$ as the starting point for the line regardless of its location. If absolute locations cannot be divulged, relative distances between electrodes should be recorded. This is a fairly common practice, but not a good one. First, the data are not self-documenting and data reduction and processing are dependent entirely on maintaining written field notes. Second, the apparent resistivities calculated by the instrument are inaccurate. The locations of all four electrodes are required to calculate apparent resistivities. With the pole-pole array, the effects of the reference electrode can be ignored, only, if they are placed a very large distance away from the survey line. To achieve an accuracy of $1 \%$, the reference electrodes must be more than 100 times the largest transmitter- 
receiver separation. This would require separations of several tens of kilometers for the surveys at the BCCT. It is not clear whether the instrument apparent resistivities were used in subsequent interpretation, or, if the correct apparent resistivities were recalculated using the correct locations and measured voltage/current.

Most resistivity systems, including the SuperSting ${ }^{\mathrm{TM}}$, do not have sufficient detail within the data headers for the data to be fully and adequately self-documenting. It is important that field notes, whether hand written or typed into a portable computer, be complete and be closely associated with the raw field data files. One advantage of the SuperSting ${ }^{\mathrm{TM}}$ over some competitors' equipment is that it timestamps each data point. Timestamps potentially provide a useful, important check on data, if they can be compared with field notes, where the time and date is noted and with field/project schedules.

\subsubsection{Documentation of Data Processing}

There is very little documentation of data processing with the reports. These reports should include: data reduction procedures, data statistics, and data processing flow charts. Data elimination was based upon a percentage standard deviation not always defined. Filtering procedures were poorly documented. Of substantial concern are references to data-processing steps that could substantially alter data interpretations. One of the presentations (Rucker, 2007a, Overview of Electrical Resistivity in Tank Farms) showed a data series where it appears that not only data had been removed by an ad hoc method, but that a number of original data were replaced with interpolated points using a cubic spline (Figure 3.3). Clearly defined, unbiased criteria are needed to choose which data are removed prior to plotting or interpretation. When data are removed, they should be left out of pseudo-section plots. Furthermore, such interpolated points violate basics assumptions of typical inversion routines and will likely produce erroneous results. In general, data entered into resistivity inversion routines should not be manipulated by applying low pass or averaging filters to spatial data. Such filters may violate the basic theory of the modeling routine and will likely produce erroneous results. 


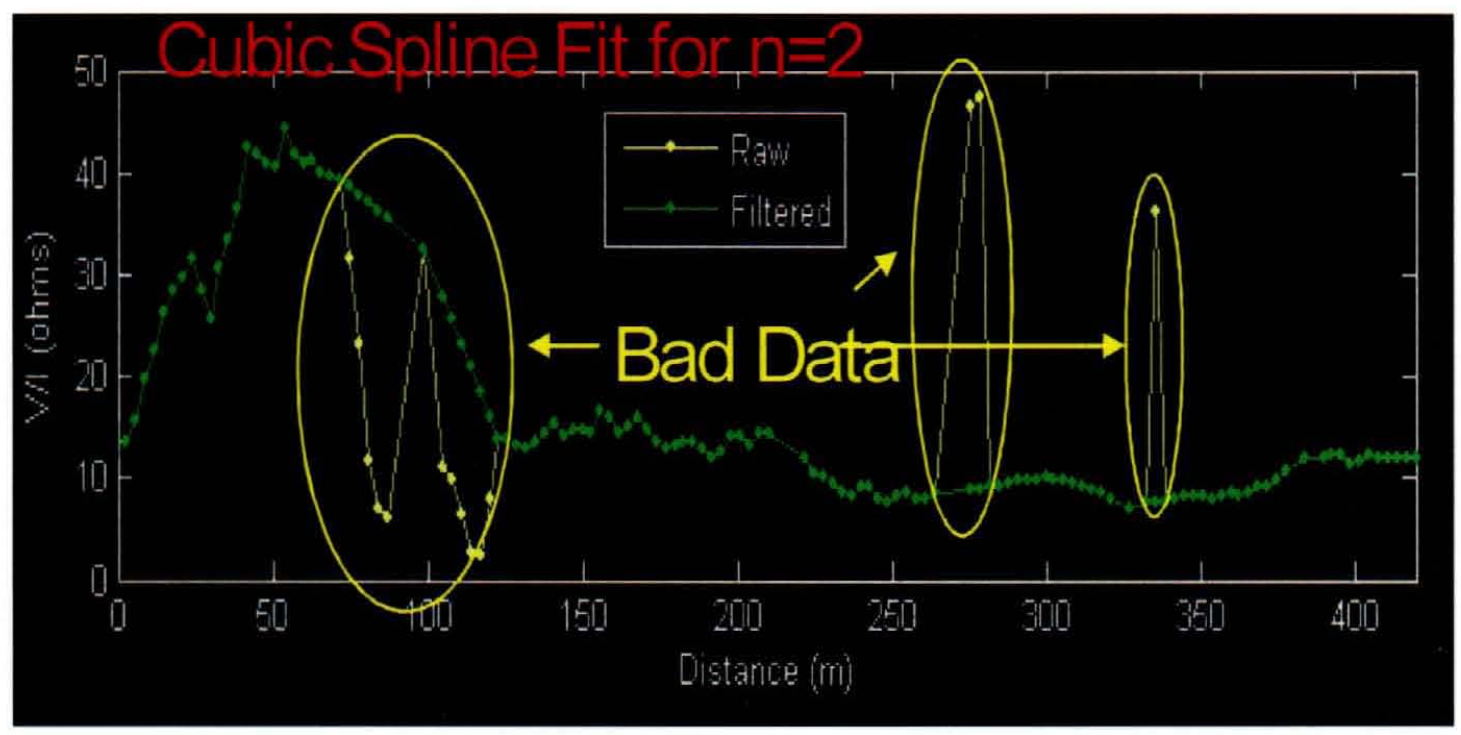

Figure 3.3. Figure from Rucker 2007 presentation showing data replaced using cubic-spline interpolation

\subsubsection{Audits}

No external or internal audit results were presented to the panel. Suggestions for audits are included in the following section.

\subsection{SUGGESTED IMPROVEMENTS FOR FUTURE PROJECTS INVOLVING ELECTRICAL RESISTIVITY METHODS}

\subsubsection{Instrument Calibration and Drift}

As no documentation of system calibrations were provided to the panel, the following are general, suggested guidelines for instrument calibration, some of which may have already been implemented. Full-system instrument calibration is usually performed by the manufacturer using NTS traceable standards and is performed annually or whenever the system is returned for repair. Full instrument calibrations involve checking and adjusting internal calibration standards in the instrument. Alternatively, calibration checks are used to find if the instrument is operating within its specifications and should be performed periodically. At a minimum, calibration checks should always be performed at the start of a survey, at the completion of a survey, and any time there are any indications that the instrument is malfunctioning. The panel recommends more frequent intervals. As surveys may span days or even weeks, more frequent intervals are recommended. If the system fails a calibration check, or otherwise malfunctions, and must be returned for repair and recalibration, any data collected after the previous calibration check is suspect and should be discarded. Thus, the choice of intervals between calibration checks is largely a question of how much data one can afford to lose versus the amount of time required for a calibration check (generally a few minutes). Intervals can range 
from checks as frequent as the beginning, middle, end of the day to as long as the beginning and end of a survey, which often may be several weeks.

The basic concept of the calibration check is simple. The system is connected to a resistor circuit similar to that shown in Figure 3.4. Current is placed through one or more resistors and the induced potential is measured across one or more one ultra-high precision resistors. However, to be effective, the calibration circuit must be designed to test the full operating range of the instrument. In modern instruments, the electrical potential is measured at a discrete set of gain settings, each of which may have a different calibration constant. The gain is the amount that the signal is amplified in the system. To provide accurate measurements, the gain is varied, such that the signal is increased to roughly the middle of the voltage range measured by the instrument. The SuperSting ${ }^{\mathrm{TM}}$ has a voltage range of $+/-10$ volts and gain ranges of $1,2,5,10,2050,100$, and 200 .

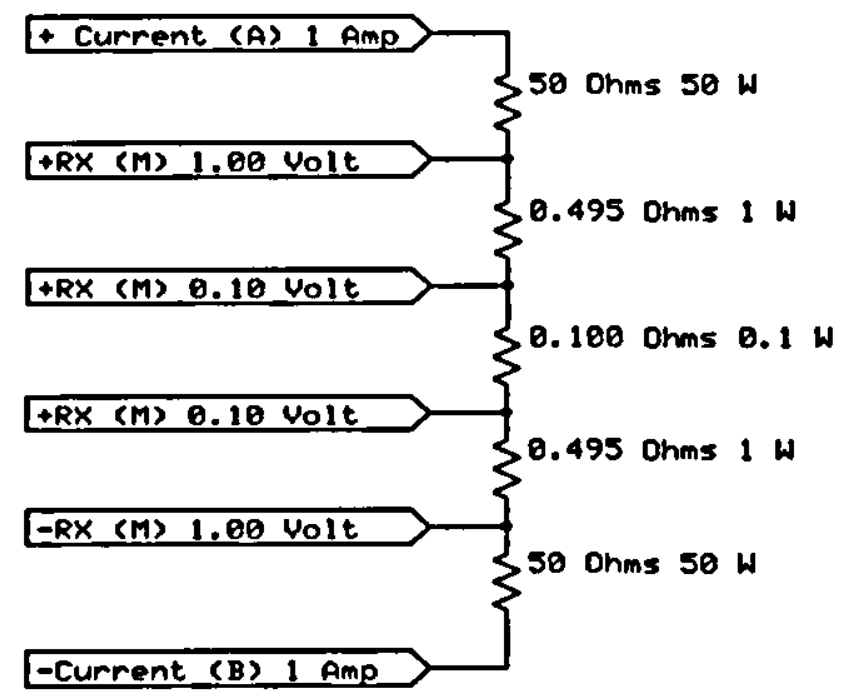

Figure 3.4. Example of calibrator circuit

The current flow must also be known with the same or better accuracy than the potential. One approach is to produce a precisely controlled current flow at one of a discrete set of levels; for example 1 millamp, 2 milliamps, 5 milliamps, and so on. Alternatively, the current is measured in a manner similar to the method of measuring the voltage. In this second type of instrument, the current measurement system will often have a set of distinct current flow measurement ranges similar to the gain ranges used in the potential measurements. For instruments, such as the SuperSting ${ }^{\mathrm{TM}}$, that fall into this second category, it is important to contact the manufacturer to determine these current flow ranges prior to designing a calibration check, because fully checking the system calibration requires testing of all combination of current flow and potential ranges. Thus, for an instrument with $\mathrm{N}$ potential ranges (eight for the SuperSting ${ }^{\mathrm{TM}}$ ) and $M$ current settings/ranges (unknown for the SuperSting ${ }^{\mathrm{TM}}$ ), the calibration check would require $\mathrm{N} \times \mathrm{M}$ measurements. 
The resistor circuit shown in Figure 3.4 consists of relatively high resistance power resistors designed to dissipate the power of the transmitter over the various current flow ranges. The induced potentials are measured across one or more ultra-high precision resistors that are in series with the power resistors. These resistors are readily available with tolerances (the rated accuracy) of $0.1 \%$ or better.

\subsubsection{Noise Evaluation}

Internal quality estimates from resistivity instruments do not provide a sufficient method to evaluate data accuracy. To evaluate data accuracy, one must perform:

- systematic checks of instrument calibration,

- reciprocal checks where the receiver and transmitter are interchanged,

- repeated measurements of targeted portions of surveys whenever changes in site conditions may affect readings or from external audits.

In reciprocal checks, the transmitter and receiver locations are interchanged and the readings repeated. In theory, the readings should repeat exactly. Note that to achieve true reciprocals with pole-pole data, the reference electrodes must be exchanged when the survey electrodes are exchanged. Some electrical geophysicists believe that an electrode should never be used as a receiver after using it as a transmitter (Carlson et al., 2001), and in general, it is best to wait as long as reasonably possible between reusing a transmitting electrode as a receiver. However, on examining the raw data from previous HRR surveys, we found that many of the receiving electrodes were previously used as transmitters; thus, this does not appear to be an issue. Nonetheless, it is still good practice to arrange acquisition sequences to maximize the average time after an electrode is used for current injection until it is used for voltage measurements. The panel recommends that reciprocal measurements be made for all readings. The use of full reciprocal measurements provides the most reliable method of locating and removing noisy data on a point by point basis. Conducting reciprocity measurements on a small percentage of data will allow for more accurate assessment of the noise levels in the data, but does not provide a method for discriminating between good and bad data.

\subsubsection{Environmental Conditions}

The following section includes suggestions for future operations. Some of these have likely already been implemented, but are not fully documented in existing reports. Environmental conditions should be addressed through survey design and testing. For rainfall and temperature effects, the primary concern is that data jointly interpreted should be collected under similar conditions. It is important to monitor and evaluate the impact of environmental changes by repeating representative segments of surveys. Sections of surveys should be routinely repeated during normal operations. If surveys are internupted by events, such as thunderstorms, the last few readings of the previous survey period should be repeated prior to continuing the survey. Particular attention should be paid to areas at high risk for environmental effects, such as areas where water puddles or infiltrates, retention ponds, and near perennial and intermittent streams and rivers.

Where possible, cultural noise should be minimized, and when necessary, cultural features modeled. Surveys should be oriented perpendicular to features, such as pipclines, fences, and power lines. Survey lines should be located as far from power poles (due to the ground plates attached to the poles) and fence poles as possible. The electrodes themselves should be as far 
as possible from fences and pipelines. Often, the line start point can be shifted so that pipes fall midway between electrodes (Nelson, 1977).

Ideally, pipeline cathodic protection should be turned off during survey operations.

Alternatively, the field crew chief may want to try test runs near the pipeline with different base frequencies and stack intervals to find the combination that minimizes the effects of the cathodic protection. Metal pipes and fences are strongly polarizable and are generally observable as induced polarization anomalies. The effects of pipes and fences can be minimized, if the sections of the pipe or fence near the survey line are isolated. For example, it may be possible to place ceramic insulators in barbed-wire fences and either temporarily open flanges or insert plastic gaskets in pipe flanges. IP data can generally be effectively used for evaluating cultural noise; data strongly affected by cultural features should be removed from data interpretation.

Interpretation of data collected in areas with large amounts of cultural noise will need to be performed using routines that include the explicit modeling of metal pipes and well casings. Attempts at ad-hoc correction for cultural effects are not effective (LaBrecque et al., 1998).

\subsubsection{Documentation}

\subsubsection{Documentation of Data Acquisition}

We strongly recommend incorporating the recommendations outlined in the report: Evaluation of Geophysical Technologies for Subsurface Characterization (Fogwell et al., 2006) including:

- All raw field measurements should be stored on digital storage media and backups should be verified and archived. Archival and documentation procedures should be specified in any contracting document.

- Measurements in the field should be documented in a standard accepted manner using field notes, and/or an acceptable automated computer documentation of measurements. Field notes should form the basis of providing information regarding measurement directions, coordinates of lines, scaling, and enable another qualified geoscientist to produce repeatable results from the raw field data.

- Names of field crew, instrument identifier (manufacturer's serial number), presences of anthropomorphic structures, time of day, weather and any unusual activity or occurrences should be recorded in the field notes.

- All field settings on equipment should be documented in field notes. All field processing parameters (e.g., bandwidth filtering, amplitude gains, etc.) should be noted.

In addition to following the overall recommendations of the previous panel, it is important that contractors make full and correct use of the internal data documentation capabilities of the instrument. This includes inputting the correct user, line orientation, and coordinate information internally in the system. Because of the need for a mixture of internal instrument and external field notes for system documentation, it is important to create a systematic method of naming files, note file names within the field notes, and archive field notes and field data together. 


\subsubsection{Documentation for Data Processing}

Geophysical data processing occurs in a series of discrete steps.

1. Data are transferred to a field computer and stored on disk or removable media

2. Data should be assessed for accuracy, repeatability, and completeness

3. Data are edited based on a standardized set of criteria

4. Data are averaged and corrected

5. Interpretational strategies (inversion) are applied to the data

6. Interpretative images are presented.

Physical data samples are routinely handled and transferred using a rigid set of procedures that include documentation to ensure the traceability of the sample. These same concepts can be adapted for geophysical data. The first step in data processing is always to create a complete, self-documenting, unaltered archive of raw field data, as it is retrieved from the field system. This archive should contain electronic copies of the data; the format of the data; field notes, and other pertinent information sufficient to allow others to determine the type and serial number of the acquisition system(s), the field crew chief, any problems or known issues with the data, and the person responsible for downloading and archiving the data. The data should be archived, and protected copies made, such that the data and documentation cannot be accidentally altered or lost.

Subsequent to data collection, there must be clear documentation of all steps used to process the data. This documentation should include the source of the data, software versions used to process the data, and who processed the data. Altered data should be clearly identified as such. This should include the creation of a set of file-naming conventions for data at various stages of processing. Processing should be based on clear, scientifically valid, repeatable criteria not project goals, preconceived notions, or intuition. Although it is acceptable to remove data that fail quality control criteria, it is usually not acceptable to synthesize data by interpolation or other methods.

Data documentation should include a summary of quality control information, including the number of data collected, the number of noisy data removed, and summarized errors, either as standard deviations for large numbers of repeats or tabulated values for repeated data points.

\subsubsection{Audits}

Two types of audits are performed, internal audits and external audits. Internal audits are typically performed by a senior staff member or subcontractor with an expert knowledge of the geophysical method. The expert reviews the performance of the field crew and data processing personnel to determine if they are following prescribed procedures, and if there are any unusual conditions that require special attention or a revision of procedures. Typical questions addressed by the internal audit include:

- Is the field crew properly trained on the equipment and field procedures?

- Is the field crew following the prescribed field procedures?

- Are there copies of operation and troubleshooting manuals available? 
- Is the appropriate test and troubleshooting equipment available?

- Are field notes complete, accurate, legible, and up to date?

- Are instruments, cables, and connectors in good repair?

- Are system settings correct for the survey?

- Is the survey location correct (ie., are line and survey designations correct?)?

- Are the electrodes properly and accurately located; are the lines straight and interelectrode spacing correct?

- Are the correct QA procedures being followed?

- Are the data being monitored in real-time or near real-time to determine possible problems?

- Are noisy or non-realizable data investigated prior to removing the field setup and appropriate troubleshooting and corrective action taken?

- Are the data within specifications for noise levels and current flow?

- Are the unusual site conditions requiring a change in field procedures or line locations?

- Are the data properly archived on a regular (usually daily) basis?

- Are proper data handling procedures being followed?

- Are data plots properly and clearly annotated?

Internal audits are relatively inexpensive and all medium to large-scale surveys should include one or more internal audits. Audits should be conducted within a few days of the start of field operations and periodically thereafter. Results of the audit and any corrective actions taken should be reported to the client.

External audits are expensive and time consuming and thus used only on relatively rare occasions; primarily when a client has concerns over the applicability of a technology or wishes to assess the abilities of contractors at performing difficult, cutting-edge work. An external audit should be conducted if the DOE is considering a large (millions of dollars) long-term (years) commitment to use resistivity for characterization at the Hanford Site. In external audits, an independent contractor or contractors are brought in to repeat a survey and/or survey data interpretation. External audits of resistivity data require a number of special considerations. First, to compare data, resistivity surveys must be performed in the same locations. One approach is to survey and flag the actual electrode locations to allow each contractor to occupy the same locations within a centimeter or so. This has the advantage of allowing point-by-point comparison of data, but does not fully assess field procedures, because the location and placement of electrodes is a common source of error. The second approach is to provide a more realistic assessment; each contractor is provided only with the start and end locations of survey lines. Small errors in location may preclude point-by-point comparison of data; instead, the interpreted images will be compared.

Multiple resistivity instruments generally cannot be operated in the same area at the same time, because the transmitted signals interfere with each other. As resistivity surveys are sensitive to surface conditions, particularly changes in moisture content and temperature, the surveys must be performed within a relatively "short" time interval. The time interval between the start of the first contractor survey and end of the last contractor survey must be much less that the time between the survey start time, the last major precipitation event, and the last major seasonal change in ambient temperature. The issue of surface effects is most critical for point-by-point 
SGW-34795, Rev. 0

comparison of data. Generally, this means that the first survey must be accomplished within a single day, the second the following day, and it should have been weeks since the previous rainfall.

Because of the scale of ongoing and planned surveys at the Hanford Site at least one external audit should be performed. This should include a segment with point-by-point data comparison and one or more complete survey lines with a full comparison of the survey methodology. 
SGW-34795, Rev. 0

\subsection{DATA PROCESSING AND PRESENTATION}

\subsection{EVALUATION OF RECENTLY COMPLETED AND ONGOING ELECTRICAL RESISTIVITY PROJECTS AT HANFORD}

\subsubsection{Processing}

Although the steps of data processing are listed in the reports (Rucker et al., 2006c and Rucker and Benecke, 2006), the details are not described well enough for evaluation, and the vagueness is of concern to the panel members.

The reduction processes were based on several criteria of error, current transmission, and out-of-range resistivity data, such as negative apparent resistivity. The percentage standard deviation is calculated from multiple stacks, and filtering removes values with an error greater than a calculated cut-off, but the criteria for establishing the threshold and the value of the threshold has not been specified. Several data quality procedures have been used. Normalized measured potentials are plotted as a function of electrode separation along a profile line. Multiple lines are plotted together to observe trends and smoothness; infrastructure and other anomalies appear within the plot, allowing for their removal. However, it is not clear how these methods were applied.

A box filter (i.e., running average) was applied to smooth noisy data, effectively removing the high wave-number components. The size of the filter and number of times the filter is applied depends on the degree of noise. In the HRR plots presented for the T Tank Farm, the interpolated data represent this level of processing; not all lines required this level of processing. Typically, only those lines running through the tank farm required this kind of filtering, but it is not stated what size filter was used or how many times was it applied to what data. It was not stated if filtering was applied to data used for inversion; if this were the case, the filtering of data would likely violate the assumptions of inverse modeling, resulting in incorrect results.

\subsubsection{HRR Data Plotting Method}

The HRR data plotting method (HRRDPM) has been presented as an inversion method that converts electrode spacing to depth of investigation. The HRRDPM is not a parameter estimation technique (inversion), but is a transformation to depth from electrode spacing for a depth that represents the maximum sensitivity for a given array. The HRRDPM carries with it similar distortion patterns as traditional apparent resistivity pseudosections, such as pantlegs and horizontal smearing. References from 1957, 1971, and 1972 were used by the geophysical contractor to justify the use of the HRRDPM. However, parameter estimation methods (inversion) have been in use for the past $30+$ years to focus these apparent resistivity patterns into approximations of the subsurface resistivity distribution.

Traditional pseudosections or HRRDPM plots may be useful for evaluating data quality and the approximate range of resistivity values within the survey area. They should not be used for interpretation or presented as alternative images to inverted models. Pseudosections are also 


\section{SGW-34795, Rev. 0}

helpful to appraise inversion models through comparison of the data with model response in the compact pseudosections format.

Figure 4.1 illustrates (a) a simple model of a $20 \mathrm{ohm}-\mathrm{m}$ plume in a $400 \mathrm{ohm}-\mathrm{m}$ half space, the corresponding (b) traditional apparent resistivity pseudosection, (c) the HRRDPM results (a nonlinear pseudosection), and (d) robust and (e) smooth inverse models. The white box outlines the target. It is clear that the pseudosection and HRRDPM plots both exhibit horizontal smearing. The HRRDPM changes the pseudo-depths of the apparent resistivity; the depth section is stretched near the surface, moving the top of the anomaly downward. At depth, pseudo-depths are compressed, making the base of the anomaly shallower and more abrupt. However, the resistivity value is greatly underestimated.

Note that the color scale is different for the apparent resistivity plots (275-395 ohm-m) and inverse models (40-690 ohm-m). If all plots were on the same color scale as the inverse models, the plume would be difficult to see in the apparent resistivity plots. Although generally well recovered, the inversion also smears the target, although much less so than the HRRDPM horizontally. The bottom of the conductor is poorly recovered, as is consistent with the electrical resistivity method.

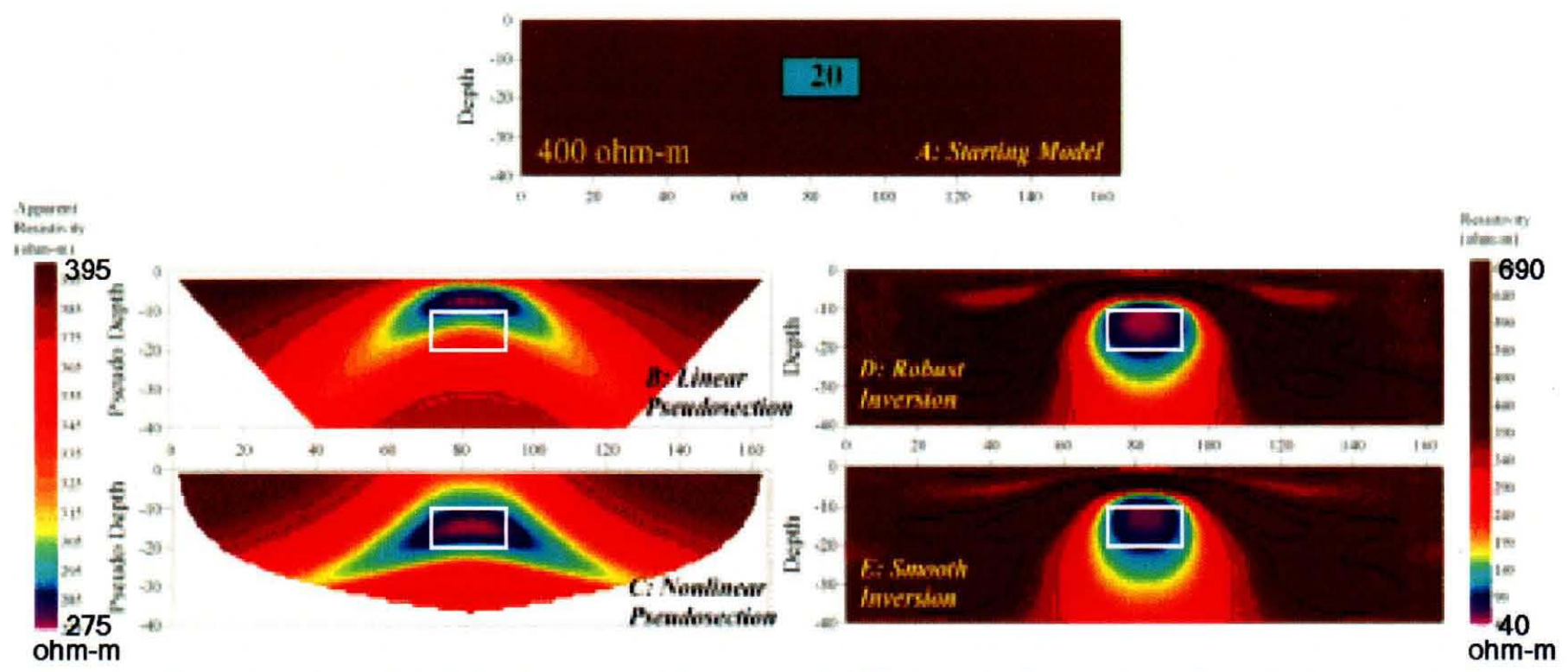

Figure 4.1. (a) Model of a simple plume in a half space and corresponding (b) apparent resistivity pseudosection, (c) HRRDPM apparent resistivity plot or nonlinear pseudosection, (d) robust and (e) smooth inversion

[note that the color scale is different for the apparent resistivity plots (275-395 ohm-m) and inverse models (40-690 ohm-m)] (Rucker, 2007a)

To illustrate further complications in using the HRRDPM for interpretation, Figure 4.2 shows three progressively more complex models and the corresponding HRRDPM plots. In Figure 


\section{SGW-34795, Rev. 0}

4.2a, groundwater $(100 \mathrm{ohm}-\mathrm{m})$ is added to the simple plume $(10 \mathrm{ohm}-\mathrm{m})$ in a $1000 \mathrm{ohm}-\mathrm{m}$ homogeneous background. The HRRDPM shows conductive anomalies on either side of the plume and no indication of the groundwater. The conductive anomalies are often called pantlegs and are merely an artifact of the plotting. With the addition of another plume target in Figure $4.2 \mathrm{~b}$, the pantleg feature from both plumes combine, and a third conductive anomaly appears in the center of the profile. To the unsophisticated eye, one might see a resistive (blue) layer over a conductive half space (green) in which are embedded resistive targets - very different from the true model. A knowledgeable interpreter would be able to identify the pantleg artifacts, but would not be able to tell whether another conductive target was present as in Figure 4.2c.

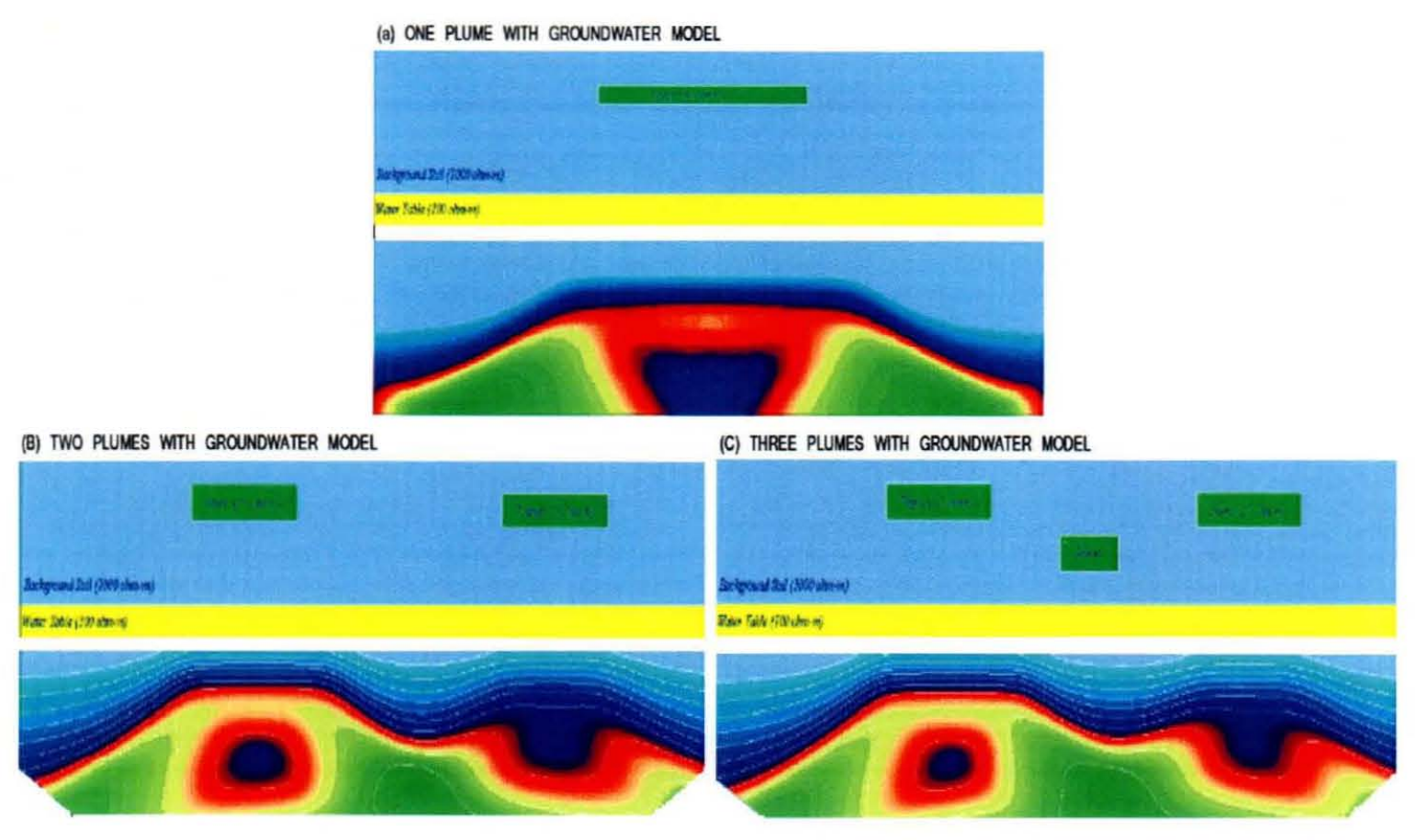

Figure 4.2. Three models showing (a) a plume and groundwater, (b) two plumes and groundwater, and (c) three plumes and groundwater, and the corresponding HRR apparent resistivity plots (Rucker and Benecke, 2006)

Although documented model studies highlighted the problems of the HRRDPM, it has been continually used for interpretation, as can be seen in Figure 4.3, where BCCT Lines 1 and 2 were plotted with the HRRDPM and subsequently interpreted. However, the majority of conductive anomalies were identified as artifacts. In the conclusions of the report (Rucker and Benecke, 2006), the artifacts are documented as such, and they conflict with the 3D inverse model presented, but the HRRDPM plots were still presented, creating confusion as to the validity of the electrical resistivity method.

The claim that HRRDPM offers a realistic geometric image of the data is shown in modeling and data not to be the case, especially in multi-dimensional environments. The presentations are riddled with artifacts and unrealistic geometry, and do not focus apparent resistivity data to 


\section{SGW-34795, Rev. 0}

an approximation of the true location and magnitude of the subsurface resistivity distribution. Commercial inversion packages routinely plot data and inverted model responses as pseudosections for comparison in solution appraisal, but they are not used for interpretation or final model presentation. Hence, the HRRDPM should only be used for internal data quality evaluation, not interpretations. It should not be used as a primary method for determining resistivity estimates or for making presentations.

hydroGEOPHYSICS, lnc.

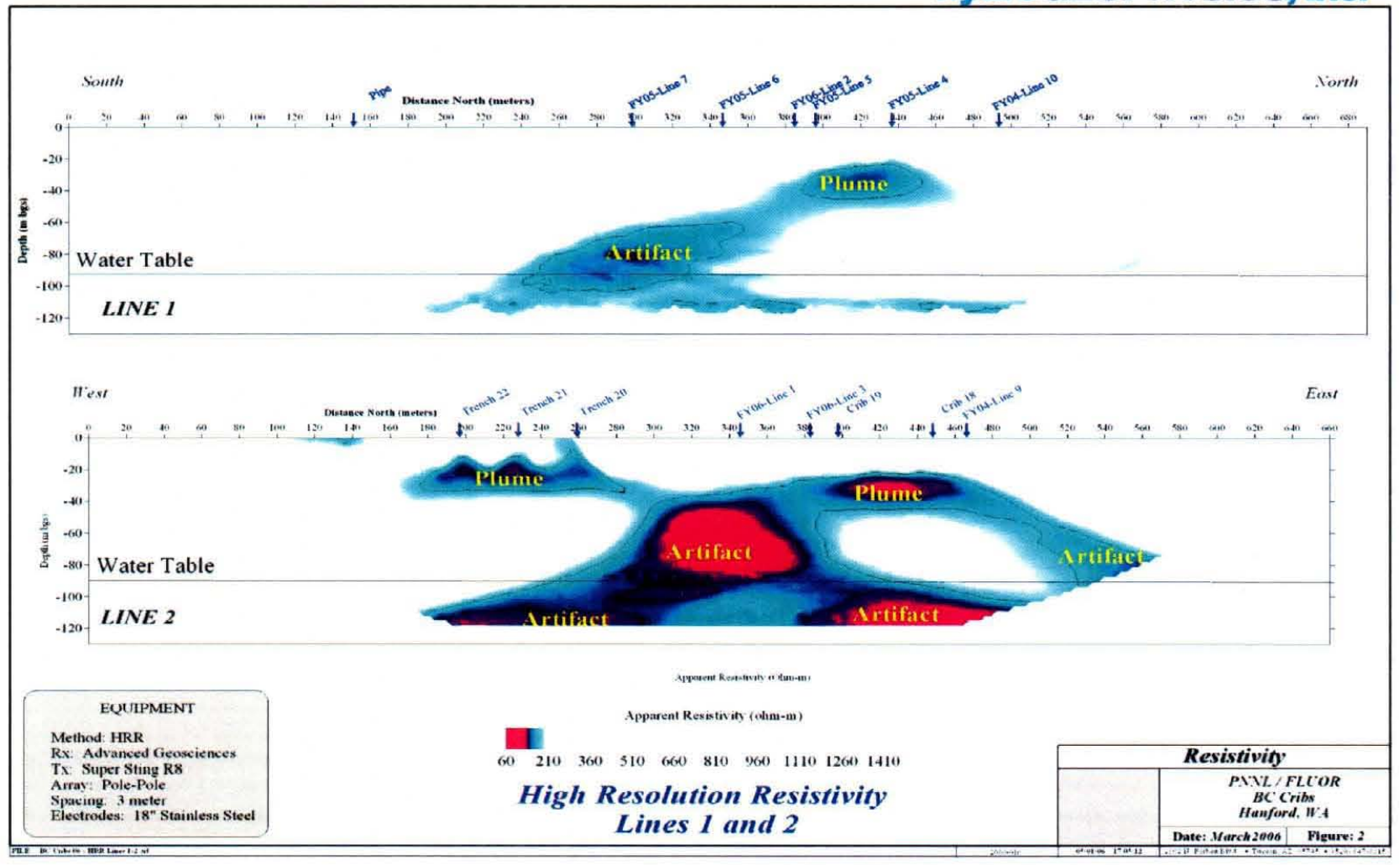

Figure 4.3. Interpretation of BCCT Lines 1 and 2 using the HRRDPM

(the majority of anomalies are identified as artifacts [Rucker and Benecke, 2006])

\subsubsection{D Inversion}

Because of the high level of infrastructure at the tank farms, a 2D model study was initiated to understand the response and resolution of the plume target within the presence of a pipeline. The EarthImager2D Software (AGI) was used. Figure 4.4 shows the HRRDPM plot superimposed on a model of a $10 \mathrm{ohm}-\mathrm{m}$ plume under a $0.01 \mathrm{ohm}-\mathrm{m}$ pipe in a $1000 \mathrm{ohm}-\mathrm{m}$ half space and the corresponding 2D response. In Rucker et al. (2006c), it is stated, "For processing simplistic survey lines, a filtering algorithm removes the virtual "pant leg" effect caused by the pipe. These pant leg features can be seen just below the position of the pipe. Wells have a similar response. The drawback of filtering is that it does not move the plume back to the original position and size." This filter is not described further, and it is unknown 
when it was used. The characteristic response of the pipeline is commonly observed in many HRRDPM plots.

The 2D inversion image shows the pipe as a distinct and separate, although deep and large, feature from the plume. The inversion parameters were not recorded in the report, but it was commented that the inversion results reproduced the plume more accurately than the HRRDPM alone. However, the bottom of the plume is not well resolved, and the plume is highly pockmarked with the effects of pipe removal. Modeling the pipe response was a good start, but there is concern whether the inversion code was used correctly, because a smoothness constraint is not consistent with the pockmarks. More testing and analysis should have been performed to determine that the inversion code was properly implemented and used to evaluate resolution.
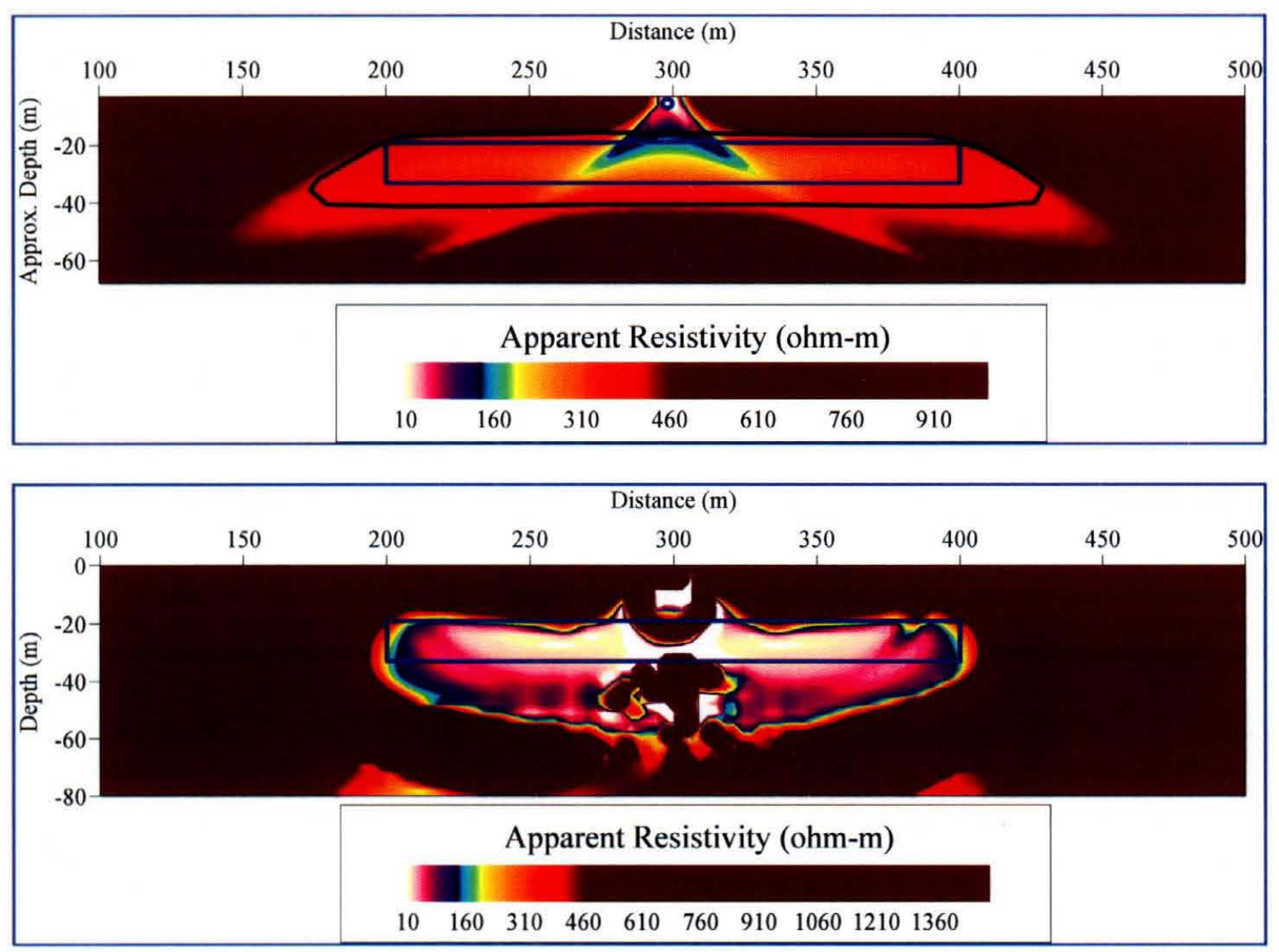

Figure 4.4. HRR plot of a single plume (10 ohm-meters) and a pipe (0.01 ohm-meter) in a homogeneous background of 1,000 ohm-meter (above) and corresponding 2D inversion. (Rucker et al., 2007c). Note the term apparent resistivity is incorrectly used in the lower plot (2D inversion); the proper term is estimated resistivity.

Many lines in the T Tank Farm were processed with 2D inversion, but the results were disappointing. The description of the preparation of data for inversion was vague - "data were selected so that a minimal amount of filtering was performed, but sufficient enough for model 
SGW-34795, Rev. 0

convergence." Table 1 lists parameters used in inversion of several lines in the T Tank Farm survey area; Figure 4.5 shows the corresponding $2 \mathrm{D}$ inverse models. Of all models presented in the reports, these have the lowest root mean squares (RMS) fit, which is an estimate of the quality of the inverse solution. We note that models $6 \mathrm{~N}-9 \mathrm{~N}$ are smoother than $0 \mathrm{E}-3 \mathrm{E}$, although all, but $2 \mathrm{E}$, have a smoothing level of 10 . Also $6 \mathrm{~N} \& \mathrm{NN}$ are listed as robust inversions.

Table 1 Summary of selected 2D inversion model parameters and inversion statistics

\begin{tabular}{|l|l|l|l|l|l|l|l|}
\hline Line & $\begin{array}{l}\text { Trial } \\
\text { Number }\end{array}$ & $\begin{array}{l}\text { Inversion } \\
\text { Method }\end{array}$ & $\begin{array}{l}\text { Starting } \\
\text { Model }\end{array}$ & $\begin{array}{l}\text { A Priorl } \\
\text { Information }\end{array}$ & $\begin{array}{l}\text { Smoothing } \\
\text { Level }\end{array}$ & $\begin{array}{l}\text { Results } \\
\text { L2 }\end{array}$ & $\begin{array}{l}\text { Results } \\
\text { RMS }\end{array}$ \\
\hline OE & 5 & Smooth & Pseudosection & None & 10 & 1.59 & 3.78 \\
\hline IE & 4 & Smooth & Pseudosection & None & 10 & 1.9 & 4.14 \\
\hline 2E & 4 & Smooth & Pseudosection & None & 1 & 0.99 & 2.98 \\
\hline $3 \mathrm{E}$ & 7 & Smooth & Constant Value & Tanks & 10 & 1.04 & 8.17 \\
\hline $6 \mathrm{~N}$ & 9 & Robust & Constant Value & Tanks & 10 & 0.81 & 5.41 \\
\hline $7 \mathrm{~N}$ & 1 & Robust & Pseudosection & None & 10 & 3.71 & 2.89 \\
\hline $8 \mathrm{~N}$ & 3 & Smooth & Pseudosection & None & 10 & 0.85 & 2.68 \\
\hline $9 \mathrm{~N}$ & 4 & Smooth & Pseudosection & Water table & 10 & 0.75 & 3.11 \\
\hline
\end{tabular}

It is difficult to reconcile the character of the various images with the different inversion smoothness choices. In addition, an optimal set of smoothness constraints would typically be selected after numerical experimentation and applied to all the lines. It is not clear why different smoothness criteria were selected for inverting different lines.

Use of a pseudosection (HRRDPM) as a starting model can trap the solution into a minimum that contains artifacts, such as pantlegs. In general, a half space (constant value) is a safer choice for a starting model, in that no artifacts are introduced in the final model. The use of $a$ priori information can be problematic given dimensionality issues: the tanks are more 3D than $2 \mathrm{D}$, and the 2D approximation may not be valid. In addition, the panel questioned their ability to evaluate the performance of the inversions, because it was unclear whether the profiles crossed the tanks through the center and were located perpendicular to the pipes or at some angle, thus violating the $2 \mathrm{D}$ assumption. 
SGW-34795, Rev. 0

2D Electrical Resistivity Tomography at the 241-T Farm
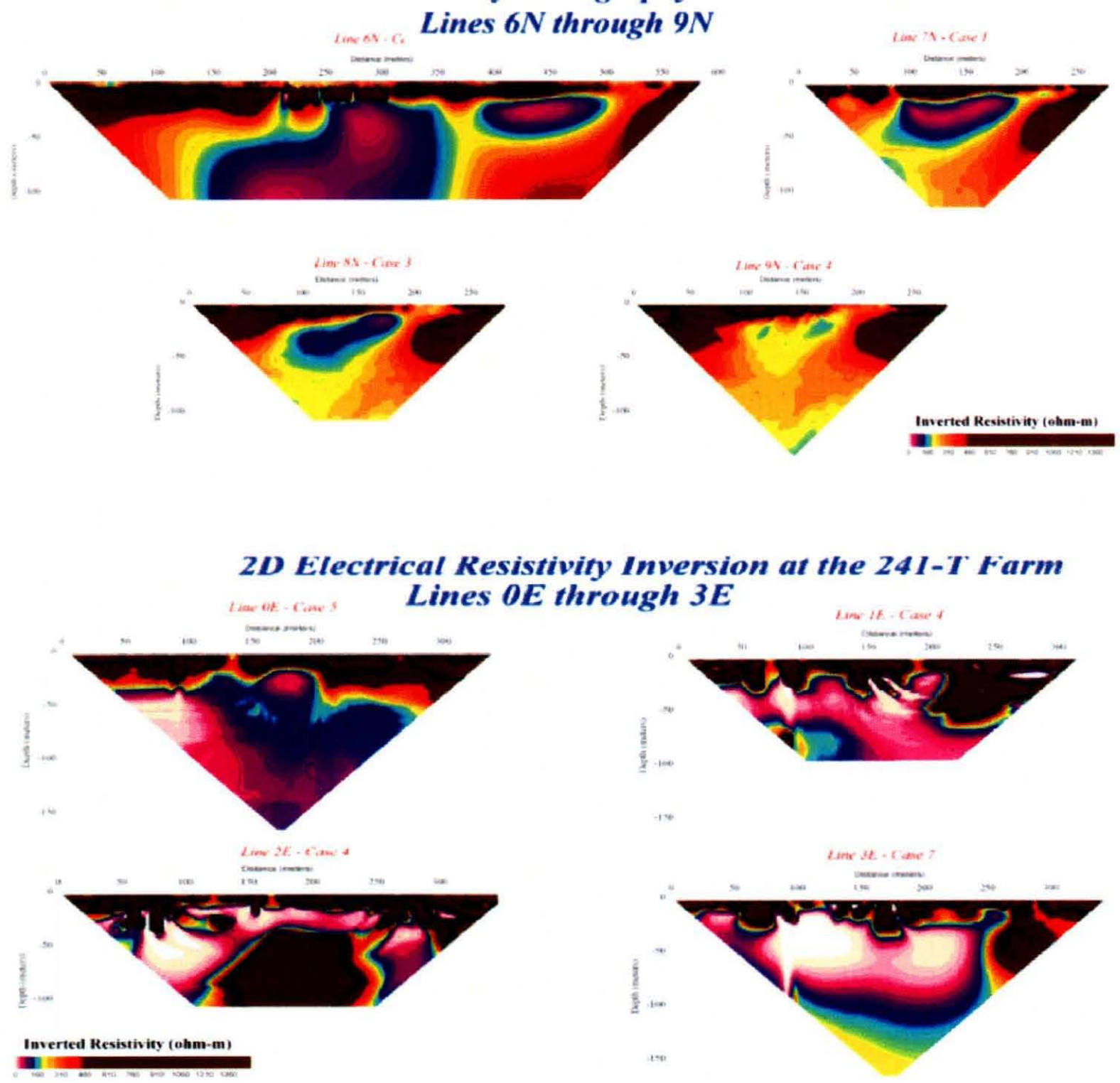

Figure 4.5. 2D inverse models for the profile lines described in Table 1 (Rucker, 2007a) 
SGW-34795, Rev. 0

\subsubsection{D Inversion}

Three-dimensional inversion (AGI EarthImager3D) was the most reasonable and promising of all processing and presentation methods. While solution appraisal was not available and correlation of resistivity estimates with geochemistry to define the plume boundary was minimal, the BCCT 3D inversion model is very encouraging (Figure 4.6). This image was achieved with half of the acquired data, and as discussed earlier, it is not clear how much improvement will be gained by using the full dataset.

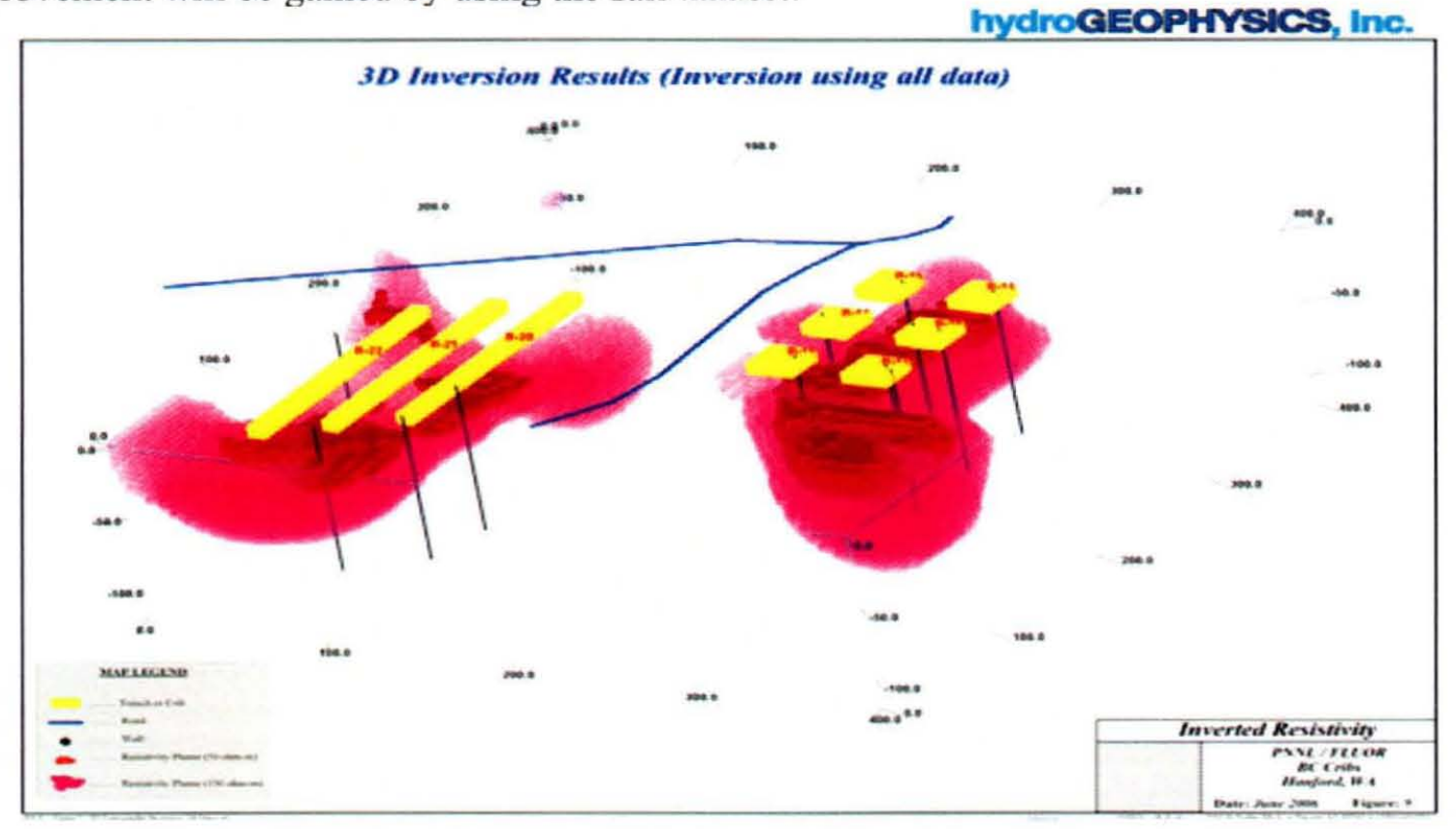

Figure 4.6. 3D inverse model of the BCCT using data acquired in 2004-06 decimated by half (Rucker, 2007a)

For computational consideration, the T Tank Farm surface resistivity surveys were divided into four areas: (1) the northeast portion of the site over trenches T-14 through T-17, the location of most of the radionuclide inventory (2) the western trenches and cribs, where the majority of the liquid waste disposal occurred, (3) the southeastern portion of the site, where there is a high concentration of pipes, and (4) data collected inside the tank farm footprint boundary. Data were decimated by one-half and a smooth inversion scheme was used. For Areas 1 and 2, no $a$ priori information was included, but pipelines were included in areas 3 and 4 . A collage of the four areas is presented in Figure 4.7. The quality of the inverse model seemed to degenerate as the density of pipes increased (areas 3 and 4), a significant result when testing the validity of the method in an area of high infrastructure. 


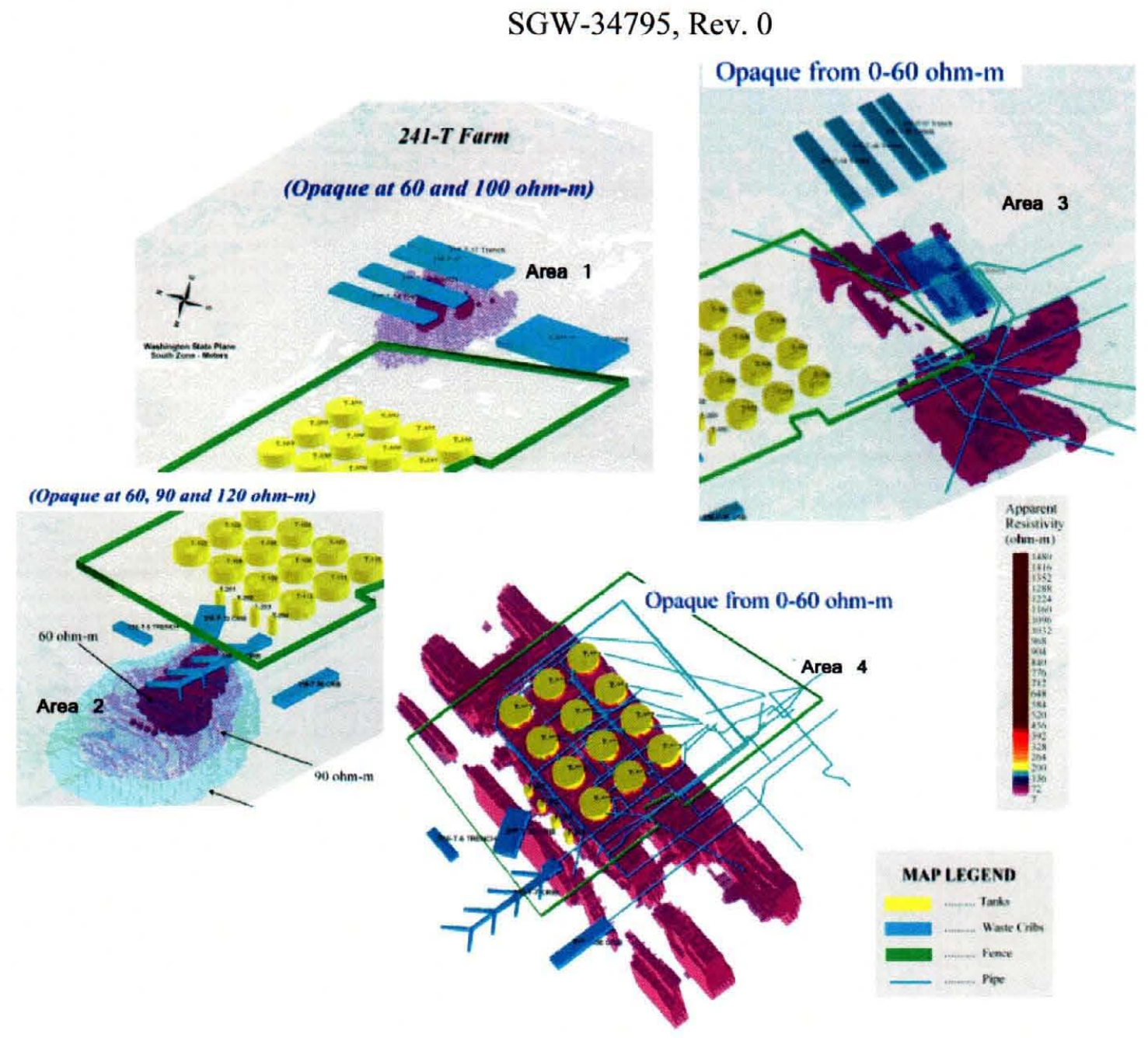

Figure 4.7. Collage of $3 D$ inverse models for the four areas of the T Tank Farm (perspective is slightly different; dark green perimeter line can be used as a reference)

(Rucker, 2007a)

\subsubsection{Solution Appraisal}

Solution appraisal consisted of RMS fit for 2D models and apparent resistivity cross plot with RMS fit and number of iterations for 3D models. Normal practice for 2D resistivity surface data inversion is to present pseudo-section plots both in field data and computed response of best model. These plots were not included in the reports. Numerical simulations and experimental model simulations should be used to determine achievable resolution quantitatively.

\subsubsection{Data Presentation}

There were many concerns about presentation of the results, including model studies, maps, HRRDPM plots and inverse models. The use of different color scales to compare different results, as in Figure 4.1, was very misleading. The same standard gray or color scales should be used throughout and detailed explanations provided, on plots as well as in text, when nonstandard scales are used and how and why they were chosen. There were several plots and a lengthy discussion as to the choice of the color scale used for the majority of the plots, but 
SGW-34795, Rev. 0

considering the distribution of resistivity values, the panel suggests consideration of log scale and the standard rainbow color scale.

Resistivity and coordinate scales were often missing or difficult to read. The panel realizes that there are limitation to using Universal Traverse Mercador (UTM) or state plan coordinates and a north arrow (although it was present on some figures), but a local grid should be well defined and easy to follow between survey maps and model results. Volume rendering for isocontours of interest was nice for 3D visualization; however, defining the appropriate resistivity contour value is problematic, given the small amount of geochemical data available for correlation to the resistivity estimates. The visual impact inferring dimensions of the plume is strong.

\subsection{SUGGESTED IMPROVEMENTS FOR FUTURE PROJECTS INVOLVING ELECTRICAL RESISTIVITY METHODS}

\subsubsection{The HRR Data Plotting Method (HRRDPM)}

The HRRDPM should only be used for data quality evaluation and internal processing. It should not be used as a primary method for determining conductivity, for making interpretations as to what contaminants might be present in the subsurface, or for making presentations.

\subsubsection{D and 3D Inversion}

2D and 3D inversion should be used as the primary methods for determining, interpreting, and presenting subsurface conductivity. Because $3 D$ is the most accurate and least subject to artifacts, it is to be preferred over $2 D$ inversion. Two-dimensional inversion may still be used when the assumption that the conductivity distribution is essentially varying in only two dimensions is accurate. Prior information should be incorporated into the forward models and inversion algorithms.

When one knows that there are subsurface structures, like pipes and tanks or regions of known conductivity, this information should be used to improve both the forward models and the inversion algorithm's accuracy. For example, if one knows the location of a pipe, it may be modeled by putting appropriate boundary conditions on the exterior surface of the pipe or low resistivity voxels where the pipe is located. The inversion algorithms should then solve only for the resistivity in the regions where it is unknown. These deterministic numerical models should be verified by quantitative comparison with experimental model studies. The performance of the algorithms that incorporate prior information in a deterministic manner should be compared to the algorithms that do not assume any prior information in order to quantify the extent that the predicted voltages and reconstructed resistivities are changed by the inclusion of prior information. Methods for incorporating prior information are presented in Kaipio and Somersalo (2006).

Alternate forward models and inversion algorithms, e.g., statistical models and inversion, should be considered. Statistical models and inversion methods are especially useful when one only has partial prior knowledge of some features of the conductivity distribution to be imaged. 
SGW-34795, Rev. 0

References to the use of statistical modeling and inversion (e.g., Kaipio and Somersalo [2006]; Rubin and Hubbard [2005]) are provided in the references section at the end of this report.

\subsubsection{Solution Appraisal}

Numerical and experimental model simulations should be used to determine achievable resolution quantitatively. The numerical simulations, as well as the experimental model studies, should agree with the precision of the measurements used. These simulations should be performed to precisely answer questions, such as "what is the size of the smallest inhomogeneity at a given depth whose conductivity is greater than the background by a given amount that can be detected or imaged by the proposed measurement schemes and inversion algorithms?" The resistivity structure of the experimental model should be compared quantitatively with the reconstructed resistivity structure to determine how reliable the reconstructions are in this setting.

The inversions will yield a single or set of resistivities that may be present in the subsurface. One measure of the accuracy of the reconstructed resistivities is the residual error (i.e., the difference between the field measured value and the calculated measurement value using the reconstructed model) that results when the proposed resistivity is used in the forward model. These should be computed and displayed. A stronger test of the accuracy of the computed resistivity is to add a few more electrodes on the surface or in some wells and predict the voltages at these new electrodes using the reconstructed model and then compare the calculated values from the forward models with measured voltages at the new electrodes. This is a less expensive method of testing the accuracy of the reconstruction than the gold standard, which is drilling more holes and sampling the resistivity to compare it with the algorithm predictions. This final step should be performed and guided by simulations to try to determine where the reconstructions might be the weakest as well as where they show the most important features of interest.

\subsubsection{Data Presentation}

Use the same scales when comparing different methods. Different scales may be used sometimes, but one should always show results that are compared on the same scale as well. Compare quantities with the same units. Use standard gray or color scales. Non-standard scales may be used, but only after standard scales are shown and the reasons for the use of nonstandard scales are carefully explained.

Present data and error analysis in quantitative as well as graphical form. It is desirable to see quantitative comparisons using numbers as well as pictures to be sure that everyone understands the meaning of the data and images presented. Use labels and scales on pictures and graphs that can be easily read and interpreted. 
SGW-34795, Rev. 0

This page intentionally left blank 


\subsection{IYDROGEOLOGICAL INTERPRETATION AND VALIDATION}

The objectives of this section of the report are: (1) to evaluate the efforts that have been made to provide a hydrogeological interpretation of the resistivity datasets collected at Hanford; and (2) to provide recommendations on how to improve understanding of the hydrogeological significance of these geophysical data. Establishing the hydrogeological significance of the resistivity images is not trivial, as the currently available ground-truth data are sparse. This is understandable given that the cost of drilling a single borehole in the 200 Area can exceed $\$ 1 \mathrm{M}$. Consequently, the task of addressing the hydrogeological significance of the resistivity images within the BCCT based on a single borehole (C4191, located in the center of Trench 216-B-26 (Rucker and Benecke, 2006), is challenging. More borehole data are available at the T-Tank Farm, where geochemical data were collected during installation of seven wells (drilled to between 50-70 m) (Rucker et al., 2006c). Seven wells also exist around the periphery of the U-Tank Farm, although geochemical data from core samples obtained during installation of these wells was not available to the review panel. Geochemical data from core samples from boreholes installed in the S-Tank Farm were also not available to the panel (Rucker et al., 2006b). There are fourteen wells around the S Tank Farm, but the panel could only find nitrate concentrations in groundwater, as opposed to nitrate concentrations in vadose-zone pore water, which is the target of the investigation (Rucker et al., 2006b).

\subsection{EVALUATION OF RECENTLY COMPLETED AND ONGOING ELECTRICAL RESISTIVITY PROJECTS AT HANFORD}

5.1.1 Theoretical Basis for Plume Detection from Resistivity Measurements: Applicability to the Hanford Site

The resistivity surveys conducted at Hanford rely on the fundamental premise that electrical resistivity measurements provide a proxy measure of contamination in the vadose zone due to the dependence of resistivity on pore fluid conductivity $\left(\sigma_{w}\right)$ (hence, ionic concentration) and moisture content $(\theta)$, as well as lithology. A correlation between resistivity $(\rho)$ and pore fluid conductivity $\left(\sigma_{w}\right)$ is consistent with basic established petrophysical relations linking earth resistivity to physical and chemical properties. Electrical current flow is primarily ionic, occurring via ions in the free electrolyte and ions in the electrical double layer at the mineralfluid interface. These two current flow pathways are often modeled with an electrolytic conductivity $\left(\sigma_{\mathrm{cl}}\right)$ and interfacial conductivity $\left(\sigma_{\mathrm{in}}\right)$ added in parallel. The electrolytic term is a function of the pore fluid conductivity, porosity $(\phi)$ and interconnected pore geometry, whereas the interfacial term is related to the size of the interconnected surface, the surface ion mobility, and surface charge density. Equation 5.1 is a parallel conduction model for the electrical conductivity $(\sigma=1 / \rho)$ of a porous medium based on an Archie (Archie, 1942; Sen et al., 1981) representation of water electrical conductivity $\sigma_{\mathrm{cl}}$, and a theoretically derived expression for the interfacial conductivity, $\sigma_{\text {int }}$ in sandstone (Pride, 1994; Revil and Glover, 1998).

$$
\sigma=\frac{1}{\rho}=\sigma_{e l}+\sigma_{\text {int }}=\left(\sigma_{w} \phi_{e f}^{m} S^{n}\right)+\left(\frac{e \mu_{s} \Sigma_{0} S_{0}}{f}\right) \quad 5.1 \text {, }
$$


$\phi_{e f f}$ is the effective porosity, $S$ is the degree of saturation $(\mathrm{S}=\theta \mid \phi), e$ is electronic charge, $\mu_{s}$ is the interfacial ionic mobility, $\Sigma_{o}$ is the surface charge density, $S_{0}$ is a weighted surface area to pore volume, $f$ is a geometric factor describing the pore geometry, $m$ is the Archie parameter dependent on the size and distribution of pore throats (Revil and Cathles, 1999), and $n$ is the saturation exponent dependent on the distribution of moisture within the pore space (Knight, 1991). The measured electrical conductivity therefore depends on the electrolyte chemistry (determining $\sigma_{w}, \mu_{s}$ and $\Sigma_{a}$ ), the moisture content (determining $S$ ) and the lithology (determining $\phi_{e p}, S_{0}, f, m$ and $n$ ).

The theoretical basis for the application of the resistivity method for detecting contaminant plumes in the vadose zone at Hanford is that the combination of (1) increased dissolved ion concentration, and (2) increased moisture content, will present an electrically conductive target that can be distinguished from the variability in conductivity due to variable lithology within the aquifer. This premise is reasonable given that the Hanford Formation, comprising the bulk of the vadose zone at the site, is a flood deposit predominantly comprised of coarse to fine gravels, sand, and silt. Interfacial conduction is typically only significant in fine-grained silts and clays of high surface area $\left(\mathrm{S}_{0}\right)$, although it is enhanced in unsaturated soils.

However, one possible complication to the interpretation of the resistivity datasets is formation heterogeneity and anisotropy. The Hanford Formation is extremely heterogeneous and anisotropic as demonstrated in the photograph in Fig. 5.1, highlighting the complex internal structure of the Hanford Formation and a number of stratigraphic facies. This heterogeneity likely drives spatially variable electrical conductivity, due to variations in porosity and surface charge density, as well as degree of saturation (porosity will be higher in fine-grained facies). Spatial variability in resistivity driven by aquifer heterogeneity is currently uncertain and may be insignificant relative to spatial variability in resistivity driven by ion concentration associated with contaminant plumes. However, thin $(0.5 \mathrm{~m}$ or less) laminated clay layers within the Hanford Formation, known to limit the downward migration of water and contaminants, while enhancing lateral flow under certain conditions (Ward et al., 2004), may be an important factor to consider in the interpretation of resistivity data in the vadose zone at Ilanford. As clay can profoundly increase conductivity, it is likely that spatial variability in these layers could result in spatially variable resistivity structure. Figure 5.2a shows the lithology from C4191, where such laminar layers are shown as black bands. These laminated layers are known to be spatially discontinuous (Ward et al, 2004).

\subsubsection{Comparison of Resistivity with Borehole Data}

The panel noted that the validation of the resistivity data collected at Hanford largely focused on the comparison of resistivity data and inversion results with borehole C4191at the BCCT. This is not meant as a criticism, as the panel understands the difficulties and expense involved in obtaining borehole data from this site. However, also presented were some data from the TTank Farm, where resistivity inversion results were compared with a limited amount of geochemical data from some of the boreholes at that site. The correlation between the resistivity and data from $\mathrm{C} 4191$ is encouraging, given the considerable disparity in the scale of the borehole (essentially a point) measurement and the resistivity image obtained from only surface electrodes. Figure 5.3 shows a correlation of a 2D smoothness-constrained resistivity inversion along ' $L$ ine 1' of the BCCT with pore-water fluid conductivity determined for 
C4191. Note that the image contains artifacts, the color scale is grossly biased towards highresistivity features, and the goodness of fit of the predicted data to the measured data was not specified. Despite these limitations, the two datasets appear consistent in that the center of the imaged zone of low resistivity obtain from the geophysics is at the same depth as the center of elevated pore-water conductivity as measured in C4191.

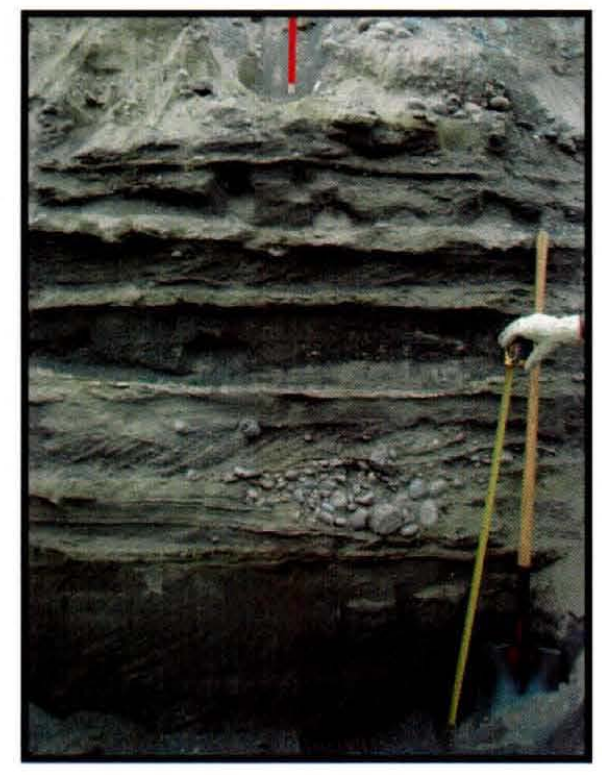

Figure 5.1. Exposed trench face showing layered heterogeneity in Hanford's 200 East Area

(Ward et al., 2004)

The basic hydrogeological interpretation of the resistivity data at BCCT presented to the review panel is that the low resistivity anomalies are a consequence of elevated pore fluid conductivity primarily due to very high nitrate concentrations in the contaminant plume (Fig. 5.2d). Concentrations of ${ }^{99} \mathrm{Tc}$, being the primary contaminant of concern at the BCCT, were recognized as not high enough to directly impact fluid conductivity. However, data from C4191 show that the ${ }^{99} \mathrm{Tc}$ vadose zone anomaly correlates with the nitrate and pore fluid conductivity anomaly (Fig. 5.2b), presumably due to the co-location of the ${ }^{99} \mathrm{Tc}$ and nitrate plumes. It may, therefore, be reasonable to assume that conductivity obtained from resistivity surveys can be used as a proxy indicator of ${ }^{99} \mathrm{Tc}$ activity, as was suggested during the workshop. However, it is critically important to stress the two major assumptions that are required to reach this conclusion: (1) the ${ }^{99} \mathrm{Tc}$ plume and nitrate plume detected with resistivity are co-located and share the same reactive transport behavior; and (2) pore fluid conductivity exerts the major control on conductivity at the site relative to the effects of spatially variable moisture content and lithology. Resistivity imaging is an indirect method for mapping contamination, and it is critical that the non-uniqueness of the petrophysical interpretation be clearly specified. However, the results from the BCCT survey, compared with the data at C4191, certainly encourage the application of this geophysical method for indirect mapping of the ${ }^{99} \mathrm{Tc}$ plume with follow-up invasive confirmation. 


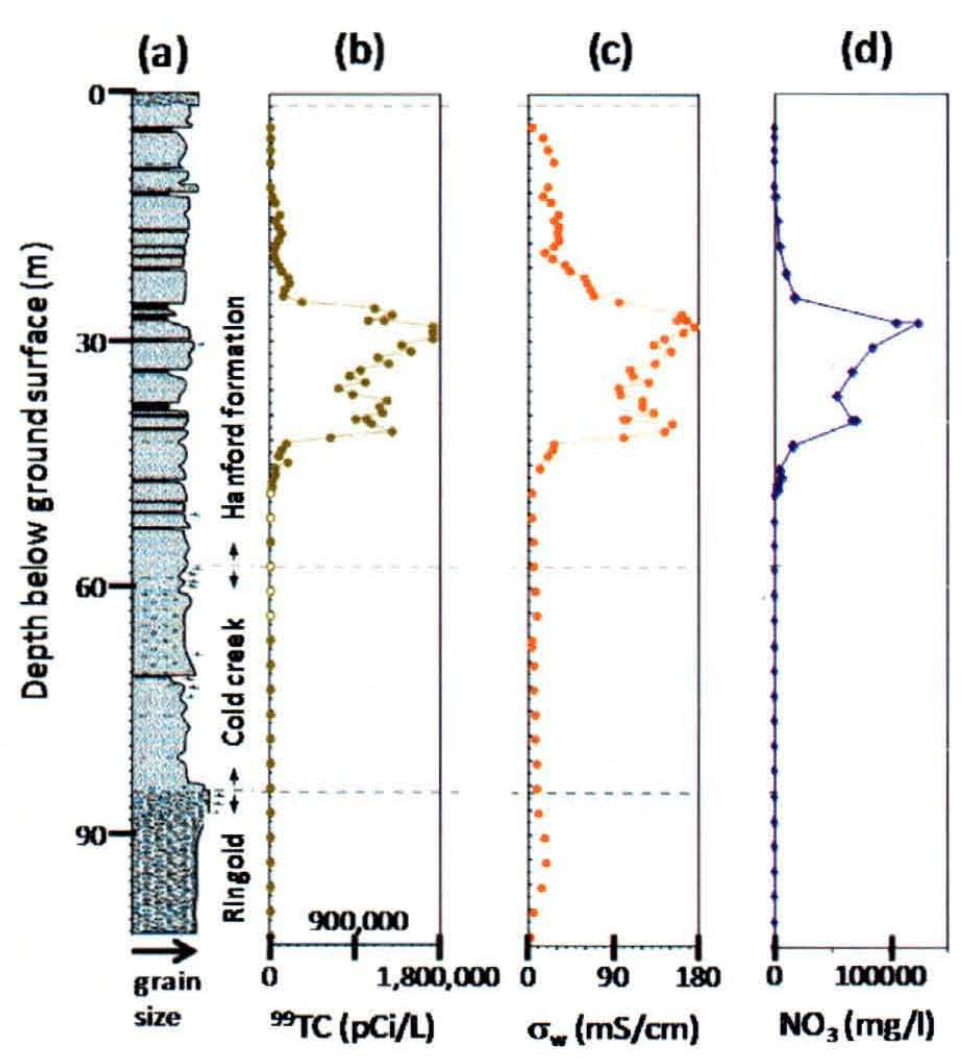

Figure 5.2. Borehole data from C4191 (1) lithology showing laminar clay layers as black bands (b) ${ }^{99}$ Tc concentrations (c) fluid conductivity (d) nitrate

A strong correlation between resistivity obtained from the HRRDPM and nitrate concentrations measured in C4191 (Figure 5.4) ${ }^{4}$ was presented. The panel was concerned that C4191 may have been used to both correlate and then subsequently 'validate' the HRRDPM. Furthermore, only high nitrate values $(>1000 \mathrm{mg} / \mathrm{L})$ have been used in this comparison; it is unclear if the correlation extends to lower values. Finally, the relationship presented in Fig. 5.4 suggests a log-linear relationship between electrical conductivity and nitrate, whereas a linear relationship is expected from theory (Equation 5.1), if variations in lithology and moisture content are small. Despite these concerns, the plot again suggests a good correlation between resistivity and nitrate exists at the site. The panel was very encouraged by the apparent correlation between pore fluid conductivity and the inverted resistivity model that was obtained without applying any constraints based on C4191. Also presented was a cross plot of inverted. resistivity against nitrate concentration for data from the T Tank Farm (Fig. 5.5). Although the trend is largely controlled by the lowest nitrate concentration point, the result is again encouraging. Petrophysical studies in progress should hopefully constrain the applicability of the resistivity- nitrate relationship and quantify the expected confidence in nitrate estimation from resistivity, given the complex site conditions.

\footnotetext{
${ }^{4}$ Figure 5.4 is reproduced from Rucker (2007a), although it is general scientific practice to present the independent variable $\left(\mathrm{NO}_{3}\right)$ on the $\mathrm{x}$-axis and the dependent variable $\left(1 / \rho_{\alpha}\right)$ on the $\mathrm{y}$-axis.
} 
SGW-34795, Rev. 0

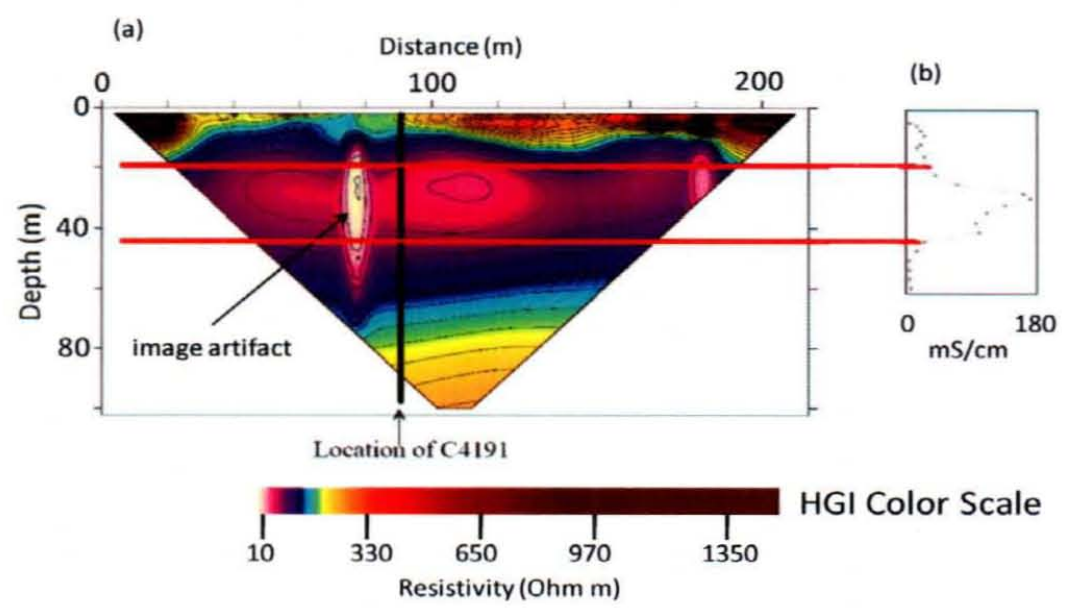

Figure 5.3. Comparison of (1) 2D smoothness-constrained resistivity inversion along 'Line 1' of resistivity data from the BCCT with (b) the pore fluid conductivity measured from cores of the C4191 borehole

(image from Rucker and Benecke (2006); goodness of fit between the predicted data for vs. the field data is unspecified; color scale is biased to emphasize conductive parts of the image).

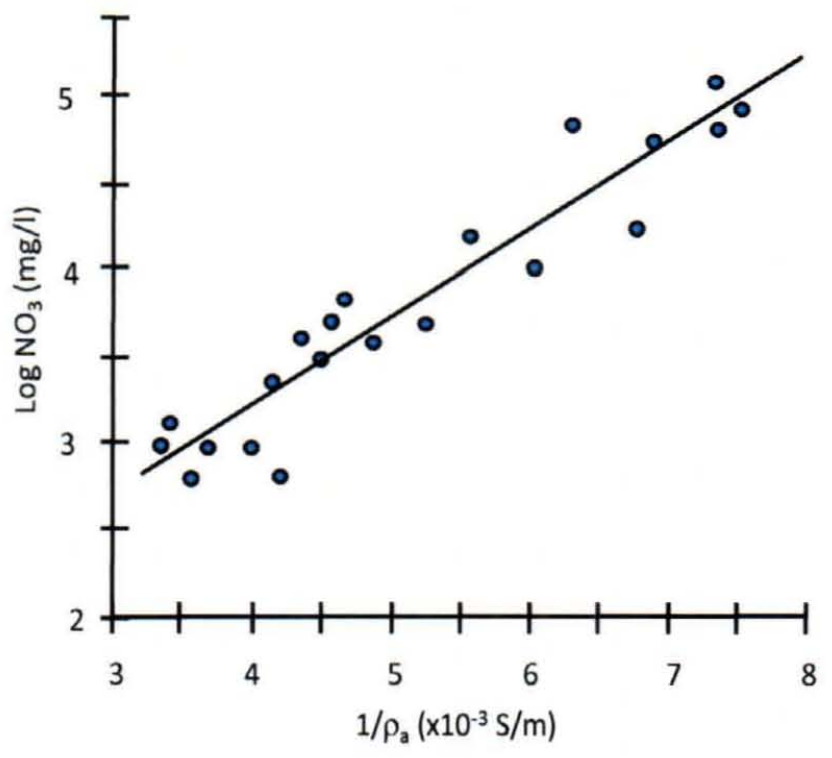

Figure 5.4. The correlation between $\mathrm{NO}_{3}$ concentration in C4191 and conductivity plotted at depth based on the HRRDPM as presented to the panel

(plot suggests a log-linear relationship between $\mathrm{NO}_{3}$ and conductivity $\left(1 / \rho_{\propto ;}\right)$; relationship was apparently obtained after using

C4191 to calibrate the plotting coefficients used in the HRRDPM)

(Rucker, 2007a) 
SGW-34795, Rev. 0

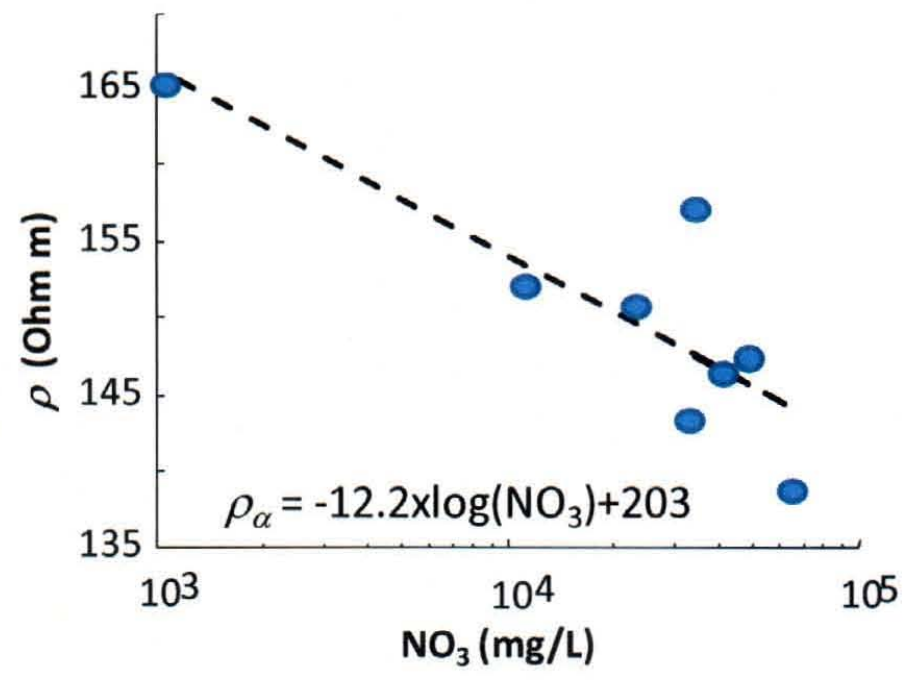

Figure 5.5. The correlation between $\rho$ and nitrate $\left(\mathrm{NO}_{3}\right)$ concentration based on a well within the T Tank Farm as presented to the panel (the plot suggests a log-linear relationship between nitrate and resistivity at high nitrate concentrations) (Rucker 2007a)

\subsubsection{Petrophysics}

The review panel believes that petrophysical research on the electrical properties of the vadose zone at Hanford is essential for improving the interpretation of existing, and future, resistivity data from the site. A petrophysical research project was initiated on a suite of samples extracted from the Hanford and Cold Creek Formations. The project approach was to investigate the electrical properties of laboratory samples as a function of pore fluid ionic concentration (for $\mathrm{NaCl}, \mathrm{KCl}$ and $\mathrm{NaNO}_{3}$ solutions) and moisture content. The datasets have been modeled with a simplified form of the parallel conduction model presented in Eq. 5.1,

$$
\sigma=\left(\sigma_{w} a \phi_{e f f}^{m} S^{n}\right)+\sigma_{\text {surf }} \quad 5.2,
$$

where $\sigma_{\text {surf }}$ is a fitting parameter representing the surface conductivity of the soil in $\mathrm{S} / \mathrm{m}$ and $a$ is an additional, unitless fitting parameter that is normally close to 1.0. The approach is to attempt to perform a least-squares regression on the datasets of sample resistivity as a function of $\sigma_{w}$ and $S$ to estimate empirical, site specific model parameters that fit the dataset.

The panel strongly supports this petrophysical research, but was concerned about 1) the quality of the data, 2) the interpretation of the model parameters, 3) inability to duplicate published values for solute-filled test cells, 4) procedures used for building and saturating samples, and 5) the lack of quality control. One significant problem identified by the panel was the apparent deviation of the datasets from the parallel conduction model. The problem is illustrated in Figure 5.6, reproduced from the April 2007 presentation, for the Cold Creek material. Fig 5.6a is a cross plot of modeled versus measured resistivity, neglecting the surface conduction term in Eq. 5.2, whereas Fig 5.6b includes surface conduction. The argument presented at the workshop was that the plot illustrates that surface conduction is required to correctly model the dataset. However, only those points falling above the 1:1 line in Fig. 5.6a could be corrected 
by the inclusion of a surface conduction term. The improved fit of the points below the line in Fig 5.6a probably reflects an interdependence of the model parameters within a broader model space as a result of the addition of the $\sigma_{\text {surf }}$ term. Furthermore, the panel noted that the best fit empirical model parameters obtained from the modeling were often not theoretically reasonable values. For example, the Archie parameter $m$ was in numerous cases significantly less than 1.0, which is inconsistent with theory (e.g., Sen et al., 1981). These issues led the panel to suspect problems with the laboratory measurements; it is the experience of members on the panel that the accurate determination of soil resistivity as a function of fluid conductivity and moisture content is complex.

(a)

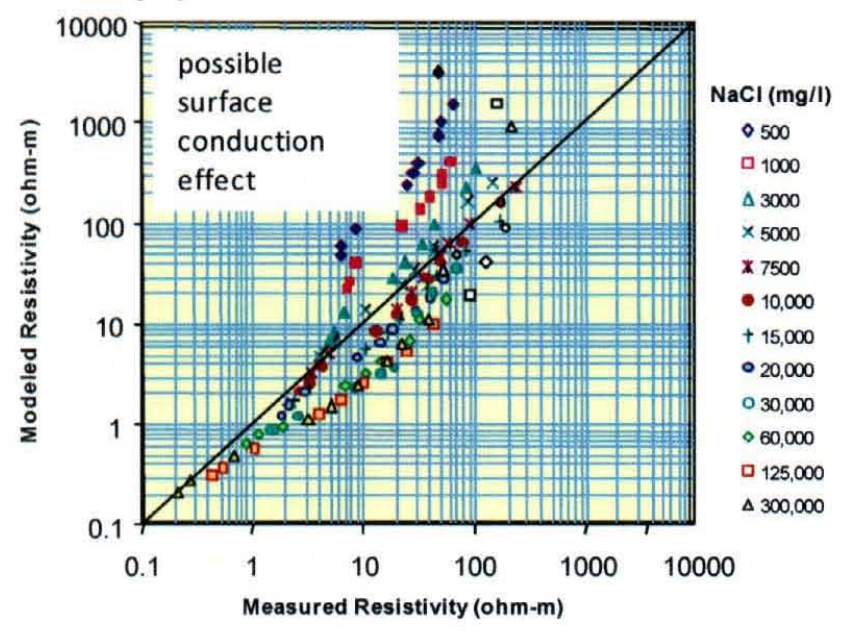

(b)

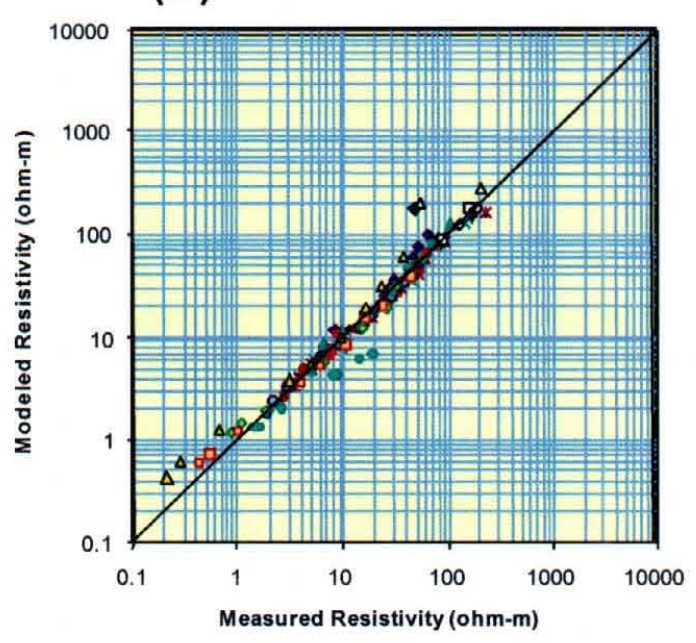

Figure 5.6. Cross-plot of modeled versus measured resistivity based on the parallel conduction model (a) no surface conduction (b) surface conduction

(Rucker, 2007a)

\subsubsection{Geostatistics}

Some relatively simple geostatistics were employed to extract statistical parameters describing the resistivity distribution from the inverted images. Such approaches have shown potential for estimating the correlation structure of lithofacies and/or hydraulic properties from GPR data (Rea and Knight, 1998; Oldenborger et al. 2003). Many variogram plots describe the correlation structure of the data in the HRRDPM for the second BCCT survey. This information has been used to define a model for krigging interpolated points where data quality is poor or data are missing. Some spatial-moments analyses to demonstrate how the center of mass of a plume might be estimated from resistivity images, assuming that these images define a plume structure, were performed. The panel was encouraged to see the application of geostatistics in the interpretation of resistivity datasets. 
SGW-34795, Rev. 0

\subsection{SUGGESTED IMPROVEMENTS FOR FUTURE PROJECTS INVOLVING ELECTRICAL RESISTIVITY METHODS}

\subsubsection{Borehole Data and Methods}

There is an obvious need to focus on validating the geophysical datasets already collected at Hanford. The panel, therefore, recommends that Fluor and CH2MHIIl prioritize obtaining data that can be used to confirm the significance of the inverted resistivity images obtained to date over collection of more resistivity data at new sites. We stress that all efforts to validate the datasets should be based on inverted data and full 3D inversion, wherever possible. The panel first recommends that a comprehensive effort be made to utilize all existing borehole data from the sites in the validation effort. There appear to be seven existing boreholes within the vicinity of the T Tank Farm (C4104; C4105; W11-39; W11-25B; W11-43; W11-44; W11-47) with nitrate concentration and moisture content measurements to $50 \mathrm{~m}$ depth. Two cross-plots of resistivity plotted at depth based on the HRRDPM versus nitrate appear to show no significant correlation'. However, an apparently significant correlation between inverted resistivity and nitrate concentration was demonstrated for one of these wells as shown in Fig. 5.5. ${ }^{6} \mathrm{~A}$ more comprehensive effort to make use of the seven wells to validate the resistivity inversions at the T-Tank Farm is recommended.

The panel also recommends an expert evaluation of advanced geophysical logging technologies that could be used to obtain validation information. Technologies exist to log formation resistivity within the vicinity of a borehole through metal casing. A conceptual diagram of a tool developed by Schlumberger is shown in Fig. 5.7. This tool is reported to have a radius of investigation of up to $30 \mathrm{ft}$ from the borehole. Assuming the technology is appropriate for application at the Hanford Site (requiring consultation with Schlumberger or other experts), an opportunity would exist to collect a spatially dense dataset of vertical profiles of electrical conductivity close to existing wells at the one of the tank farms, such as the B Complex farms. This could be a very useful dataset for validating surface and WTW imaging without requiring new drilling. It should also be possible to run moisture probe logs in existing cased wells, perhaps allowing a validation of plume location based on an elevated moisture content signature. Given that the wells at the T Tank Farm consist of two metal casing strings separated by a grout of unknown thickness and continuity, these techniques might be more successful at the B Complex farms, where the well construction is simpler.

The panel also supports new drilling efforts specifically designed to validate the resistivity anomalies identified in the resistivity survey at Hanford. An evaluation of the current plan for drilling at the BCCT is presented in Section 6 of this report.

\footnotetext{
${ }^{5}$ It is unclear which of the seven boreholes at the T Tank Farm were used in this correlation and the statistical significance of the correlations was not quantified.

- Again, it is unclear which borehole was used here and the statistical significance of this correlation was again not stated.
} 
SGW-34795, Rev. 0

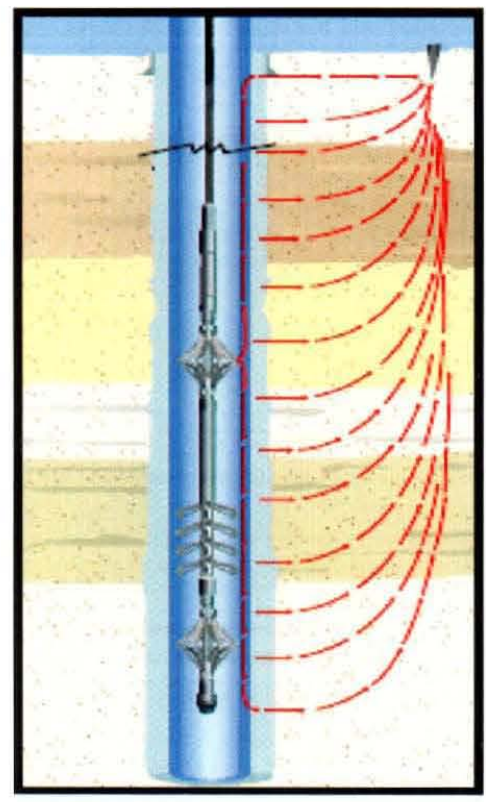

Figure 5.7. Concept of resistivity formation logging from metal-cased boreholes

(Although most of the current is channeled along the metallic casing, a small leaking current is induced to pass through the formation to an electrode at the surface; this leakage current can be quantified from high-precision voltage measurements made along the casing)

\subsubsection{Petrophysics}

The panel recommends that petrophysical studies continue in an effort to improve the interpretation of the resistivity datasets. The attempt to determine the dependence of resistivity of Hanford sediments on moisture content and ionic concentration is important in this respect. The potential role of surface conduction in controlling the dependence of Hanford soils on moisture content and ionic concentration has been recognized. The likely spatial dependence of surface conduction on formation heterogeneity should be quantified to reduce the ambiguity between changes due to concentration variation and changes due to formation heterogeneity. The panel hopes that these efforts will continue and a more comprehensive study to relate soil resistivity to petrophysical properties be initiated through partnership with a university researcher proficient in this study area.

\subsubsection{Geostatistics}

The panel recognizes that there is potential value in using geostatistics to extract quantitative information on subsurface structure from geophysical images. Geostatistical parameters should be extracted from the results of 3D inversion where possible. Furthermore, it is now well recognized that extracting physically significant spatial moments of a contaminant plume from resistivity images of a plume structure is non-trivial, as tomographic resolution, and hence image structure, is dependent on geophysical data acquisition, regularization, data error and the physics of the underlying measurements (Day-Lewis and Lane, 2004; Linde et al., 2006). In general, the panel was impressed by the efforts to apply these geostatistical concepts, and further exploration of such ideas is encouraged once some validation of the hydrogeological significance of the resistivity images as proxies of plume structure is established via confirmation drilling. 
SGW-34795, Rev. 0

This page intentionally left blank 


\subsection{EVALUATION OF TIIE SAMPLING \& ANALYSIS PLAN FOR BC CRIBS AND TRENCHES}

The panel was specifically charged with reviewing the draft sampling and analysis plan (SAP) for validating the resistivity surveys at the BCCT Area (DOE, 2007). The decision to embark on a limited program of verification drilling is strongly endorsed, as it is clear that some validation of the geophysics is urgently needed to demonstrate the capabilities of the technology with respect to contaminant plume delineation. The panel is concerned about the skepticism regarding the resistivity geophysical method that was expressed by numerous attendees of the open forum part of the workshop, including scientists, regulators and other stakeholders. A carefully designed sampling plan could alleviate some of these doubts by providing a statistically significant (hopefully successful) validation dataset.

The draft SAP proposes up to five boreholes in the BCCT placed at locations based on the resistivity results. Unfortunately, the plan emphasizes locating these boreholes based on the structure observed in the pseudosections generated using the HRRDPM rather than the structure observed in resistivity inversions. The plan makes frequent references to investigating structures in these pseudosections (such as the 'pants leg') that are simply artifacts of the plotting method and unrepresentative of the subsurface resistivity structure. However, the panel found that the suggested locations of the five boreholes, based on a preliminary review, may be reasonable choices to enable a validation of the resistivity method.

The panel strongly recommends that the five borehole locations proposed in this plan be carefully reevaluated based on the resistivity inversion results for the BCCT (preferably the full 3D inversion that was due to run during the week of the workshop). The 3D inversion may indicate some repositioning of proposed borehole locations, and the SAP should be revised to include appropriate technical justification for the borehole locations based upon the 3D inversion results. As with the reports reviewed by the panel, it is recommended that all references to the HRRDPM be removed from the SAP; the sampling should be based on the statistically best estimate of subsurface resistivity structure. It is the opinion of the panel that this best estimate is obtained from inversion. For example, the problem statement should be changed from "The purpose of this SAP is to ascertain the degree to which HIRR apparent resistivity data for the BCCT Area correlate with targeted parameters in the vadose zone" to "The purpose of this SAP is to ascertain the degree to which estimated resistivity models for the BCCT Area correlate with targeted parameters in the vadose zone. "

The panel also questioned the need for some of the physical and geochemical analyses of borehole samples, e.g., for example the proposal to estimate hydraulic conductivity as a function of saturation. Presumably, such analyses are being done in an effort to obtain data on the heterogeneity in physical properties of the Hanford Formation, rather than specifically to determine the significance of the resistivity data. However, some of the other physical and geochemical analyses are highly relevant to understanding the spatial variation in the imaged resistivity, e.g., cation exchange capacity (closely related to surface conduction) and grain size distribution, which controls moisture retention characteristics. Furthermore, the panel was supportive of the tentative plan to emplace vertical electrode arrays in some of the boreholes in order to (a) provide much needed electrodes at depth, and (b) permit measurement of temporal resistivity changes within the plume in the vicinity of the boreholes. In addition, the panel 
SGW-34795, Rev. 0

found parts of the plan poorly worded, and scientifically incorrect, when referring to the science of the resistivity geophysical method. However, this is a relatively minor concern, as it does not adversely impact the appropriateness of the proposed borehole locations. 


\subsection{CONCLUSIONS AND RECOMMENDATIONS}

\subsection{INTRODUCTION}

Extensive resistivity surveys were successfully completed over sites, including the $\mathrm{BCCT}, \mathrm{S}$ and T Tank Farms. These surveys show substantial resistivity anomalies that likely correlate with some contaminants of concern, particularly nitrates and ${ }^{99} \mathrm{Tc}$. The resistivity method has the potential to work at the necessary depth of exploration and within the proximity of significant anthropomorphic culture to delineate the extent of these contaminants in many areas at the IIanford Site. This method offers broad spatial sampling at relatively low cost, and potentially could support site characterization using far more precise, but spatially limited, expensive and invasive borehole data. It can be applied to guide future characterization efforts, including specification of borehole locations for additional sampling, and design of remedial actions.

We believe that if the recommendations above are followed, the methods that result for future applications of electrical resistivity surveys at the Hanford Site will have the highest possible degree of reliability. Reports should clearly delineate the limitations of the methods used.

\subsection{SUMMARY OF STRENGTHS AND LIMITATIONS OF THE ELECTRICAL RESISTIVITY METHOD}

\subsubsection{Cultural Effects}

Cultural effects, due to tanks, pipelines and power lines, can be daunting at the Hanford Site; however, the electrical resistivity method is robust in the presence of many cultural features relative to other geophysical methods. There are a large variety of array configurations that are designed to minimize noise and the response of infrastructure within a survey area while optimizing sensitivity to targets. Careful survey design and sophisticated interpretation approaches are necessary to separate the response of the infrastructure from that of the more subtle plume response.

\subsubsection{Plume Delineation}

The bulk resistivity of the Hanford and Ringold Formation is high (hundreds of ohm-m). The plume chemistry includes elevated concentrations of nitrate, which has a conductive signature (tens of ohm-m). The high contrast is very encouraging for the use of the electrical resistivity method as a contaminant mapping technique.

The depth to the top of a conductor and the lateral distribution are well-resolved parameters. The depth to the bottom of a conductor, such as a plume, is less well resolved, making the $3 D$ estimate of plume geometry problematic. However, the integrated use of both surface and subsurface electrode arrays can overcome this limitation. Small stratigraphic features, which may control contaminate transport, can be difficult to delineate. 


\subsubsection{Plume Chemistry}

Interpretation of resistivity anomalies may be ambiguous, because the resistivity varies due to changes in moisture content, lithology, and contaminant constituents. Nitrate seems to be a driving source of the low resistivity and may be correlated to ${ }^{99} \mathrm{Tc}$.

\subsection{PANEL RECOMMENDATIONS}

The panel concludes with a number of recommendations.

- Because the DOE Hanford Site contractors do not necessarily have in-house geophysical experts, the panel recommends they acquire the services of an independent expert in electrical resistivity methods to assist with future procurements (RFP preparation), technical oversight during conduct of the work, and independent review of results.

- Validation of existing work is extremely important and should be given the highest priority. The draft SAP proposes up to five boreholes in the BCCT placed for validation/confirmation. The panel supports a confirmation investigation based upon approximately five boreholes; initial locations appear to be reasonable, but several were based upon the HRRDPM plots; as such, the panel recommends re-evaluating the borehole locations based on interpretation of 3-D inversions. After the reevaluation is completed, the SAP should be subsequently revised to justify the borehole locations based upon 3-D inversion interpretation.

- Future work should begin with survey design using rigorous numerical and experimental model studies. Assumptions and field predictions should also be validated and image resolution investigated using model studies.

- Data collection and processing need to be fully documented. Recommendations from the previous panel need to be followed, as well archiving of data and fully following manufacturers' procedures for data entry.

- Rigorous quality control should be conducted through the use of audits, repeated data sets, and reciprocal checks.

- Data processing should follow rigidly defined and documented protocols, not ad hoc methods.

- The panel recommends data processing by 3D inversion, because it produces more realistic locations and magnitudes of anomalous zones. The inversion routine should rigorously incorporate cultural features, such as pipes and tanks. HRRDPM should not be used for final data presentation or interpretation.

- The panel has many concerns about presentation of the results including, model studies, maps, HRR plots and inverse models. The use of different color scales to compare different results was very misleading. The same standard gray or color scales should be used throughout and detailed explanations provided, on plots as well as in text, when non-standard scales are used and how and why they were chosen.

- Petrophysical studies should be continued, as they are important to interpretation of resistivity data. However, a partnership with an expert in resistivity properties of soils, perhaps through collaboration with a university researcher, is considered essential to this effort. 
SGW-34795, Rev. 0

\subsection{RESPONSE TO FOUR KEY QUESTIONS}

The following provides the panel's response to the four key questions presented in Section 1.3, Objectives.

Response to Question 1. The panel found that the resistivity work completed at Hanford todate has not conclusively demonstrated that the method can provide reliable data in areas containing significant cultural features. However, the panel believes that independent mapping of infrastructure, careful survey design, and sophisticated processing using 3D inversion and interpretational approaches may enable separation of the response of the infrastructure from that of the conductive plumes and the geological heterogeneities in the subsurface. If this is found to be the case, the electrical resistivity method would be useful at sites with significant cultural features. The panel provides further discussion of a recommended approach to address Question \#1 in the body of the report. The panel cautions that distortion and/or cultural noise may be too high in some areas to acquire useable data.

Response to Question 2. The panel believes that electrical resistivity surveys, when implemented using best practices, as described in this report, can provide a useful guide for designing future site characterization programs, supporting selection of borehole locations for characterization and monitoring.

Response to Question 3. The panel believes that electrical resistivity methods should provide good resolution of the top and lateral extent of a conductive plume. However, the bottom of a conductive plume will be less well resolved. Advanced methods integrating both surface and subsurface electrode arrays, such as well-to-well and well to surface arrays, should be used to improve the resolution of the bottom of the plume; these approaches are recommended at locations where determination of the base of the plume is of interest. The panel cautions that without these advanced methods, there will be a greater uncertainty regarding the bottom of the plume. Confirmation drilling will always be required to support the plume delineation activity.

Response to Question 4. Electrical resistivity cannot be used to identify the specific nature of the contaminants, especially those present at concentrations in the parts per billion or parts per million levels, or to distinguish between different types of contaminants. However, because nitrate is also present in the pore waters at concentrations of tens and hundreds of thousands of parts per million, anomalous conditions, as compared to the natural subsurface resistivity, have been identified. Integrating the knowledge of the nature of the contaminants from borehole data, further investigation regarding estimation of concentrations from the resistivity data should be conducted to determine its feasibility. The panel urges caution, however, because of the uncertainties in geophysical imaging and petrophysical relationships. 
SGW-34795, Rev. 0

This page intentionally left blank 


\subsection{REFERENCES}

Advanced GeoSciences, 2005, The SuperSting ${ }^{\mathrm{TM}}$ with Swift ${ }^{\mathrm{TM}}$ Automatic Resistivity and IP System Instruction Manual, Advanced Geosciences Inc., Austin, TX, 87 p.

Archie, G. E., 1942, The electrical resistivity $\log$ as an aid in determining some reservoir characteristics, Transactions of American Institute of Mineralogists Metallurgists and Petroleum Engineers 146: 54-62.

Beard, L. P. and Tripp, A. C., 1995 Investigating the resolution of IP arrays using inverse theory Geophysics, v. 60, no. 5, 1326-1341.

Carlson, N. R., Hare, J. L., Zonge, K. L., 2001, Buried landfill delineation with induced polarization: progress and problems, in Proceedings of the 2001 Symposium on the Application of Geophysics to Engineering and Environmental Problems (SAGEEP), Denver, Colorado, March 4-7, 2001.

Dahlin, T. and Zhou, B., 2004, A numerical comparison of 2D resistivity imaging with 10 electrode arrays, Geophysical Prospecting 52 (5), 379-398.

Day-Lewis, F. D. and. Lane, J.W. Jr., 2004, Assessing the resolution-dependent utility of tomograms for geostatistics, Geophysical Research Letters 31: L07503, DOI: 10.1029/2004GL019617.

DOE, 2007, Sampling and analysis plan for high-resolution resistivity correlation for the BC Cribs and Trenches Area, Richland, Washington, United States Department of Energy, Draft.

Fogwell, T., Petersen, S., Kaback, D., Pellerin, L., Hubbard, S., Daniel, J., and Steeples, D., 2006, Evaluation of geophysical technologies for subsurface characterization, WMP 31707 rev.0, November 2006, Fluor Hanford, contractor to the Department of Energy Richland.

Hallof, P.G., 1992, Grounded Electrical Methods in Geophysical Exploration, in Practical Geophysics Il for the Exploration Geologist, Richard Van Blaricom etc., Northwest Mining Association, p. 39-138.

Kaipio, Jari and Somersalo, E., 2006, Statistical and Computational Inverse Problems, Springer.

Kappelmeyer, O., and Haenel, R., 1974, Geothermics, Geoexploration Monographs, Series 1, No. 4, Chapter 3, Geopublication Associates, 238 p. 
SGW-34795, Rev. 0

Knight, R., 1991, Hysteresis in the electrical resistivity of partially saturated sandstones, Geophysics 56: 2139-2147.

LaBrecque, D. J., Bennett, J., Heath, G., Schima, S., and Sowers, H., 1998, Electrical resistivity tomography for process control in environmental remediation, in Proceedings of the Symposium on the Application of Geophysics to Engineering and Environmental Problems, p. 613-622.

Last, G.V., Horton, D. G., 2000, Review of geophysical characterization methods used at the Hanford Site, PNNL-13149.

Linde, N., Chen, J., et al. 2006, Hydrogeophysical parameter estimation approaches for field scale characterization, Applied Hydrogeophysics, H. V. e. al. Dordrecht, Springer: 9-44.

Nelson, P. H., 1977, Induced polarization effects from grounded structures: Geophysics, 42, 124111253.

Oldenborger, G. A., Schincariol, R. A., et al., 2003, Radar determination of the spatial structure of hydraulic conductivity, Ground Water 41(1):24-32.

Pride, S., 1994, Governing equations for the coupled electromagnetics and acoustics of porous media, Physical Review B 50(21): 15678-15696.

Rea, J. and Knight, R., 1998, Geostatistical analysis of ground-penetrating radar data: A means of describing spatial variation in the subsurface, Water Resources Research 34(3): 329 229.

Revil, A. and Cathles, L. M., 1999, Permeability of shaly sands, Water Resources Research 35(3): 651-662.

Revil, A. and Glover, P. W. J., 1998, Nature of surface electrical conductivity in natural sands, sandstones, and clays, Geophys. Res. Letters 25(5): 691-694.

Roy, A. and Apparao, A., 1971, Depth of investigation in direct current methods. Geophysics 36(5), 943-959.

Rubin, Y and Hubbard, S., 2005, Stochastic forward and inverse modeling: the hydrogeophysical challenge, in HydroGEOPHYSICS, Springer, Netherlands, p. 487512.

Rucker, D. and Benecke, M., 2006, Geophysical investigations by high resolution resistivity for BC Cribs and Trenches area, 2004-2006, D\&D 31659, Rev. 0, Draft. 


\section{SGW-34795, Rev. 0}

Rucker, D., Levitt, M., Henderson, C. and. Williams, K., 2006a, Subsurface geophysical exploration of the U Tank Farm at the Hanford Site, RPP-RPT-31557, Rev. 0, December.

Rucker, D., Levitt, M., Henderson, C., and Williams, K., 2006b, Subsurface geophysical exploration of the S Tank Farm at the Hanford Site, RPP-RPT-30976 Rev. 0, September.

Rucker, D., Levitt, M., Henderson, C., and Williams, K., 2006c, Subsurface geophysical exploration of the T Tank Farm at the Hanford Site, RPP-RPT-28955, Rev. 0, June 2006.

Rucker, D., 2007a, Overview of electrical resistivity in tank farms: presentation to the HRR review panel.

Rucker, D., 2007b, personal communication.

Sasaki, Y., 1992, Resolution of resistivity tomography inferred from numerical simulation: Geophysical Prospecting 40 (4), 453-463.

Sen, P. N., Scala, C., et al., 1981, A self-similar model for sedimentary rocks with application to the dielectric constant of fused glass beads, Geophysics 46: 781-795.

Telford, W.M., Geldart, L.P. and Sheriff, R. E., 1990, Applied Geophysics: Cambridge University Press, Cambridge, UK.

Ward, A.L., Gee, G.W., Zhang, Z.F., and Keller, J.M., 2004, Vadose zone contaminant fate and transport analysis for the 216-B-26 Trench, PNNL-14907.

Waxman, M. H, and Smits, L. J. M, 1968, Electrical conductivities in oil-bearing shaly sands: Trans. Am. Inst. Min., Metall. \& Petr. Eng., 243, Part Il, 1077122.

Wilkinson, P. B., Meldrum, P. I., et al., 2006. Improved strategies for the automatic selection of optimized sets of electrical resistivity tomography measurement configurations, Geophysical Journal International 167: 1119-1126. 
SGW-34795, Rev. 0

This page intentionally left blank 
SGW-34795, Rev. 0

APPENDIX A

WORKSIIOP AGENDA 
SGW-34795, Rev. 0

This page intentionally left blank

A-ii 


\title{
WORKSHOP AGENDA
}

\section{Technologies Workshop for Evaluating Resistivity Methods for Characterizing Contaminant Plumes in the Unsaturated Zone at the Hanford Site}

\author{
1200 Jadwin Avenue \\ Richland WA \\ April 16-19, 2007
}

Monday, April 16, Room B-1

\begin{tabular}{|c|c|c|}
\hline \multicolumn{2}{|r|}{ Welcome and Introductions } & $\begin{array}{l}\text { John Morse \& } \\
\text { Tom Fogwell }\end{array}$ \\
\hline $1: 10-1: 20$ & Workshop Objectives and Logistics & $\begin{array}{l}\text { Tom Fogwell \& } \\
\text { Dawn Kaback }\end{array}$ \\
\hline $1: 20-1: 50$ & Regulatory Perspective & $\begin{array}{l}\text { Craig Cameron \& } \\
\text { Dib Goswami }\end{array}$ \\
\hline \multicolumn{2}{|l|}{$1: 50-2: 20$} & Hanford Site \\
\hline \multirow{2}{*}{\multicolumn{2}{|c|}{$\begin{array}{l}\text { Conditions: Geology and } \\
\text { Contaminant Plumes }\end{array}$}} & George Last \\
\hline & & \\
\hline $\begin{array}{l}2: 20-2: 50 \\
2: 50-3: 00\end{array}$ & $\begin{array}{l}\text { BC Cribs and Trenches } \\
\text { Break }\end{array}$ & Mark Benecke \\
\hline $3: 00-3: 30$ & Tank Farms Vadose Zone Characterization & Dave Myers \\
\hline $3: 30-4: 30$ & HRR Studies Completed (T-Farm, S-Farm) & Dale Rucker \\
\hline $4: 30-5: 00$ & Other Geophysical Methods at Hanford & Andy Ward \\
\hline
\end{tabular}

Tuesday, April 17, Room B1

8:00-9:30 Further Discussion of Completed HRR Dale Rucker

Projects

9:30-9:45

9:45-10:15

$10: 15-4: 30$

Break

4:30-5:00

HRR Developments (Petrophysics)

Team Discussions

Discussion/Questions w/Hanford personnel
Dale Rucker

Team

Team $\mathbf{w}$

Hanford staff

Wednesday, April 18, Room B1

8:00-5:00 Team Writing/Discussion Team

Thursday, April 19, Room B1

8:00-10:30

$10: 30-12: 00$

Preparation of Outbriefing, Assignments Team

Out-briefing/Discussion w DOE, Fluor, etc.

All

Panel Members

Dr. Larry Bentley - Professor, Department of Geology and Geophysics, University of Calgary 


\section{SGW-34795, Rev. 0}

Dr. Lee Slater - Professor, Department of Earth/Environmental Sciences, Rutgers University

Dr. Louise Pellerin - Green Engineering, Inc.

Dr. Douglas LaBrecque - Multi-Phase Technologies, LLC

Dr. David Isaacson - Professor, Department of Mathematics, Rensselaer Polytechnic Institute 
SGW-34795, Rev. 0

Objectives of the Workshop:

\section{Evaluating Resistivity Methods for}

Characterizing Contaminant Plumes in the Unsaturated Zone at the Hanford Site

The overall goal is to evaluate the utility of electrical resistivity methods to characterize contaminants in the vadose zone in the 200 Area of the Hanford Site.

- Evaluate recently completed and ongoing electrical resistivity projects at Hanford in terms of methodology used, results obtained, and lessons learned, with specific focus on

o data collection (e.g., electrode placement, electrode composition, instrumentation)

- data processing (e.g., inversion methods)

- data reliability

- data confirmation

- data interpretation.

- Review plans for confirmation of current and future electrical resistivity projects.

- Suggest specific improvements to each of the above activities as part of the recommendations for future projects where electrical resistivity will be utilized. Recommendations should include discussion of an approach to vadose-zone characterization that could include other geophysical and non-geophysical methods. 
SGW-34795, Rev. 0

This page intentionally left blank 
SGW-34795, Rev. 0

\section{APPENDIX B}

ATTENDEES LIST

B-i 
SGW-34795, Rev. 0

This page intentionally left blank

B-ii 
SGW-34795, Rev. 0

Workshop Attendees List

\begin{tabular}{|c|c|c|c|}
\hline Name & Organization & Phone & Email \\
\hline Dawn Kaback & Geomatrix & 303-534-8722 Ext 111 & dkaback@geomatrix.com \\
\hline Shelley Cimon & $\begin{array}{l}\text { Oregon Dept of } \\
\text { Energy }\end{array}$ & $541-965-0853$ & scimon@oregontrail.net \\
\hline $\begin{array}{l}\text { Sandra } \\
\text { Lilligren }\end{array}$ & Nez Perce Tribe & $208-8+3-7375$ & sandral@nezperce.org \\
\hline David Myers & CH2M Hill & $509-373-3972$ & David.A_Dave_Myers@rl.gov \\
\hline $\begin{array}{l}\text { Colin } \\
\text { Ilenderson }\end{array}$ & Columbia Energy & $509-9+46-7111$ & chenderson@columbia-energy.com \\
\hline Stan Sobczyk & Nez Perce Tribe & $208-8+3-7375$ & stans@nezperce.org \\
\hline Ted Repasky & CTUIR & $541-966-2412$ & TedRepasky@ctuir.com \\
\hline $\begin{array}{l}\text { K. Michael } \\
\text { Thompson }\end{array}$ & DOE-RL & $509-373-0750$ & K_M_Mike_Thompson@rl.gov \\
\hline Ned Clayton & $\begin{array}{l}\text { Schlumberger Water } \\
\text { Services }\end{array}$ & $916-768-0825$ & clayton@slb.com \\
\hline Tim Parker & $\begin{array}{l}\text { Schlumberger Water } \\
\text { Services }\end{array}$ & $916-329-9199$ & tparker2@slb.com \\
\hline $\begin{array}{l}\text { Doug } \\
\text { LeBrecque }\end{array}$ & $\begin{array}{l}\text { Multi Phase } \\
\text { Technology }\end{array}$ & $775-356-7844$ & dlabrecque@MPT3d.com \\
\hline Lee Slater & Rutgers University & $973-353-5704$ & slater@andromeda.rutgers.com \\
\hline Louise Pellerin & Green Engineering & $570-704-1566$ & pellerin@ak.net \\
\hline David Isaacson & RPI & $518-276-9600$ & isaacd@rpi.edu \\
\hline Mark Benecke & Fluor Hanford & $509-376-0002$ & Mark_W_Benecke@rl.gov \\
\hline Dale Rucker & HGI & $520-907-6063$ & drucker@hgiworld.com \\
\hline Scott Petersen & Fluor Hlanford & $509-372-9126$ & Scott_W_Petersen@rl.gov \\
\hline Joe Caggiano & Ecology & $509-372-7915$ & jcag461@ecy.wa.gov \\
\hline Dib Goswami & Ecology & $509-372-7902$ & dgos461@ecy.wa.gov \\
\hline George Last & PNNL & $509-376-3961$ & george.last@pnl.gov \\
\hline
\end{tabular}


SGW-34795, Rev. 0

\begin{tabular}{|c|c|c|c|}
\hline Name & Organization & Phone & Email \\
\hline $\begin{array}{l}\text { Barbara } \\
\text { llarper }\end{array}$ & CTUIR & $541-966-2804$ & bharper@amerion.com \\
\hline R. Jeff Serne & PNNL & $509-376-8429$ & jeft.serne@anl.gov \\
\hline $\begin{array}{l}\text { Michael D. } \\
\text { Thompson }\end{array}$ & ANL & $630-252-9269$ & mdthompson@anl.gov \\
\hline David S. Miller & ANL & $509-376-4998$ & david.s.miller@anl.gov \\
\hline Craig Cameron & EPA & 509-376-8665 & cameron.craig@cpa.gov \\
\hline Martha Lentz & EPA & 206-553-1593 & lentz.martha@epa.gov \\
\hline Tony Knepp & YAHSGS & $509-438-6453$ & tknepp@yahsgs.com \\
\hline Alisa Yluckaby & Ecology & 509-372-7909 & ahuc461@ecy.wa.gov \\
\hline Tom Post & EPA & $509-376-6623$ & post.tom@epa.gov \\
\hline Jacqui Shea & Ecology & $509-372-7925$ & jash461@ecy.wa.gov \\
\hline $\begin{array}{l}\text { Nancy } \\
\text { Uziemblo }\end{array}$ & Ecology & $509-372-7828$ & nuzi461@ecy.wa.gov \\
\hline $\begin{array}{l}\text { John } \\
\text { Kristofzski }\end{array}$ & & $509-373-4225$ & John_G_Kristofzski@rl.gov \\
\hline John Fink & hydroGEOPIYYSICS & $520-647-3315$ & jfink@hgiworld.com \\
\hline Mark Sweeney & PNNL & $509-373-0703$ & mark.sweeney@pnl.gov \\
\hline $\begin{array}{l}\text { Jerry } \\
\text { Cammann }\end{array}$ & FGG & & Jerry_W_Cammann@rl.gov \\
\hline $\begin{array}{l}\text { Thomas } \\
\text { Fogwell }\end{array}$ & Fluor Hanford & $509-373-3812$ & thomas_fogwell@rl.gov \\
\hline
\end{tabular}


SGW-34795, Rev. 0

\section{APPENDIX C}

\section{STAKEHOLDERS COMMENTS AND QUESTIONS}


SGW-34795, Rev. 0

This page intentionally left blank

\section{C-ii}




\section{Oregon Department of Energy Comments and Panel Response in Italics}

Oregon appreciates the opportunity to participate in the ongoing High Resolution Resistivity (HRR) expert panel review for the Hanford site. Two staff from Oregon attended the review session yesterday (April 16), and came away with a very favorable impression of the panel's activities; they seemed well focused on important issues and were asking the right questions of the presenters at the workshop. Because discussions went beyond scheduled times, we did not have an opportunity to offer questions or comments at yesterday's session, so we are providing them to you with the understanding that they will be forwarded to the review panel.

1. We have seen HRR used at Hanford to help show lateral transport beneath the $200 \mathrm{~B} / \mathrm{C}$ cribs and other locations. This knowledge leads to better questions to guide field investigations to help guide placement of borings, wells, excavations, and cone penetrometer pushes to support investigation strategy. So long as HIRR is used as a guide to further investigations to field truth the assessments, we support this. However, there is an attempt to push this information farther to assess the inventory released and its location. It has not been demonstrated that the technology can adequately differentiate conductivity/resistivity associated with moisture from that which is associated with salts and contaminants, such that we can use this tool in lieu of field investigations.

As you stated, geophysical methods are best used to aid and optimize field investigations - both are needed for an effective and efficient program

2. After attending the briefings on Monday April 16th, we question how deep the technology can see into the soil and with what accuracy. We are also concerned regarding how prone the method is to false positives and false negatives. DOE has attempted to use the technology to develop a leak monitoring system for tanks. We are even more concerned on this use of the technology, given the "pant leg" effect explained in the presentations which shows the potential of masking, or missing large areas of contaminants, or presenting a "shadowing" effect which might be misinterpreted as a plume where none exists.

The HHR data plotting method (HRRDPM) has artifacts that are eliminated with parameter estimation (inversion) techniques and the panel recommends that the HRRDPM be abandoned and inversion be used for processing, interpretation, presentation, and for a leak monitoring system. This is addressed in detail in the report.

3. HRR may be able to see moderately large leaks. However, the first tests of this showed both large misses and reported large detections of apparent leaks where none had occurred. There is danger here both that the tool may give false confidence that no leak has occurred when one actually has and that it will falsely indicate large leaks where none have occurred. The potential for initiating tank pumping based on a false read would have fiscal impacts to all sorts of programs and activities at the Hanford site. 
We agree. Solution appraisal and resolution analysis, which has not been done, will greatly improve confidence in the resistivity models and reduce risk of making decision on these models

4. We wonder whether HRR might be able to help identify the subsurface locations of the clastic dikes under the central plateau and in particular, under tank farms, cribs, ditches, ponds, burial grounds and other waste sites.

Clastic dikes have been mapped with the Ground Penetrating Radar (GPR) and Audiomagnetotelluric (AMT) methods at Hanford (2005 geophysics report by Geomatrix). Electrical resistivity should also be sensitive to these structures. The work presented to the panel concentrated on plume delineation and no effort was made to evaluate the method for mapping of geologic structures.

5. We question the synergistic effects of multiple plumes in the vadose zone and groundwater and the ability of this technology to accurately depict them.

Imaging with $3 D$ inversion, including solution appraisal and resolution analysis, can effectively eliminate synergistic effects of multiple plumes. However the constituents of commingled plumes cannot be identified

6. We wonder how many anomalous effects currently portrayed by the presentations on HRR does it take to negate the validity of HRR as a reliable tool?

The artifacts associated with the HHRDPM casts a negative view on the capabilities of the electrical resistivity method. As stated above and in the report, with proper survey design, solution appraisal and resolution analysis the method is a reliable tool.

7. We have concerns that the current groundtruthing of this tool is too dependent on existing data. There is the potential for misinterpretation of the ability of HRR to truly define a plume. We recommend that results be compared to existing data and then validated with newly collected data to confirm the geophysical interpretation presented.

We agree and recommend that field validation be the highest priority. See the report for further comments.

8. Finally, we have concerns regarding the selections of colors and different spatial scales used in displays presenting data. The selection of colors and scales can unduly emphasize or suppress features of the data, and can substantially change the perception of information in the data that are being displayed.

We agree and this topic is treated in detail in the report.

We see HRR as a useful tool in concert with other tools to help guide further field investigation, but in no case as a replacement for field investigation. Validation of the accuracy of this technology has much further to go, and we look forward to working with DOE as application of this technology evolves to support cleanup of the Hanford site. 
Thank you for your support and for forwarding our comments to the panel for consideration. Should you have any questions or wish to discuss any of our comments, please call Tom Stoops (503-378-8328) or Dirk Dunning (503-378-3187) of my staff. 
SGW-34795, Rev. 0

This page intentionally left blank 


\section{Ted Repasky Comments and Panel Response in Italics}

- First I would like to say that I thought the last geophysical expert panel did a very good job reviewing the geophysics used at Hanford. It seems like some of the material presented today is a repeat of what that panel has already seen a couple of years ago. There still needs to be some validation and field verification of this method.

We wholeheartedly agree and recommend field verification in the report.

- Many of the HRR lines shown in the presentation were over trenches and cribs and even the tanks. These surface features have been filled in or altered since they were in operation. Does this disturbed soil have an impact on the response that the HRR method is measuring?

Changing soil conditions can change the resistivity, but it normally would not have a significant impact on the resistivity values determined by inversion for the underlying soils.

- The HIRR method appears to not be able to adequately determine the depth to a conductive body unless there is some prior knowledge...from well data (for example). Will a shallow highly conductive body generate the same results as a deeper less conductive mass?

The depth of investigation for the electrical resistivity method is a function of electrode spacing: closely spaced electrodes are used to investigate shallow feature and large arrays for deeper structures. You can distinguish a shallow from a deep body. The well data is important to correlate the resistivity to a geochemical anomaly

- One slide showed a correlation from the single well between Nitrate and Tc-99. The Uranium was appearing at a different depth in the well. How useful is this tool for determining contamination locations on Hanford if it is very selective to only show the more conductive Nitrates/Tc-99? Hanford has a lot of other contamination than just this one element.

At Hanford, the resistivity method appears to map plumes containing high concentrations of total dissolved solids. These plumes primarily contain nitrate, as well as other major cations and anions, present at high enough concentrations to be measurable using the geophysical method. Trace elements and radionuclides are not present at high enough concentrations to produce a resistive anomaly. However, if some of the contaminants such as Tc-99 are present in the same locations as the nitrate, the resistivity method will be a good indicator of the Tc-99 plume. Other contaminants that likely migrate with the nitrate may be iodine and tritium. Elements like uranium are not as mobile as the nitrate and thus would not necessarily be located in the same places. 
- Hanford also has contamination located in many different depths, overlapping events, and adjacent contamination. This tool has significant problems resolving these multiple events due to edge effects. It can not see contamination located deeper or between two conductive plumes. This tends to mask what is really present.

The method cannot distinguish different events in a temporal sense, but using $3 D$ inversion methods and proper survey design different plumes can be mapped at different depths. The HRR data plot method (HRRDPM) has edge effects and artifacts that mask multiple plumes. See the report for more information.

- The resolution of the HRR method tended to smear the data. Unless they had a previous idea of the conductive bodies depth and size, it can not approximate what is really present.

Again this is a problem with the HRRDPM, not the electrical resistivity method. More information on the problems associated with the HRRDPM is provided in the report.

- Hanford's geology is not a simple homogeneous unit. The bedding, faulting, and stratification have a significant influence on controlling plume movement. Vertical dikes tend to wick the plumes downward. Clay layers will also cause the plumes to move laterally for significant distances. The models generated from interpreting the HRR data do not show nor adequately represent this complexity.

Yes, this is true. Some features, such as small clay layers, may not be visible to the resistivity method. Dikes can be mapped. A minimal effort was made to investigate the geology; emphasis was placed on delineating the plume. In general the plume is significantly more conductive than the geologic background and that was the rational for this approach.

- From the graphics displayed at the meeting, it appears to me that the HRR method "smears" the data both vertically and horizontally. Especially when considering the edge effects and the "pant legs". It was claimed that HRR predominately "smears" the data laterally.

The HRRDPM smears the data and contains artifacts such as edge effects and pant legs. Hence the panel recommends the HRRDPM be abandoned and inversion be used for processing and interpreting the data. $3 D$ inversion eliminates pantleg effects and greatly reduces horizontal and vertical smearing. See the report for more information.

- We are greatly concerned about the selective use of colors and changes in scale for the different plots. These tend to emphasis certain features while suppressing others. How can the size of the conductive body be adequately determined when the colors are selectively adjusted to bring out a bulls-eye of contamination?

We agree and have addressed this concern in the report. Standard color scales should be used at all times. 
- In areas, such as the results around the T-tank farm, different scales were used in the graphics for adjacent surveys to give them the appearance of being continuous. The display scale of the data inside the tank farm was significantly different than the display scale of the data outside of the fence line.

We agree and addressed this issue in the report.

Overall, it appears as though this tool may be most useful only if prior knowledge of a particular plume is available.

For the resistivity method to be effective there must exist an electrical resistivity contrast sufficient enough to result in a measurable voltage response. In plume delineation this would be dependent on the ionic content/concentration. To translate an electrical resistivity anomaly to plume geometry, knowledge of the plume chemistry is required. One of the best uses of geophysics is to extend the knowledge of the subsurface from a point at a borehole to a larger survey area. The resistivity method is simply one tool to be used in collaboration with other information to produce the best understanding of the subsurface that we can obtain. It cannot be used as a stand-alone method.

Thank you and the expert panel for convening and lending comments to the geophysics used at the Hanford site. 
SGW-34795, Rev. 0

This page intentionally left blank 
SGW-34795, Rev. 0

\section{Barbara Harper Comments and Panel Response in Italics}

I would like to add a few more comments to the ones that Ted sent, most of which have already been discussed in the meeting:

- Be careful about labeling low resistivity anomalies as "nitrate signature" or "contamination" too quickly, rather than simple moisture. Similarly, anomalies related to waste sources may be residual moisture from past leaks (?) or residual conductive materials (?). Is an anomaly detected only as long as it remains moist?

We agree. Resistivity anomalies are a function of a combination of factors, including moisture content, ionic content, concentration and lithology. Geochemical and other data from boreholes can be used to determine the "source" of the resistivity anomaly for interpretation (i.e. what factors are contributing to the anomaly). For example, you could have an anomaly associated with a change in moisture content.

- I am still confused about how to sort out the various factors that influence conductivity - lithography and soil type and composition; moisture within, on, or between soil particles; ionic condition of the soil minerals, dissolved salts, $\mathrm{pH}$, temperature, or ionized contaminants; plus physical attributes (non-conductive structures or boulders, pipes, and various reflections or other things that can distort a field). There seem to be various reflections, shadows, interferences, and anomaly magnifiers (for example, the 4 HRR lines as they move toward the tanks - is this an artifact of reflections or resonance between the water table and the tanks even though they are hundreds of feet apart vertically?).

You are correct about the many sources of resistivity anomalies. However the artifacts (shadows, reflections) associated with the HRR data plotting method (HIRRDPM) can be eliminated with the use of parameter estimation (inversion) techniques. Hence, the panel recommends that the HRRDPM be abandoned and inversion used. The other factors and their individual contribution to the resistivity value can be investigated by collection of borehole geochemical data.

- Since one of the charge questions was whether different contaminants can be distinguished, please address the limitations. A discussion of the limits of precision and accuracy would be useful.

A nontrivial question - it is addressed in the hydrological interpretation section of the report. The resistivity anomalies are indications of elevated total dissolved solids, which consist of nitrate as well as other major cations and anions (such as sulfate, sodium, etc.). Trace elements and radionuclides are not present at high enough concentrations to contribute significantly to the resistivity anomaly.

- Please identify what field conditions would determine whether HRR or 3D would meet some TBD data usability guidelines. For example, if GPR shows [something shallow], then electrodes should be placed $\mathrm{x}$ far apart and $\mathrm{y}$ deep. The 
goal is to avoid repeating data collection events, yet not be stuck with too little data to be useful. This is a value of information or systems engineering question.

This falls under survey design and is addressed in the report. It is important to collect optimal data for both accurate imaging and cost effectiveness.

- Much of the contaminated areas are also highly disturbed, with pipes and electrical lines in surprising places, backfilled waste sites, some lost waste sites, and multiple overlapping and comingling contaminants plumes at various depths with dozens of tank waste contaminants. We know that a single leak contains constituents with a range of Kd's, and the Kd's change with time as the chemistry changes, resulting in smeared contaminant plumes. We need to know the central location of a blob, but also the trail of contaminants and/or moisture so we can trace back to a source. The vertical spread is a contentious issue here at Hanford, because tracking a plume back to its source might mean that different programs have to pay for its cleanup. That is why waste sites and tanks argue about where tank farm vadose and groundwater contamination came from.

The ability to determine the "trail of the contaminants/moisture" from the source using resistivity depends on the existence of sufficient electrical contrast between the zone impacted by the contaminant passing through and the undisturbed aquifer. Modeling and petrophysical studies will help determine the possibilities of detecting an anomaly. If these studies indicated that it might be possible, the field surveys would have to be designed to answer such a question.

Would a whole-Hanford HRR map help refine the STOMP model that the TC-WM EIS is using? Some of their $200 \times 200 \mathrm{~m}$ grid cells have no geologic data at all in the peripheral areas of the site, and there are questions about water tables in several areas. Would the water table reflection tell us anything useful if done over large areas? Can we see residues of the old groundwater mounds in the central plateau?

Geophysical methods, including resistivity, may be cost effectively applied over large areas, providing a continuous image of subsurface conditions. Geophysics may be able to map the water table over large areas, but we cannot comment on the usefulness of the method, because we don't have information about why more information about the water table elevation is needed, beyond current knowledge using existing well data. There might be other more cost-effective geophysical methods for mapping the entire Hanford site. More information regarding specific targets, depths, etc. is needed to provide further response to this question.

Thanks for the discussion - I now know something about a technique that I knew nothing about before.

Barbara Harper, CTUIR Department of Science and Engineering

Environmental Health and risk assessment 


\section{DISTRIBUTION}

\section{Onsite}

$3 \quad$ U.S. Department of Energy

Richland Operations Office

DOE Public Reading Room

H12-53

J. G. Morse

A6-38

K. M. Thompson

A6-38

10 Fluor Hanford, Inc.

M. W. Benecke

E6-44

D. S. Miller

E6-35

K. K. Schneider (3)

E6-35

S. W. Petersen (5)

E6-35

1 Lockheed Martin Services, Inc.

Document Processing Center

H6-08

$2 \quad$ Pacific Northwest National Laboratory

Hanford Technical Library

P8-55

G V. Last

K6-81

$1 \quad \mathrm{CH} 2 \mathrm{M}$.

D. A. Myers

H6-03

Dist. 1 